\title{
Transfer of Invasive Species Associated with the Movement of Military Equipment and Personnel
}

Alfred F. Cofrancesco, Jr., David R. Reaves,

and Daniel E. Averett

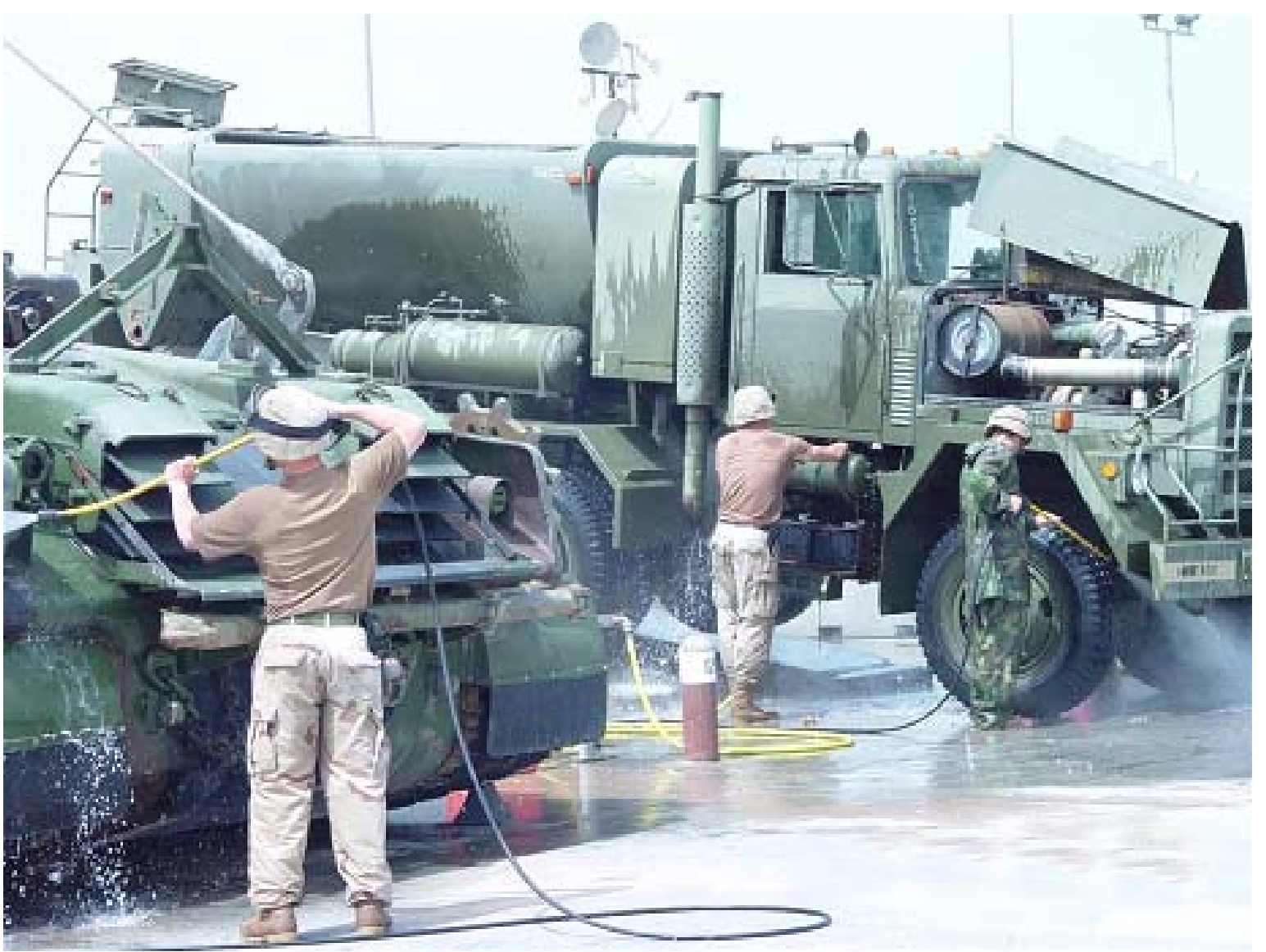




\title{
Transfer of Invasive Species Associated with the Movement of Military Equipment and Personnel
}

\author{
Alfred F. Cofrancesco, Jr. \\ Environmental Laboratory \\ U.S. Army Engineer Research and Development Center \\ 3909 Halls Ferry Road \\ Vicksburg, MS 39180-6199 \\ David R. Reaves \\ U.S. Department of Agriculture \\ Animal Plant Health Inspection Service \\ Riverdale, MD 20737 \\ Daniel E. Averett \\ Vicksburg, MS 39183
}

Final report

Approved for public release; distribution is unlimited.
Prepared for U.S. Department of Defense Legacy Resource Management Program Washington, DC

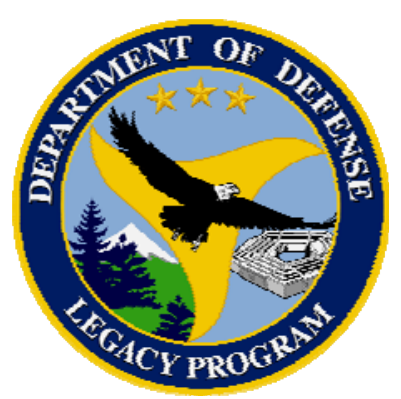




\begin{abstract}
This document provides a general overview of the current process that exists to clean, inspect, and regulate the movement of invasive species through ports of embarkation and debarkation. The Department of Defense rapidly moves extensive quantities of personnel and equipment throughout the world and invasive species are hampering these operations. Every military unit that passes through a port of embarkation and debarkation is subjected to scrutiny and inspections to preclude the movement of invasive species from one region of the world to another. Depending on the region where personnel and equipment are moving, the inspection and cleaning process can last weeks, even for small units. The costs in time and money are generally overlooked and have often been attributed to another operational requirement; however, as countries increase their awareness of invasive species, these costs and commitment will rise. Information compiled during this project indicates that over half a million man hours and \$16 million were needed to process 9 months of personnel and equipment through ports of embarkation in Kuwait during FY04. These requirements and costs will increase unless processes are established that assist the unit commanders in complying with requirements related to invasive species.
\end{abstract}

DISCLAIMER: The contents of this report are not to be used for advertising, publication, or promotional purposes. Citation of trade names does not constitute an official endorsement or approval of the use of such commercial products. All product names and trademarks cited are the property of their respective owners. The findings of this report are not to be construed as an official Department of the Army position unless so designated by other authorized documents. 


\section{Contents}

Figures and Tables................................................................................................................

Preface

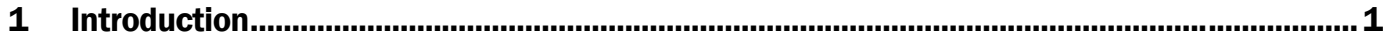

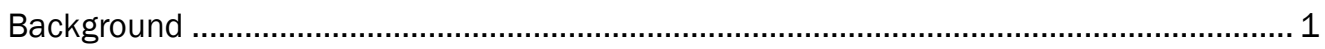

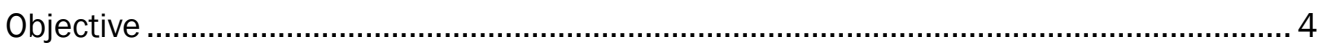

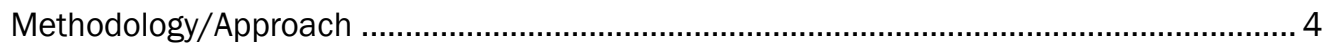

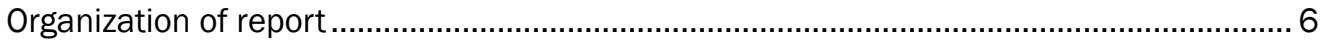

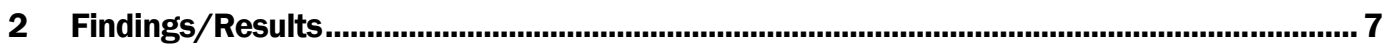

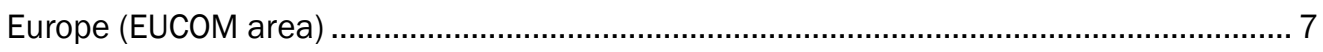

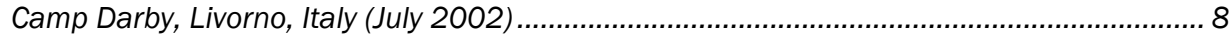

839th U.S. Army Transportation Battalion, Livorno, Italy (July 2002)................................. 11

Ramstein Air Base, Germany (July 2004) ...................................................................... 11

Southwest Asia (CENTCOM area) .............................................................................. 13

Camp Arifjan, Kuwait (August 2004) …........................................................................... 13

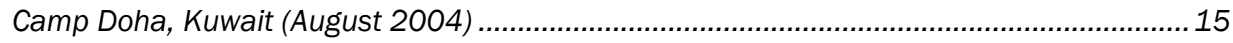

Military Sealift Command, Kuwait (August 2004)........................................................... 17

Ali al Salem Air Base, Kuwait (August 2004) ................................................................. 21

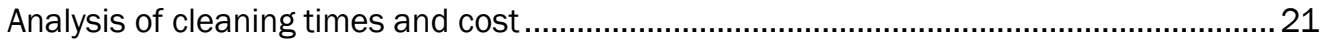

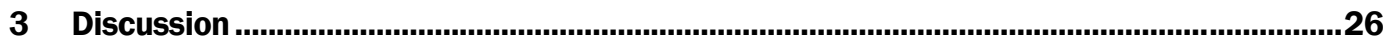

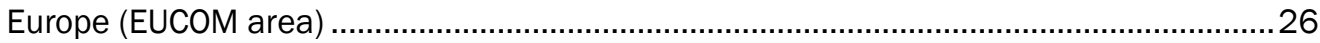

Southwest Asia (CENTCOM area) ............................................................................... 27

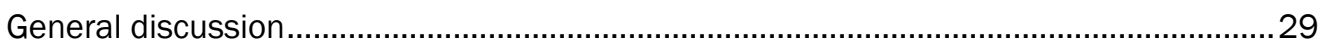

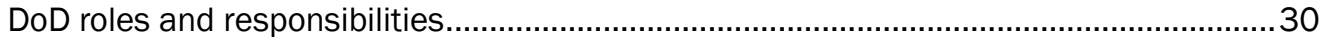

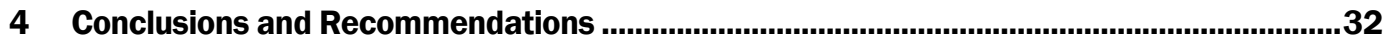

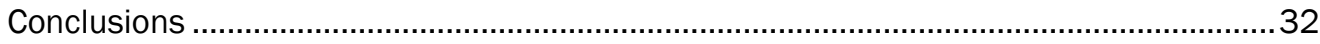

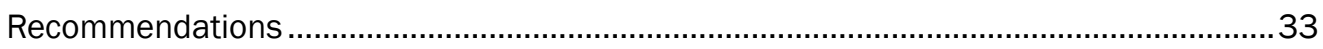

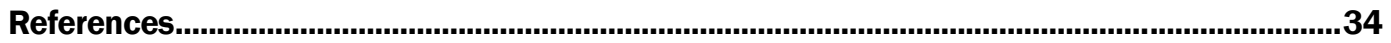

Appendix A: Laws, Rules, and Regulations Governing the Department of Defense in

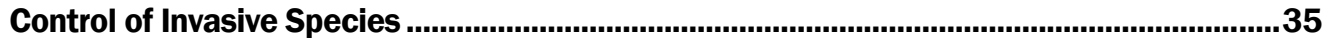

Appendix B: 886 Expeditionary Security Forces Group (ESFG) Standard Operating

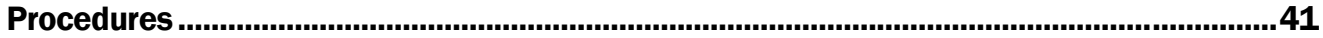

Appendix C: Correspondence Relating Agricultural Clearance Incidents Experienced

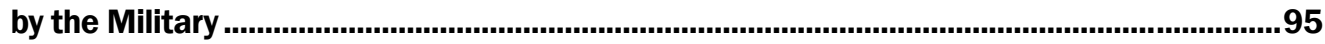

\section{Report Documentation Page}




\section{Figures and Tables}

\section{Figures}

Figure 1. Snail causing quarantine of equipment at Charleston AFB. .............................................. 8

Figure 2. Equipment in staging area at Leghorn............................................................................... 9

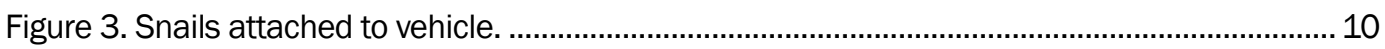

Figure 4. Canvas enclosures to prevent reinfestation of cleaned equipment.................................... 10

Figure 5. Pallets in storage area at Ramstein Air Base. ................................................................ 12

Figure 6. Soil deposits on ammunition loader.................................................................................. 12

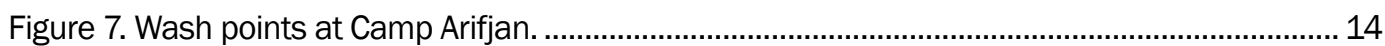

Figure 8. Lighted wash points for night operations..................................................................... 14

Figure 9. Sterile lot for equipment at Camp Arifjan...................................................................... 15

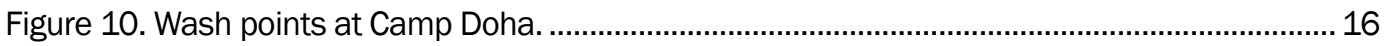

Figure 11. Aircraft prepared at Camp Doha for shipment through the port...................................... 16

Figure 12. Secure sterile lot at Camp Doha. ............................................................................ 17

Figure 13. Storage of equipment at SPOD. .......................................................................... 18

Figure 14. Final washing facility prior to loading for transport......................................................... 19

Figure 15. U.S. Naval Ship Watkins (RO/RO ship)....................................................................... 19

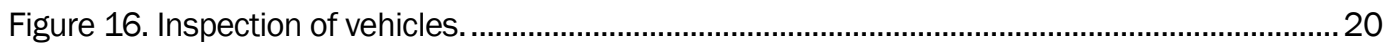

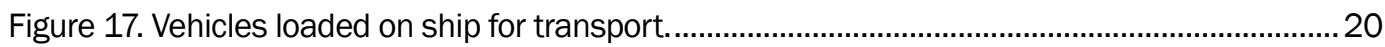

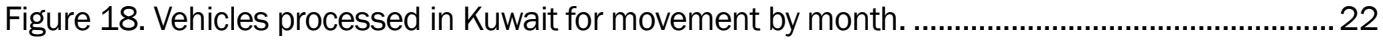

Figure 19. Cleaning times for representative vehicles (data from 886th and 887th ESFS) ...........23

Figure 20. Cleaning hours by month compared to available cleaning capacity at Kuwait. .............. 24

\section{Tables}

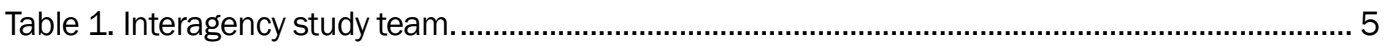

Table 2. Locations visited for study...................................................................................... 6

Table 3. Shipments from Kuwait, Nov 2003-Jul 2004.............................................................. 21

Table 4. Assumptions on numbers of vehicles cleaned by type..................................................... 24

Table 5. Estimated cleaning time for vehicles moving from Kuwait. .................................................. 24

Table 6. Estimated cost for vehicle cleaning in Kuwait...................................................................... 25 


\section{Preface}

This study was performed by the U.S. Army Engineer Research and Development Center (ERDC), Environmental Laboratory (EL), Vicksburg, MS, for the U.S. Department of Defense Legacy Resource Management Program, Project Numbers 01-163 and 03-123, under the program's Invasive Species Control Area of Emphasis.

This report was prepared by Dr. Alfred F. Cofrancesco, J r., Technical Director, EL, ERDC; Dr. David R. Reaves, U.S. Department of Agriculture, Animal Plant Health Inspection Service (USDA-AHIS), Riverdale, MD; and Daniel E. Averett, Vicksburg, MS. The authors would like to express their appreciation to the Legacy Staff for their help and assistance throughout this project. Specifically recognized are the vision, support, and assistance provided by Peter Boice, the support and guidance provided by the initial Legacy project coordinators Alison Dalsimer and Pam Behm, as well as the diligence and support provided by J ane Mallory, the current Legacy project coordinator.

This project investigated the transport of invasive species to new locations as a result of military operations, including real world contingency operations and training exercises. A team of experts familiar with invasive species supported and contributed to this study:

Agency

U.S. Transportation Command

U.S. Department of Agriculture

Armed Forces Pest Management Board

Aquatic Nuisance Species Task Force

Federal Interagency Committee for the Management of Noxious and Exotic Weeds
Name(s)

Al Bane

Howard Wit

Dr. David R. Reaves

Evelia Sosa

Dr. Peter Egan

LCDR Michael Zyzak, PhD

Dr. Al Cofrancesco

Dr. Peter Egan 
The authors also acknowledge and appreciate the contributions of the personnel they visited during the project; most of these personnel are on duty in locations outside the continental United States:

Organization or Unit
Headquarters, U.S. Army Europe and 7th Army
Headquarters, U.S. Army Europe and 7th Army
USDA-APHIS
Headquarters, U.S. Air Force Europe, Ramstein
Air Base
U.S. Army Center for Health Promotion and
Preventive Medicine - Europe
Combat Equipment Battalion - Livorno
U.S. European Command J-37
EUCOM J-4
EUCOM Customs and Border Clearance Agency
Homeland Defense Force Protection Branch
887th Expeditionary Security Forces Squadron
Coalition Forces Land Component Command,
Provost Marshals Office
Armed Forces Pest Management Board

U.S. Army ERDC Environmental Laboratory

\author{
Name \\ Martin Elyn, Command Agronomist \\ Wayne Patton \\ Delcio Rivera, Coordinator for Inspections \\ of Military Shipments \\ CPT Mark Pomerinke \\ Dr. Leonhard Engel \\ Barbara Rahrer, Executive Assistant \\ LTC Murtha \\ MAJ Pike \\ Michael Burkert, Director (USDA) \\ LT COL Rod Simmons \\ CAPT Brent D. McGuire \\ CMSGT Richard Jette \\ CAPT Herbert T. Bolton, PhD, AFPMB \\ Research Liaison Officer \\ Dr. Michael Grodowitz
}

The authors appreciate the comments and technical contributions provided by Dr. Michael J. Grodowitz and Dr. Charles V. Klimas, EL, in their review of the draft report.

The Standing Operating Procedure found in Appendix B was developed by the 886th Expeditionary Security Forces Group.

This study was conducted under the general supervision of Dr. Beth C. Fleming, Director, EL, ERDC.

COL Richard B. J enkins was Commander and Executive Director of ERDC. Dr. J ames R. Houston was Director. 


\section{Introduction}

\section{Background}

Historically, over 50,000 alien invasive species have been found in the United States, many of which are destructive to native ecosystems, agriculture, or infrastructure (Pimentel et al. 2005). Examples include fire ants, Asian gypsy moth, zebra mussels, round goby, knapweed, leafy spurge, various thistles, water hyacinth, purple loosestrife, and soybean fungus. Annual losses of over $\$ 120$ billion have been documented from the effects and control of such harmful introductions (Pimentel et al. 2005).

Any organism has the potential to become invasive when moved to a new region with suitable habitats. There are certain criteria that make a species a higher risk over another, such as unrestrained reproductive capability or growth potential. These conditions are not always apparent in an organism's native range and may only be observed in new habitats. For example, Australian pine (Casuarina equisetifolia) grows slowly and reaches an average height of $50 \mathrm{ft}(15 \mathrm{~m})$ in its native Australia. In south Florida these trees can obtain a height of $100 \mathrm{ft}$ (30 m).

Because of the multitude of factors that may influence potential invasiveness, determining the risk associated with any particular species is exceedingly difficult since every species can be a potential invader. A more logical approach is to focus on the pathways that allow the movement of organisms from ports of embarkation to ports of debarkation. Some general characteristics need to be considered to mitigate the movement of plants or animals, but detailed analysis of a species probably will provide limited benefit in precluding the movement of species between locations.

Invasive species cause significant impacts to natural ecosystems including the replacement or extirpation of native flora and fauna and decreased land use and value. Even small populations can be threatening because of their potential for rapid dissemination to nearby areas. Man-induced dispersal is of primary concern because invasive species or their reproductive structures can be disseminated across large areas by vehicles or other equipment, or on clothing. This is especially likely during military training exercises where extensive amounts of equipment and personnel are moved across large geographical areas in short periods of time. 
Military personnel often have been subjected to extensive time in the field and their personal equipment, as well as unit equipment, may provide easy access for the introduction of exotic organisms. Many exercise participants or warfighters are unaware of the potential troublesome conditions that can arise if organisms are transported to continental United States (CONUS) locations, as well as locations outside CONUS (OCONUS). Often the existing military protocols and instructional videos for cleaning and transportation of equipment deal with materiel that is obsolete or not currently in the inventory.

A recent study, Evaluation of the Quarantine Risks Associated with Military and Humanitarian Movements Between East Timor and Australia (Australia Quarantine and Inspection Service 2000), reported a significant number of invasive species that were identified and removed from personnel and equipment returning to Australia. The report describes the steps taken to preclude the movement of unwanted organisms. The document concludes that there is a serious risk in the movement of military equipment and extreme care should be taken during these rapid deployments.

Problems related to invasive species have arisen for forces deploying. U.S. Forces participating in the exercise Tandem Thrust were prohibited from entering Australia until a phyto-sanitation certificate could be obtained indicating that the ship was free of gypsy moth. Other questions have recently surfaced concerning how North American insect pests arrived in Europe. These invasive species were found in close proximity to military operations that were conducted in Bosnia - Herzegovina. Speculation has arisen that units rapidly deploying from the central United States may have carried these organisms with them as they deployed. In 2001 German military equipment was shipped from the German Port of Cuxhaven to the U.S. port of Beaumont, TX, to be used in the multinational exercise Roving Sands. Because of concern for spreading Foot and Mouth Disease from Europe to the United States, State of Texas officials inspected the equipment, declared it to be dirty and not acceptable for entry, and ordered it to be returned to Germany. Inspections by U.S. Department of Agriculture (USDA) personnel in Texas and in Germany, after it was returned, found the equipment to be acceptable for entry into the United States under USDA standards, and challenged the ruling of the Texas officials (Rivera 2001). This illustrates the difficulty and the potential economic and operational impact of agricultural inspections. 
The significant monetary and environmental impact that invasive species are having around the world has focused the responses of many agencies to this problem. Due to these costs, the pathways that allow new invasive species to enter the country are becoming increasingly scrutinized. In addition, the increased terrorist threat levels have also alerted agencies to be more judicious in introductions of equipment and materials into the United States. Since the Department of Defense (DoD) continues to have personnel and equipment throughout the world, it is no wonder that the manner in which the DoD handles the movement of personnel and equipment has come under examination. Commercial transports contribute to invasive species problems, but they do not appear to be scrutinized as closely as military cargos.

Material, equipment, and personnel all pass through ports of embarkation and debarkation. These facilities act as a conduit for the transport of military equipment and personnel. Generally, there are two types of facilitiesairports and seaports. While both provide the same or similar types of functions, there are significant differences between the two operations.

Seaports process large ships that can handle extensive cargo tonnage. Prior to embarkation, supplies and equipment are cleaned and stored in staging areas awaiting the ship. The duration of time material and equipment are maintained in this staging area varies but generally lasts for 2 to 8 months depending on requirements, and access to these areas is generally restricted. Once the cargo is loaded on the ship, travel time could be 1 to 2 months before it is off-loaded at the port of debarkation. Cargo arriving in the United States is inspected by the USDA Animal Plant Health Inspection Service to ensure that no invasive species are transported. If an invasive species is detected, the personnel receiving the material can be required to eliminate the problem or the shipment can be sent back to the port of embarkation.

In general airports process low volumes of cargo and equipment but at a rapid pace. An examination of airfields identified that most had only minimal capability to clean and process equipment. Storage areas were usually adjacent to the flight line, and access to these areas was not restricted. Aircraft move equipment rapidly between ports of embarkation and debarkation and the military's ability to have trained personnel available to monitor the introduction of invasive species at these locations is limited. 


\section{Objective}

The objective of this report is to document and review current protocols used by the DoD to protect the United States and host nations from the transfer of invasive species associated with the movement of military equipment. The goal of the study is to identify success stories and procedures to improve the DoD's efforts to reduce the transport of invasive species associated with military movements. The DoD Legacy Resource Management Program, in coordination with the Armed Forces Pest Management Board, sponsored this assessment.

Initially, the study investigators planned to evaluate units that were participating in CONUS or OCONUS exercises such as Tandem Thrust, Bright Star, Ulchi Focus Lens, or Roving Sands. However, due to funding constraints, and subsequently the war in Iraq, modifications were made in the scope and direction of the project. Many of the exercises that were scheduled to be evaluated were canceled or reduced in size and scope. The United States deployed extensive Active, Reserve, and National Guard personnel and materiel to the U.S. Central Command's (CENTCOM's) Area of Operations. These wartime military movements for Operation Iraqi Freedom provided investigators the opportunity to assess DoD's program for control of invasive species on a large scale.

\section{Methodology/Approach}

A multiple-level approach was utilized to evaluate the transportation of invasive species associated with the movement of military personnel and equipment. First, a team of experts, listed in Table 1, assembled to examine invasive species issues associated with materiel transport during military operations. 
Table 1. Interagency study team.

\begin{tabular}{|l|l|}
\hline Agency & Team Member \\
\hline U.S. Transportation Command & Al Bane \\
\cline { 2 - 2 } & Howard Wit \\
\hline U.S. Department of Agriculture & Dr. David R. Reaves \\
\cline { 2 - 2 } & Evelia Sosa \\
\hline Armed Forces Pest Management Board & Dr. Peter Egan \\
\cline { 2 - 2 } & LCDR Michael Zyzak, PhD \\
\hline Aquatic Nuisance Species Task Force & Dr. Al Cofrancesco \\
\hline $\begin{array}{l}\text { Federal Interagency Committee for the Management of Noxious } \\
\text { and Exotic Weeds }\end{array}$ & Dr. Peter Egan \\
\hline
\end{tabular}

The team met to determine the key factors that needed to be examined when evaluating the movement of personnel and equipment. A protocol was established for evaluating deployed units. The team also reviewed timeframes of upcoming unit deployments to determine which organizations would be examined.

The second phase evaluated personnel and equipment returning from OCONUS deployments at both the embarkation and debarkation areas. Selected personnel and equipment with the greatest potential for transporting invasive species were identified and evaluated. This report of the findings was prepared to identify DoD's strengths and weaknesses in preventing the introduction of invasive species. A list of recommended changes to policy and procedures designed to eliminate the movement of invasive species also will be provided.

The field examinations were conducted using the following procedures:

- Conduct discussions with personnel responsible for the movement of soldiers and equipment in the theater in order to examine the procedures and protocols used to facilitate movement.

- Conduct onsite inspections of equipment-cleaning processes at various locations to document the effectiveness of the existing procedures and to determine how to improve these processes.

- Evaluate equipment and personnel being processed for the presence or absence of invasive species or carrier material (soil or vegetation). The analysis looked at equipment placed in the staging areas after cleaning. A number of vehicles in the staging area are inspected for the presence 
of soil, vegetation, or animals. The percentage of vehicles that are not clean is reported.

- Estimate the time and cost expended by DoD units to prepare vehicles for safe transport with respect to invasive species.

Transportation activities were investigated in two theater commands-the U.S. European Command (EUCOM) and CENTCOM in 2002 and 2004 (Table 2).

Table 2. Locations visited for study.

\begin{tabular}{|c|c|c|}
\hline Country & Camp/Base & Type of Facility \\
\hline \multirow[t]{2}{*}{ Germany } & \multirow[t]{2}{*}{ Ramstein Air Force Base } & Storage area \\
\hline & & Flight line \\
\hline \multirow[t]{3}{*}{ Italy } & \multirow[t]{3}{*}{ Camp Darby, Livorno } & Wash racks \\
\hline & & Storage area \\
\hline & & Port facility \\
\hline \multirow[t]{9}{*}{ Kuwait } & \multirow[t]{2}{*}{ Camp Arifjan } & Wash racks \\
\hline & & Sterile storage lots \\
\hline & \multirow[t]{2}{*}{ Camp Doha } & Wash racks \\
\hline & & Sterile storage lots \\
\hline & \multirow[t]{3}{*}{ Military Sealift Command Kuwait } & Wash racks \\
\hline & & Storage lots \\
\hline & & Ship-U.S. Naval Ship Watkins \\
\hline & \multirow[t]{2}{*}{ Ali AI Salem Air Base } & Storage area \\
\hline & & Flight line \\
\hline
\end{tabular}

\section{Organization of report}

The results of the study described in this report are summarized in Chapter 2. Chapter 3 discusses the results, and Chapter 4 lists conclusions and recommendations. Appendix A is a summary of laws, rules, and regulations governing the control of invasive species. Appendix B outlines standard operating procedures for the 886 Expeditionary Security Forces Group (ESFG). Samples of correspondence regarding agricultural clearance incidents experienced by the military are provided in Appendix C. 


\section{Findings/Results}

\section{Europe (EUCOM area)}

Discussions were held with both the EUCOM staff and U.S. Army Europe (USAREUER) \& 7th Army staff. Military personnel conducting pre-clearance operations in EUCOM indicated they inspect equipment shipped from other countries. If the equipment is not clean, they will send it on to the final destination in that country. If it is passing through to the United States they will send it on to its destination, such as Dover, and it will be cleaned in the United States. The study team has not been able to establish if this is done and what procedures are taken at the U.S. facility to ensure that the soil and organisms are removed and treated to avoid contaminating the U.S. site. EUCOM personnel indicated that in the past they cleaned dirty equipment being transported from CENTCOM to Germany, but ceased the cleaning operations because of objections from the German government. Germany objected because EUCOM did not have a procedure in place to decontaminate the material (soil, wash water, etc.) removed from the equipment.

Historically the records indicate that there were problems occurring with material being shipped through the aerial ports of debarkation (APODs) and seaports of debarkation (SPODs) in Germany and Spain.

- Six C-17s and their cargo were placed in quarantine at Charleston AFB on $6 \mathrm{July} 1999 \mathrm{for} 24 \mathrm{hr}$ while 233,003 lb of cargo including 14 pallets and 33 pieces of rolling stock were positioned for fumigation to kill snails (Figure 1) attached to the materials. Cost for the operation was approximately \$2 million (Pomerinke 1999; Figures C10-C11)

- In October-November 1999 snails were discovered on equipment being transported to North Carolina on contract ships Motor Vessel Steven L. Bennett (Figure C4) and Motor Vessel Austral Rainbow, respectively (Bolton 1999; Figure C6).

- As noted earlier, two ships containing German Army equipment being transported into the United States for the Roving Sands exercise in 2001 were stopped at the SPOD and sent back to Germany without off loading their equipment (Rivera 2001; Figures C18-C20). Port inspectors claimed the equipment was not adequately cleaned. However, 
USDA inspection of the equipment on its return to Germany indicated the equipment was clean and should have been accepted at the port.

- Dirty equipment was found at Army Materiel Command operations at Ramstein Air Force Base, Germany, on 4 February 2004 by W.L. Manning, Military Attaché, Agriculture Advisor, EUCOM (Manning 2004; Figure C21).

- A briefing for Commander Naval Region Europe on 6 April 2006 (Naval Region Europe 2006) advises that washing of equipment at Rota, Spain, may be forbidden. Executive Order 13112, Invasive Species (The White House 1999), applies globally and Spanish Law applies in Rota.

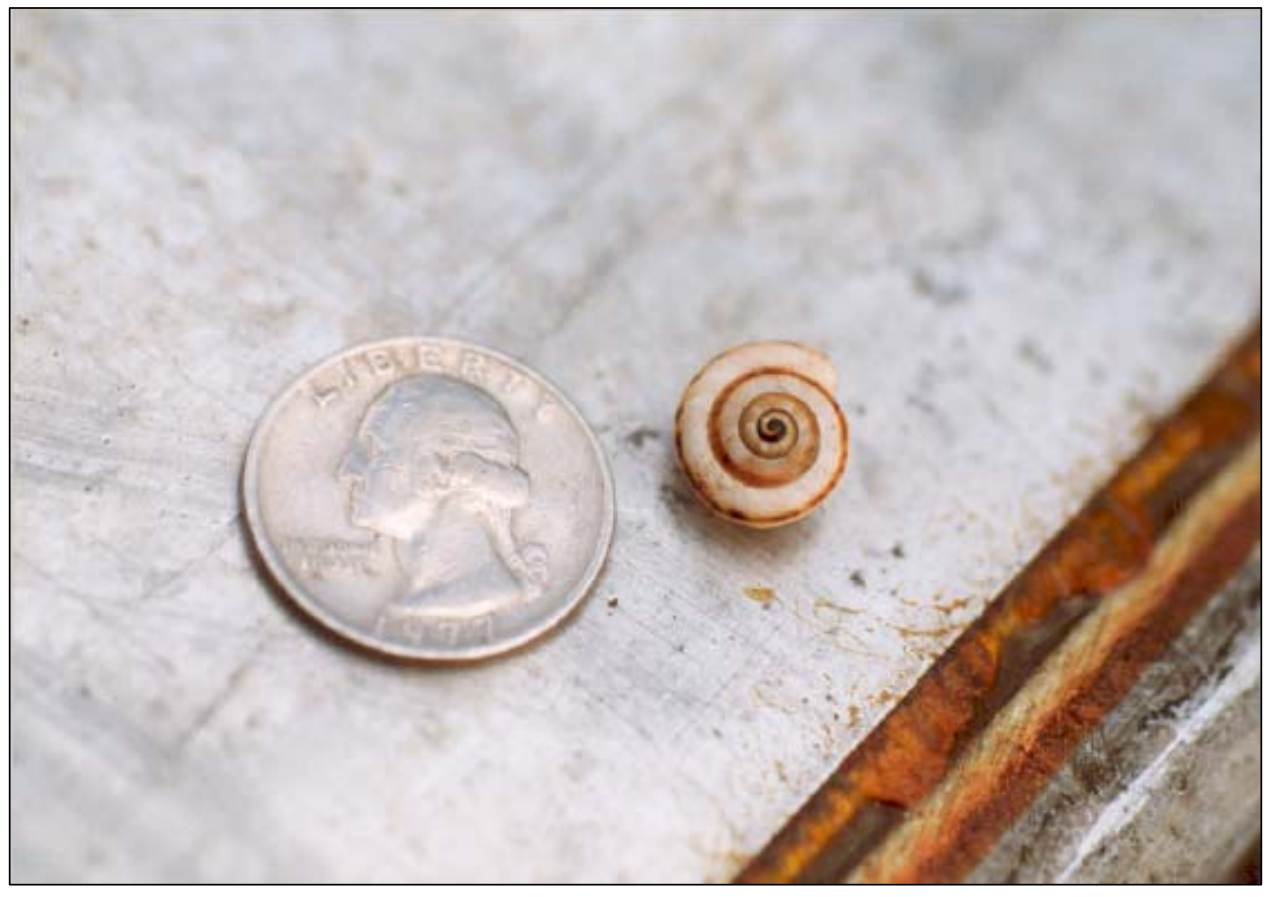

Figure 1. Snail causing quarantine of equipment at Charleston AFB.

\section{Camp Darby, Livorno, Italy (July 2002)}

Discussions with personnel at Camp Darby indicated that there were two general components that conducted shipping - the military combat equipment battalion and the munitions operations. Individuals responsible for the equipment operations indicated that often equipment would be shipped into the country that needed to be cleaned. The facility had designated areas where cleaning would generally occur; however, they also maintained portable equipment to assist in the process. Installation personnel would undertake the cleaning and then place the equipment into storage lots awaiting requests for transport to another location. The 
storage lots consisted of large protected areas where equipment would be stored in the open and within closed, zippered canvas containers. Equipment and munitions would be transported to nearby SPODs for movement.

A cursory examination of 74 pieces of equipment located in the staging area (Figure 2) at the Leghorn (Camp Darby) facility revealed the presence of significant snail infestations. While the equipment had been previously cleaned, it was maintained in the area for an extended period allowing the snails time to attach to the equipment. The snail population was so significant that even with superficial examinations over 50 snails or eggs were observed attached to a vehicle (Figure 3). Apparently, snails were also able to infest equipment that was being maintained inside zippered canvas enclosures (Figure 4). Interestingly, only four vehicles or 5 percent were observed having attached clumps of soil or vegetation, further illustrating the potential movement of invasive species even after cleaning.

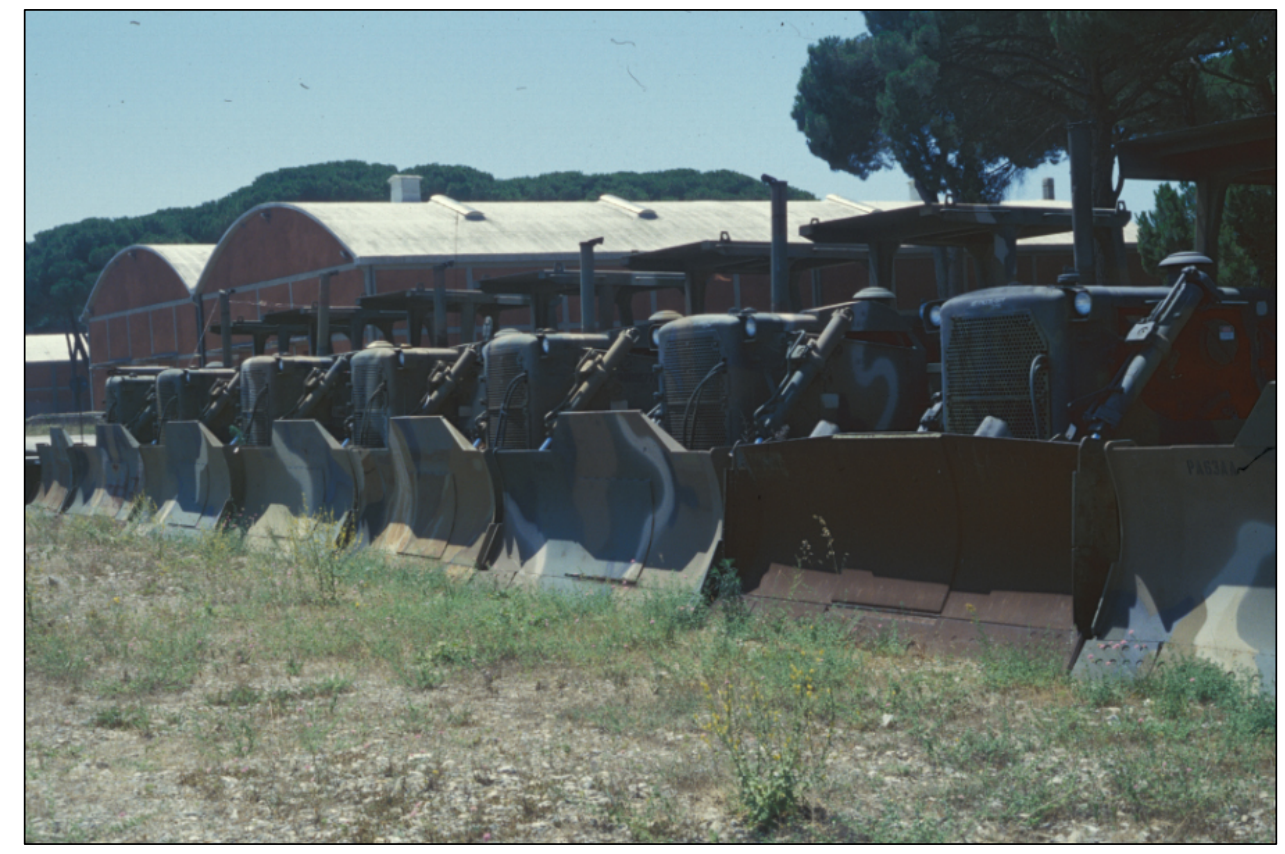

Figure 2. Equipment in staging area at Leghorn. 


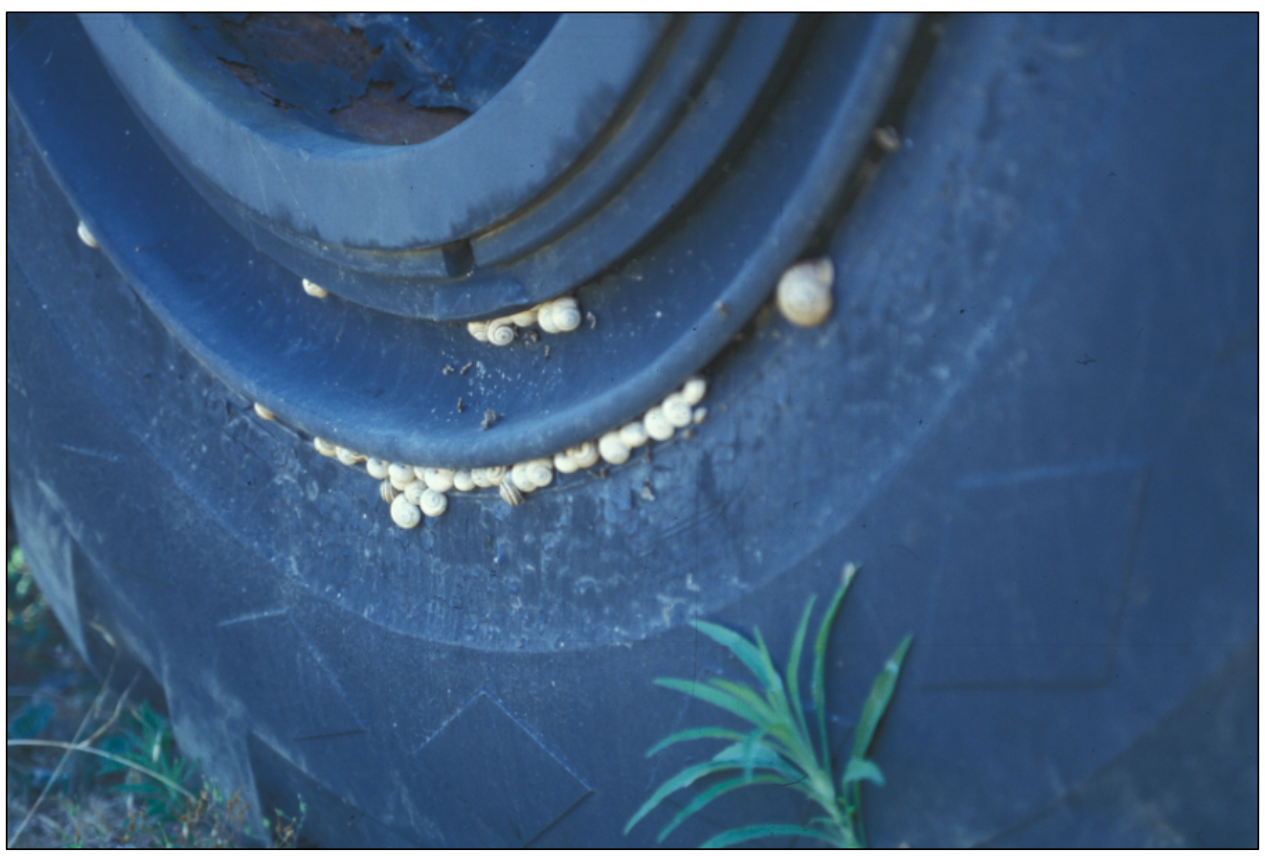

Figure 3. Snails attached to vehicle.

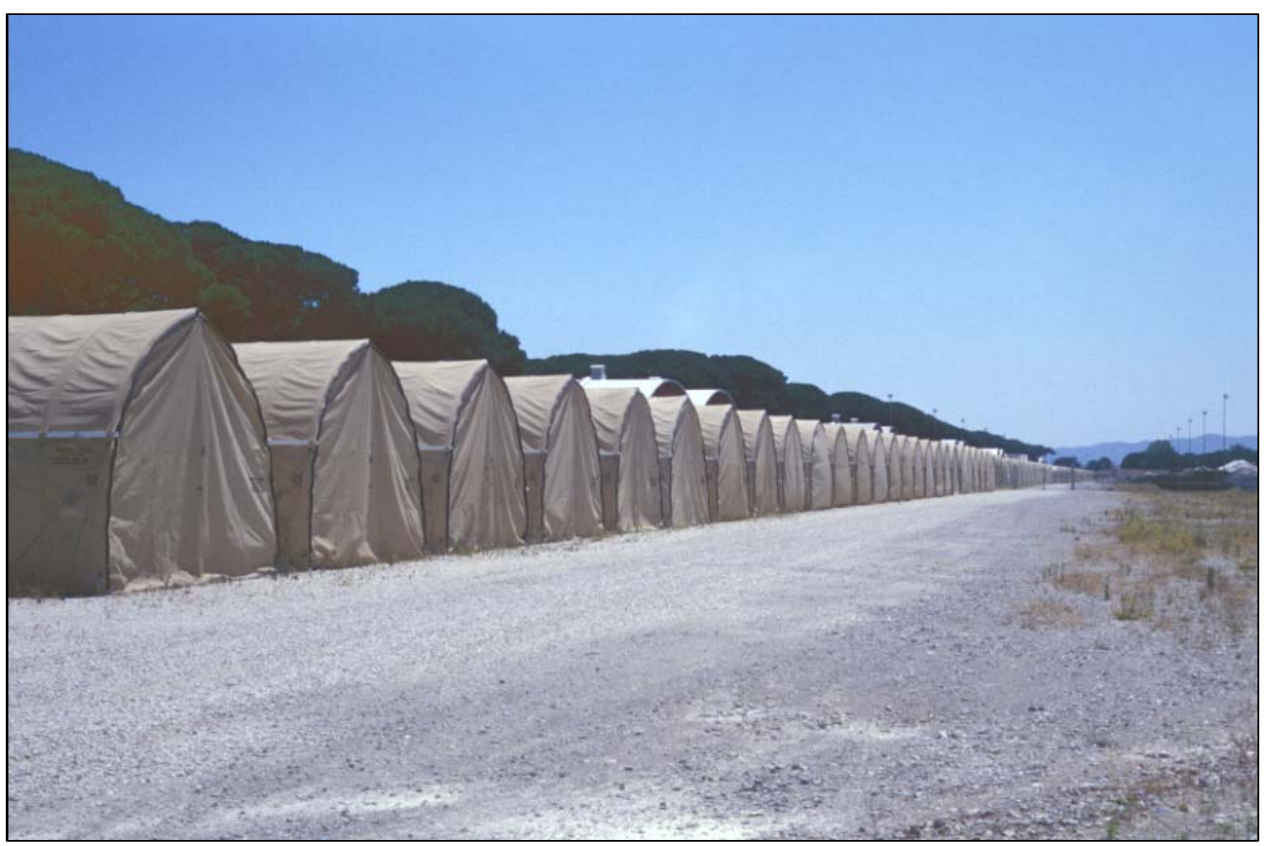

Figure 4. Canvas enclosures to prevent reinfestation of cleaned equipment.

This facility also ships numerous amounts of ammunition to locations around the world. These munitions are placed inside shipping containers that have been thoroughly cleaned. Personnel at this location have developed a stand that allows the washing practice to be done rapidly and safely. In years prior to this visit, ammo containers that were being shipped back to the United States from Leghorn were found to have snails 
attached. The USDA required that the containers be cleaned and they collected the snails for examination. While the majority of snails collected were European, scientists did find a number of North American species attached to the containers. To date it is not known if any followup was conducted at the facility in Italy to determine if North American mollusks are established at this military installation. However, Dr. David Robinson (Figure C7) indicated that European snails were established near the Military Ocean Terminal at Sunny Point, North Carolina, the SPOD for equipment from Italy.

\section{9th U.S. Army Transportation Battalion, Livorno, Italy (July 2002)}

The staff conducted briefings on port operations and the study team examined standing operating procedures (SOPs) for inspection, loading, and unloading of material and equipment. The operation appeared to work effectively and to meet regulatory requirements; however, it was noted that host nation personnel did not regularly participate in the inspections that were conducted. The snail problem often presented the operations personnel with additional requirements or delays. The removal of organisms often delayed loading.

\section{Ramstein Air Base, Germany (July 2004)}

This air base was undergoing extensive renovations at the time of the site visit. EUCOM had returned the capabilities the United States had at Rhein Main Air Base to the Germans so this meant that the entire flow of equipment through the APOD would occur at Ramstein. Discussions with the staff at the air base indicated that they previously had invasive species problems with some of the material being shipped out of CENTCOM but this had been corrected.

Only a minimal amount of equipment was being stored for transport at the APOD. An examination of 15 pallets in the storage area (Figure 5) revealed soil and water on only one pallet. Soil was observed in various compartments of three ammunition loaders at the site (Figure 6). 


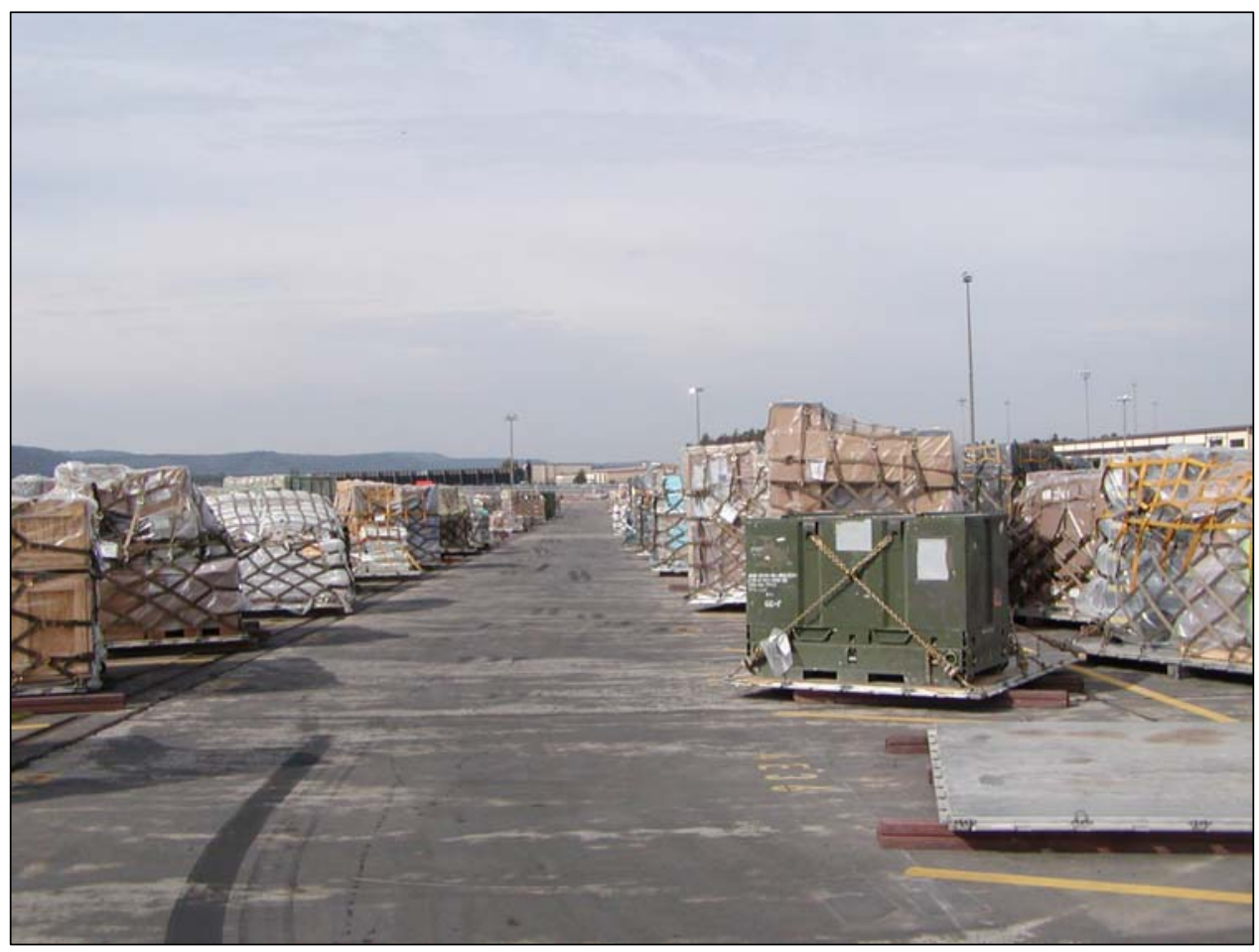

Figure 5. Pallets in storage area at Ramstein Air Base.

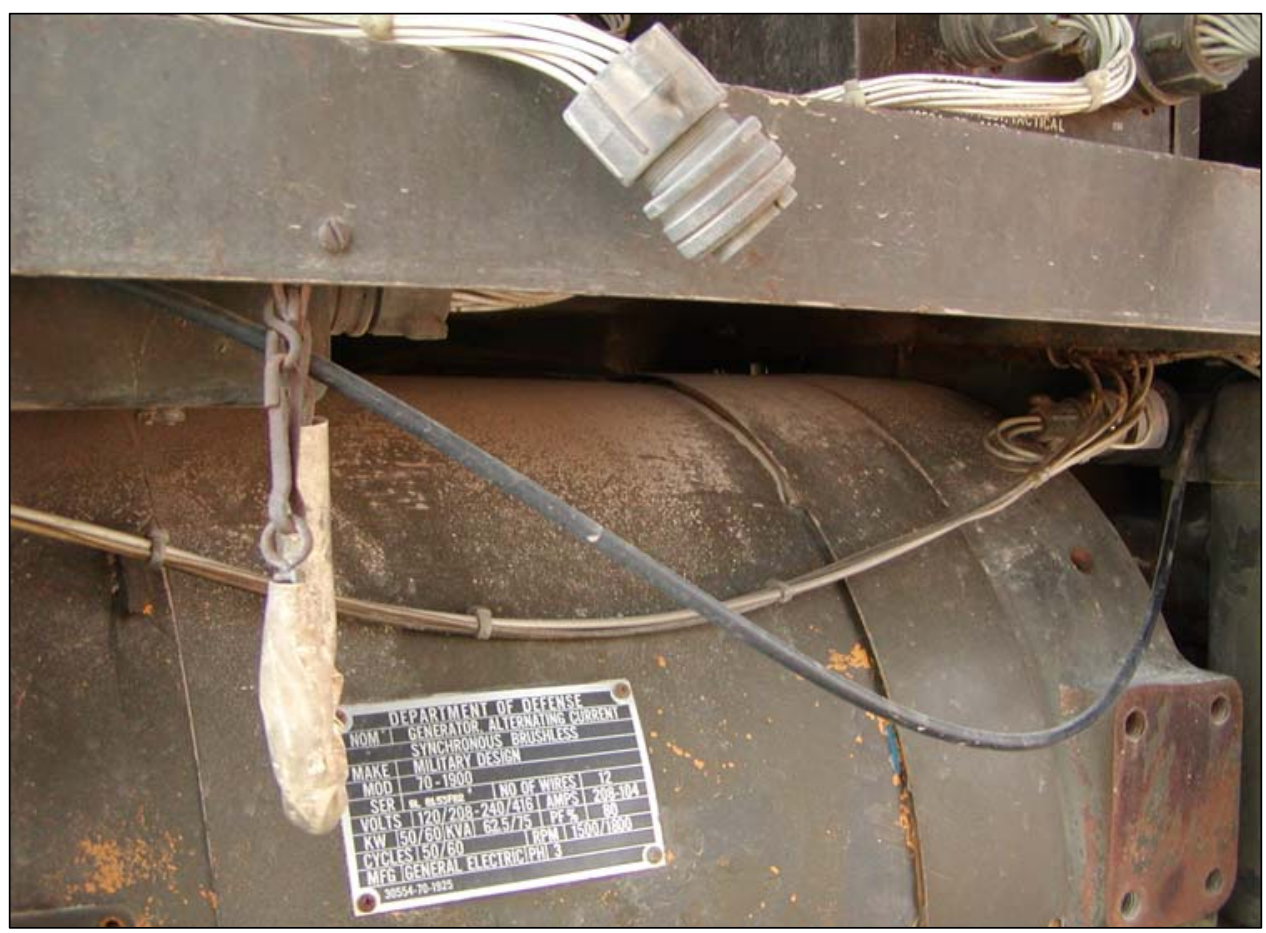

Figure 6. Soil deposits on ammunition loader. 


\section{Southwest Asia (CENTCOM area)}

Initially discussions were held with 3rd Army/Coalition Forces Land Component Command, the Area Support Group, and the units conducting inspections. The overall operations of the various facilities were discussed along with problems that had arisen because of the lack of USDA personnel in-country. CENTCOM units, including the 886th and 887th Expeditionary Security Forces Groups, have developed SOPs to lay the foundation for the cleaning process.

\section{Camp Arifjan, Kuwait (August 2004)}

In examination of the washing facilities at Camp Arifjan, the study team found numerous wash points (Figure 7). Some had concrete ramps that would allow equipment to be exposed and allow easy cleaning. Because of the presence of cleaning facilities at this location, all tracked vehicles were processed through this facility. All locations had lights that allowed for the continuous washing of equipment (Figure 8). Water was supplied through a recirculation system that allowed expended water to be captured and cleaned and reused. Procedures were established after a vehicle was inspected and approved to move it in a convoy to the sterile lot for storage. The sterile lot operations were strictly enforced and the movements of only authorized personnel were allowed inside the secured lot. At the sterile lot (Figure 9) a total of 183 vehicles were inspected and only 3 (less than 2 percent) had any plant or soil. 


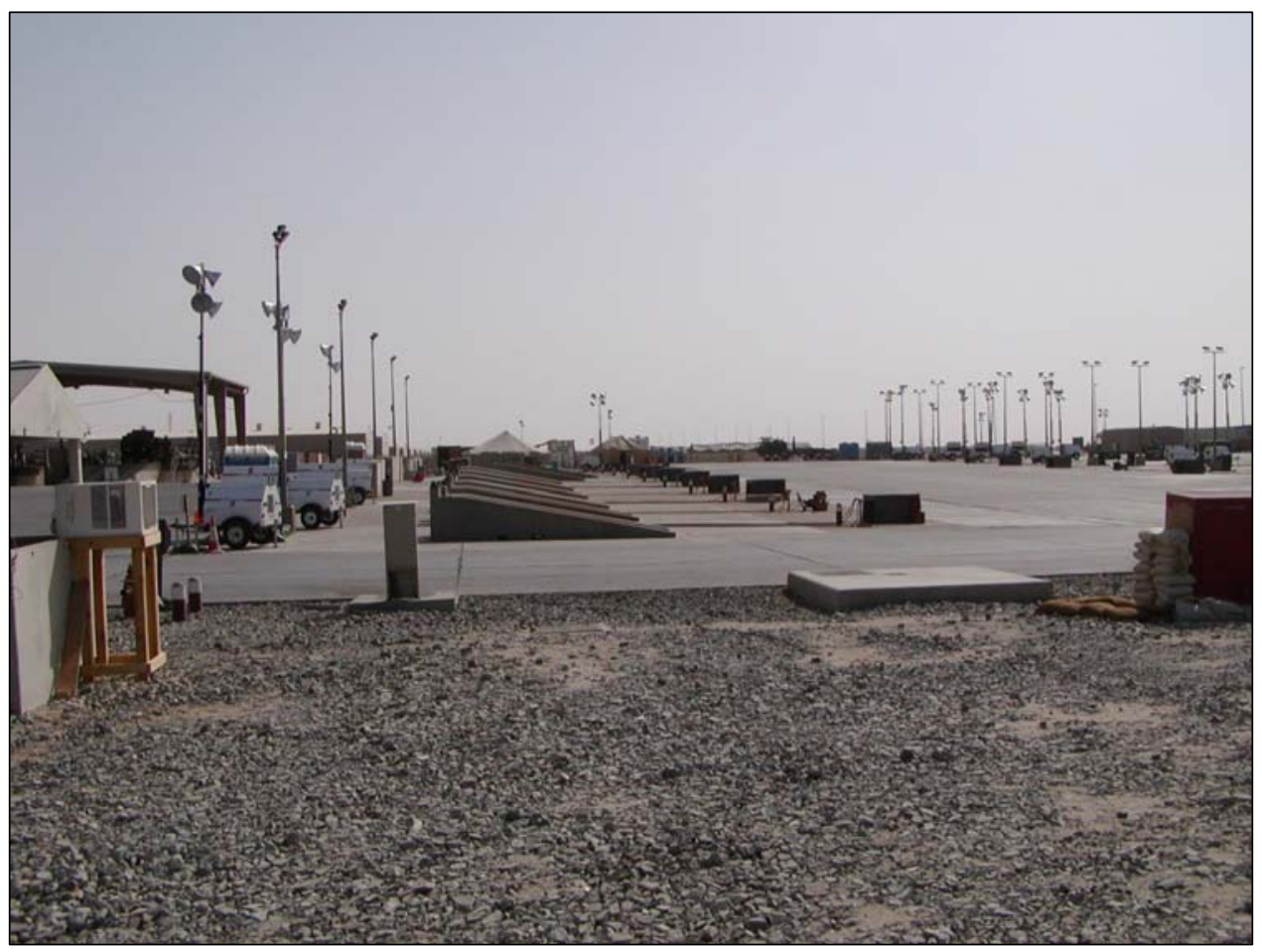

Figure 7. Wash points at Camp Arifjan.

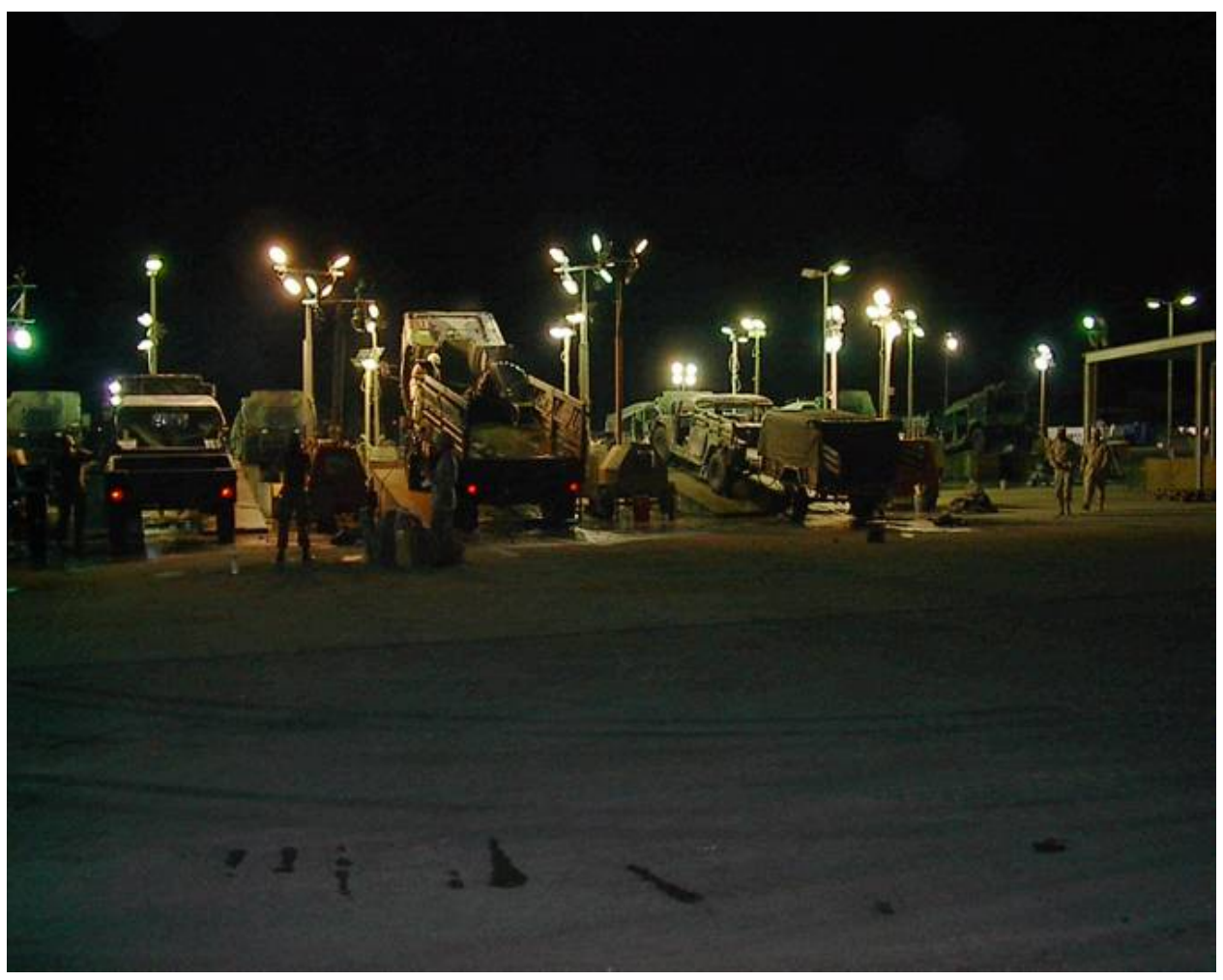

Figure 8. Lighted wash points for night operations. 


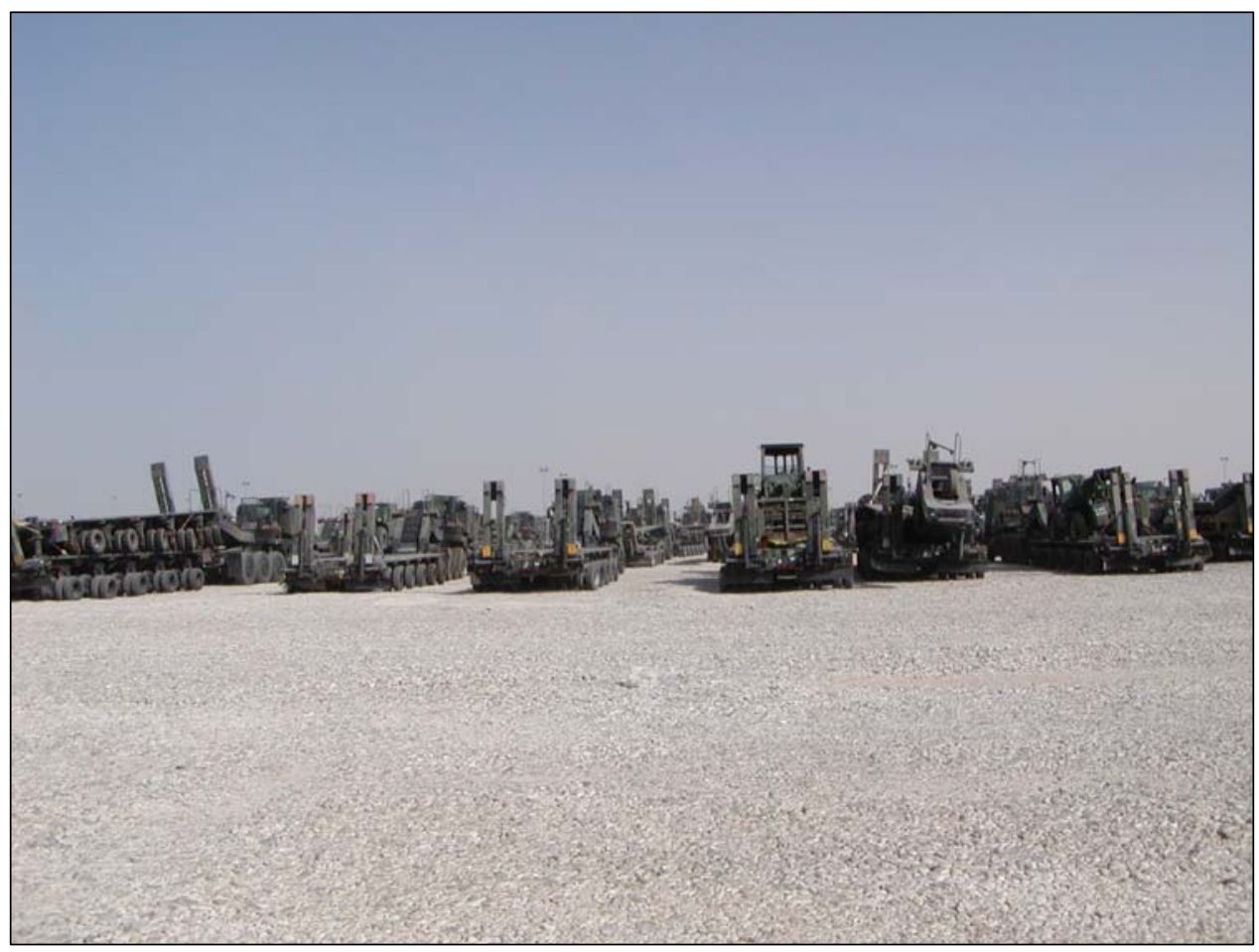

Figure 9. Sterile lot for equipment at Camp Arifjan.

\section{Camp Doha, Kuwait (August 2004)}

At Camp Doha the study team was briefed by the staff and then allowed to examine the facilities. The team found that there were wash points with and without concrete ramps (Figure 10). Generally, in the operations of this facility no tracked vehicles are cleaned. There also was a recirculation system that processed the expended water. Each wash point is set up with the same type of equipment as found at Camp Arifjan, but the total size of the operation was smaller. This facility did clean aircraft being readied for return (Figure 11). The sterile lots had only a minimal amount of equipment; however, the same level of security that was observed at other locations was also observed here (Figure 12). 


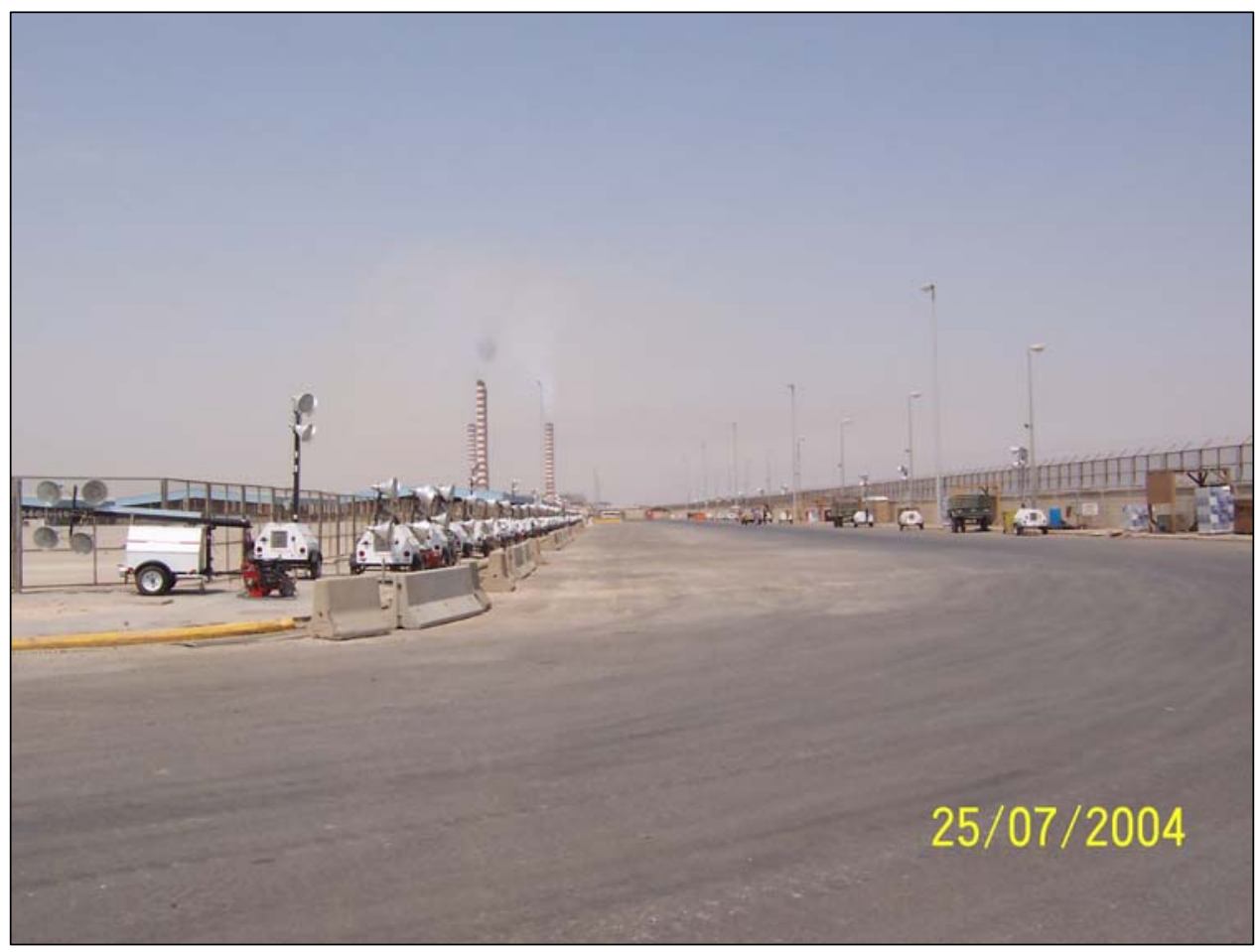

Figure 10. Wash points at Camp Doha.

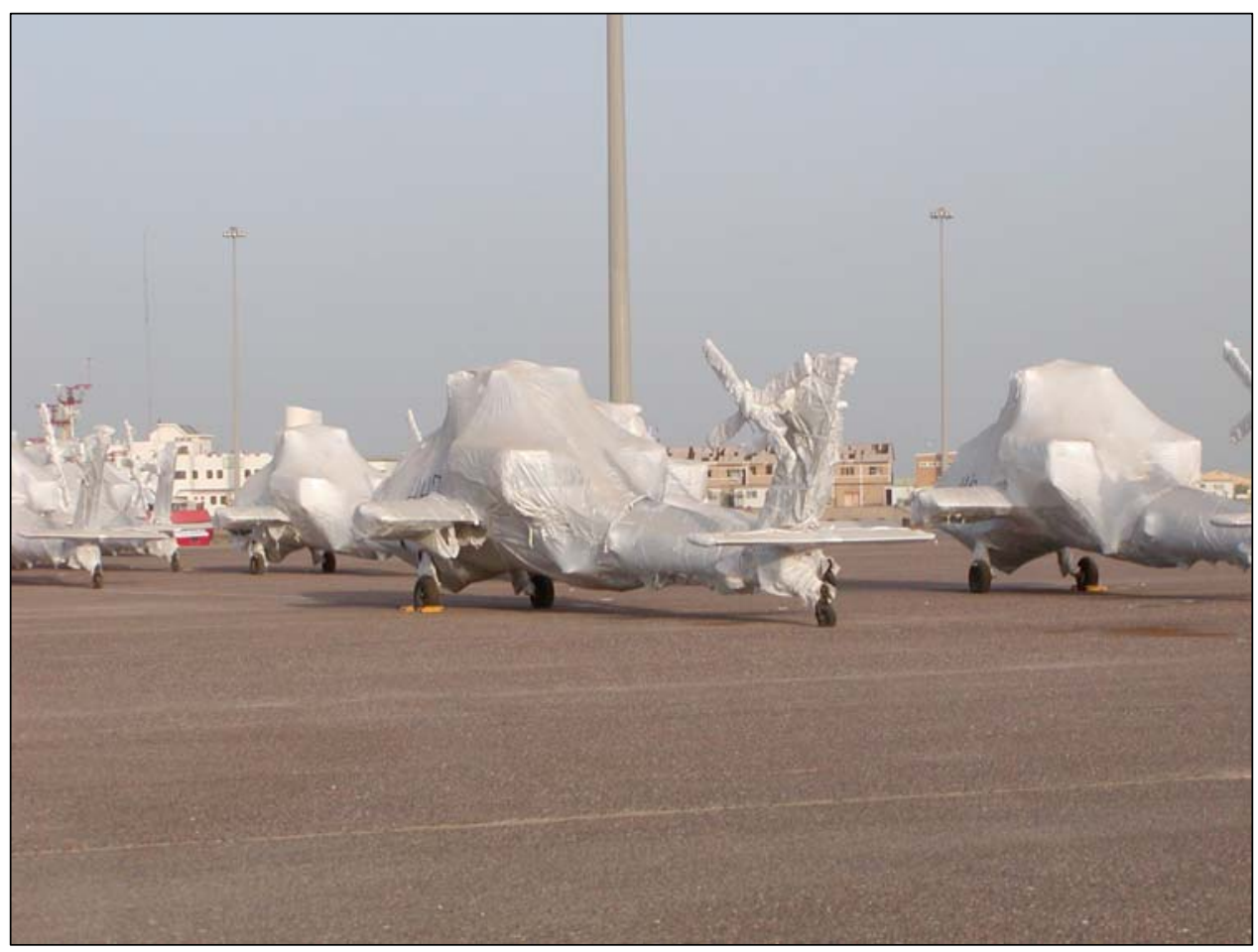

Figure 11. Aircraft prepared at Camp Doha for shipment through the port. 


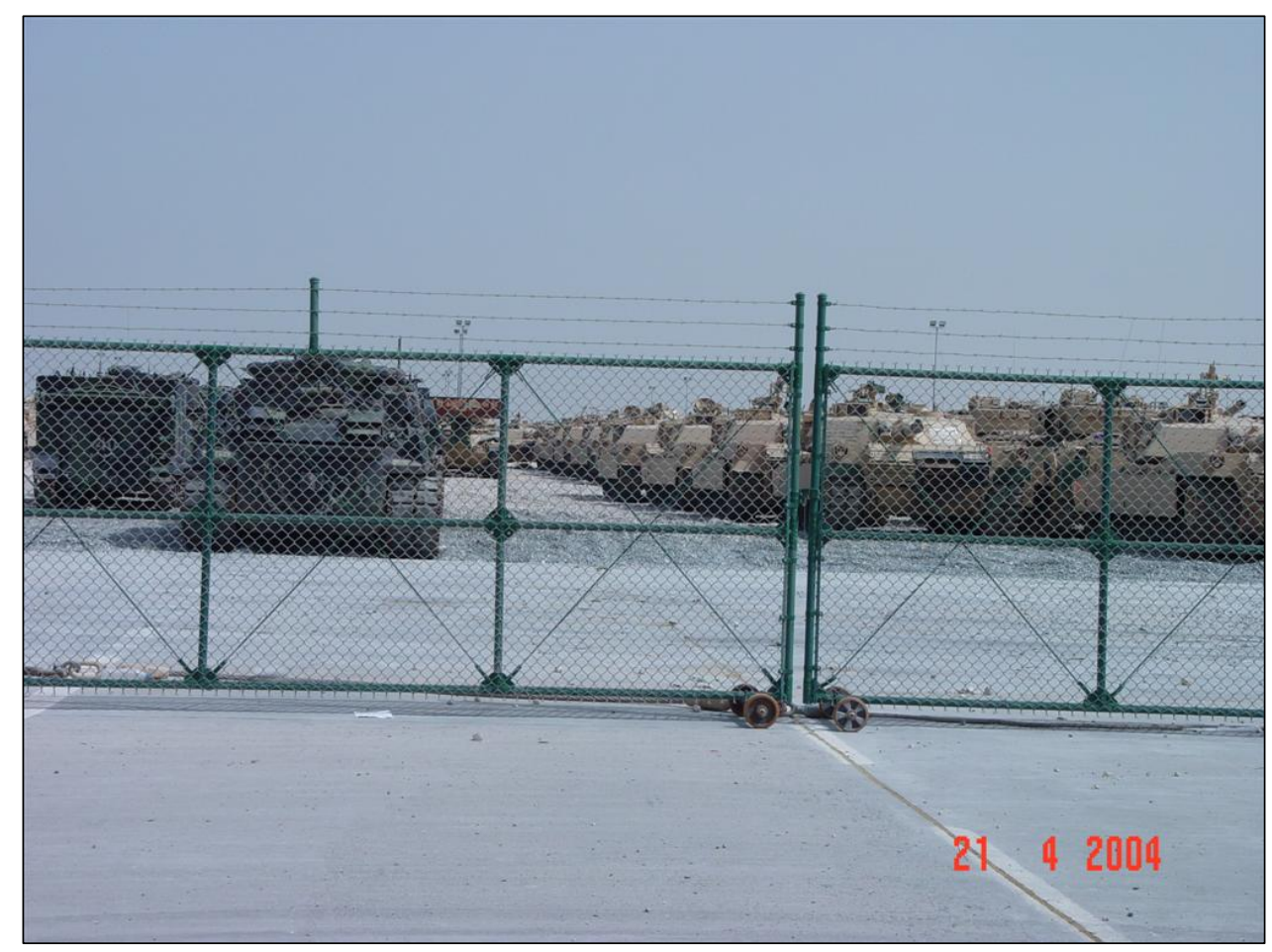

Figure 12. Secure sterile lot at Camp Doha.

The team also briefly toured other facilities that were used when the magnitude of equipment needing to be cleaned exceeded the operational capability of the main facilities. One location was the area owned by the Nestle Company. This site included extensive hardstand areas where temporary wash points were established. These facilities had no concrete ramps and were used only for small-wheeled vehicles. Tapping into the existing water system used by the Nestle Company provided the wash water. In this situation the water was not recaptured for reuse.

\section{Military Sealift Command, Kuwait (August 2004)}

The team visited the military port facilities in Kuwait to examine the final steps in moving material and equipment out of the country. The operations were quite extensive and well organized. Material and equipment are conveyed to this location prior to the arrival of ships and placed in storage yards (Figure 13) after being examined. When the ships arrive the material and equipment are processed through a final washing facility (Figure 14) and then moved onto the ship. The team examined storage areas at port facilities and on a roll-on/roll-off (RO/RO) vessel U.S. Naval Ship Watkins (Figure 15) that was being loaded. At the storage areas, 40 vehicles were examined (Figure 16) and no soil clumps or vegetation were found. Some of the vehicles had a light film of wind-blown soil that could be easily 
removed at the final wash station. The team also inspected 35 vehicles that were already loaded on the ship (Figure 17) and again the equipment was found to be clean and free of soil or vegetation.

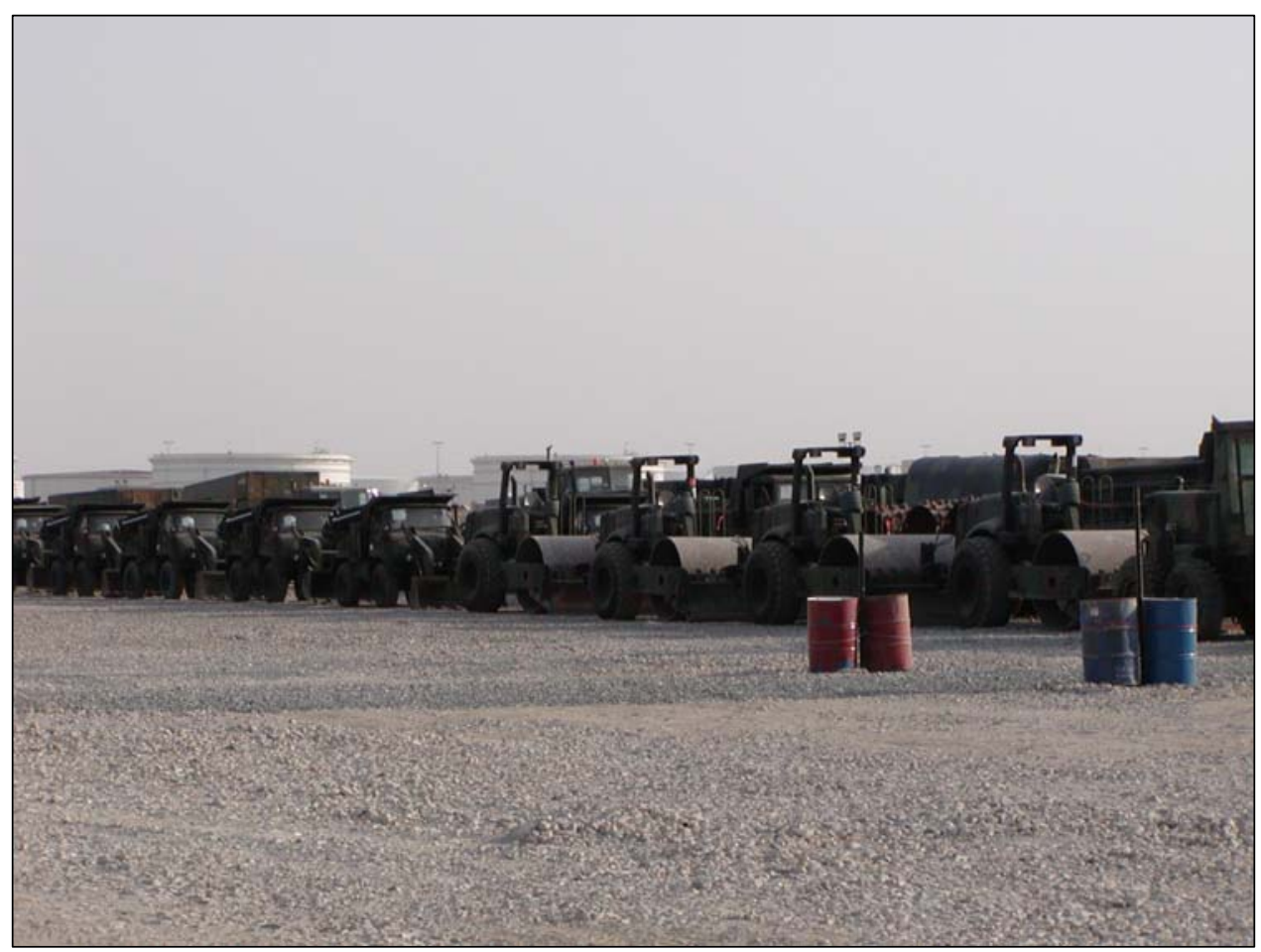

Figure 13. Storage of equipment at SPOD.

At this facility the team also saw equipment that was arriving in Kuwait. This equipment was placed in a different storage area to avoid confusion. A quick examination of this area indicated that the equipment was clean; however, discussions with personnel indicated that arriving equipment is never examined for soil or vegetation. There was no Host Nation representative station at the port to examine the incoming material or equipment. The responsibility of stopping any invasive species from entering the country was assumed to be the U.S. personnel operating the port. However, the operations staff at the port did not concur that stopping incoming invasive species was their responsibility. 


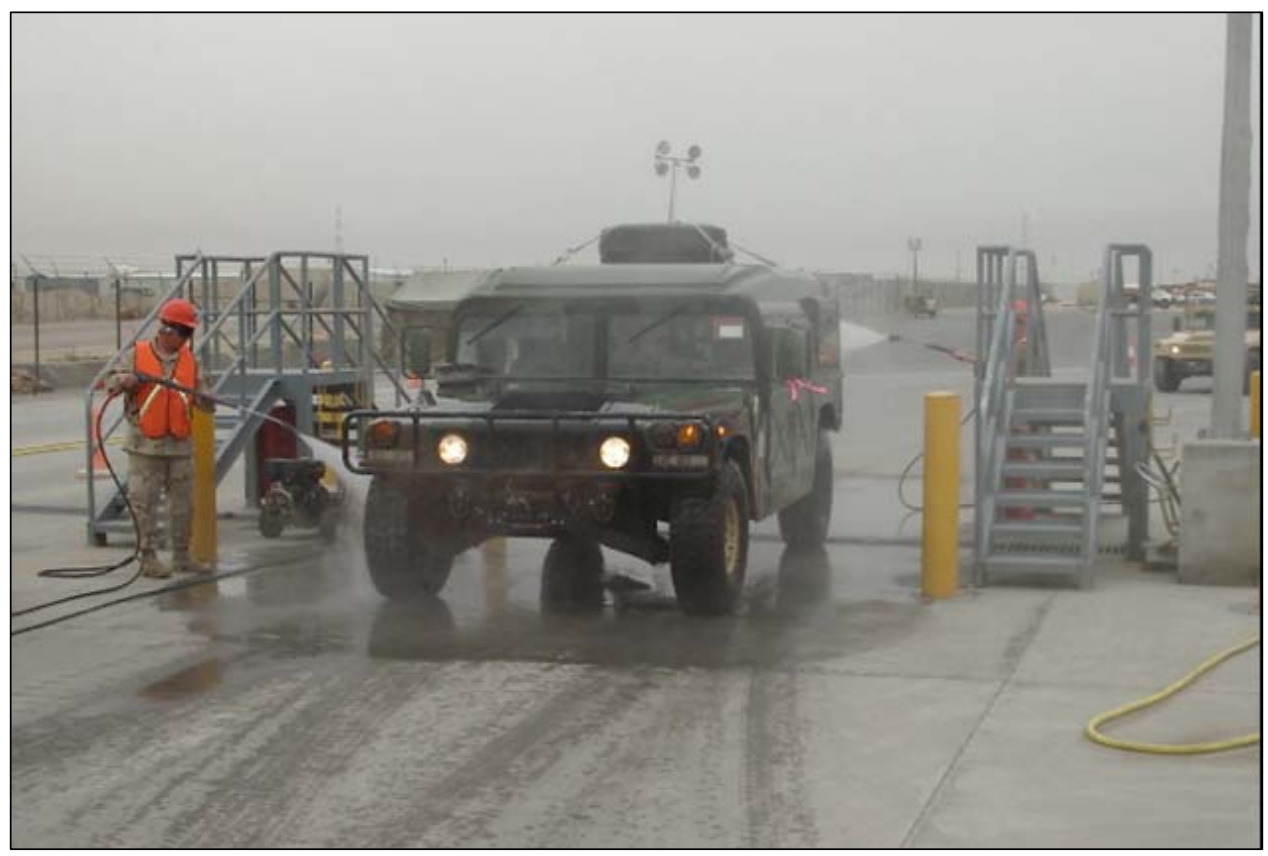

Figure 14. Final washing facility prior to loading for transport.

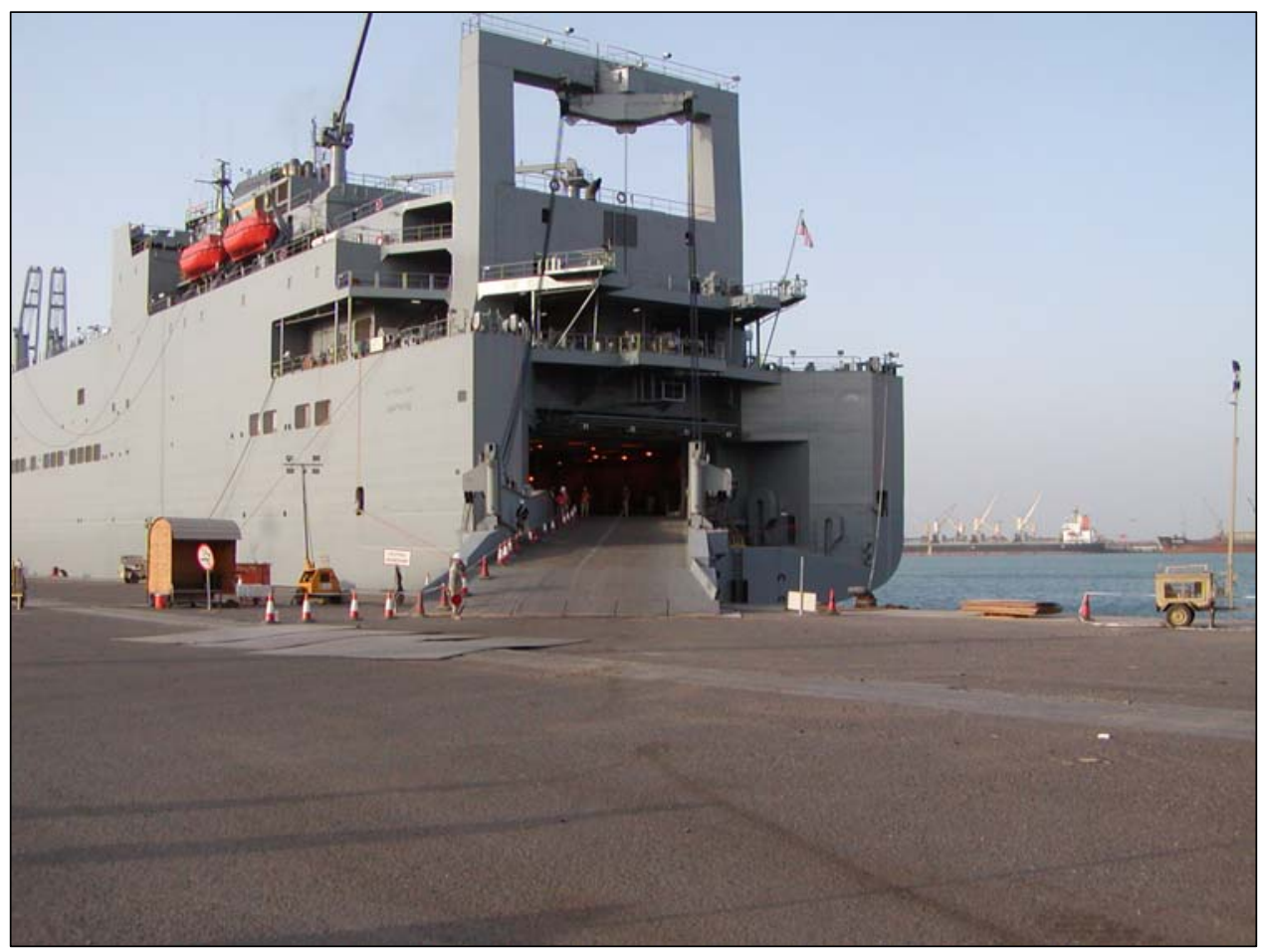

Figure 15. U.S. Naval Ship Watkins (RO/RO ship). 


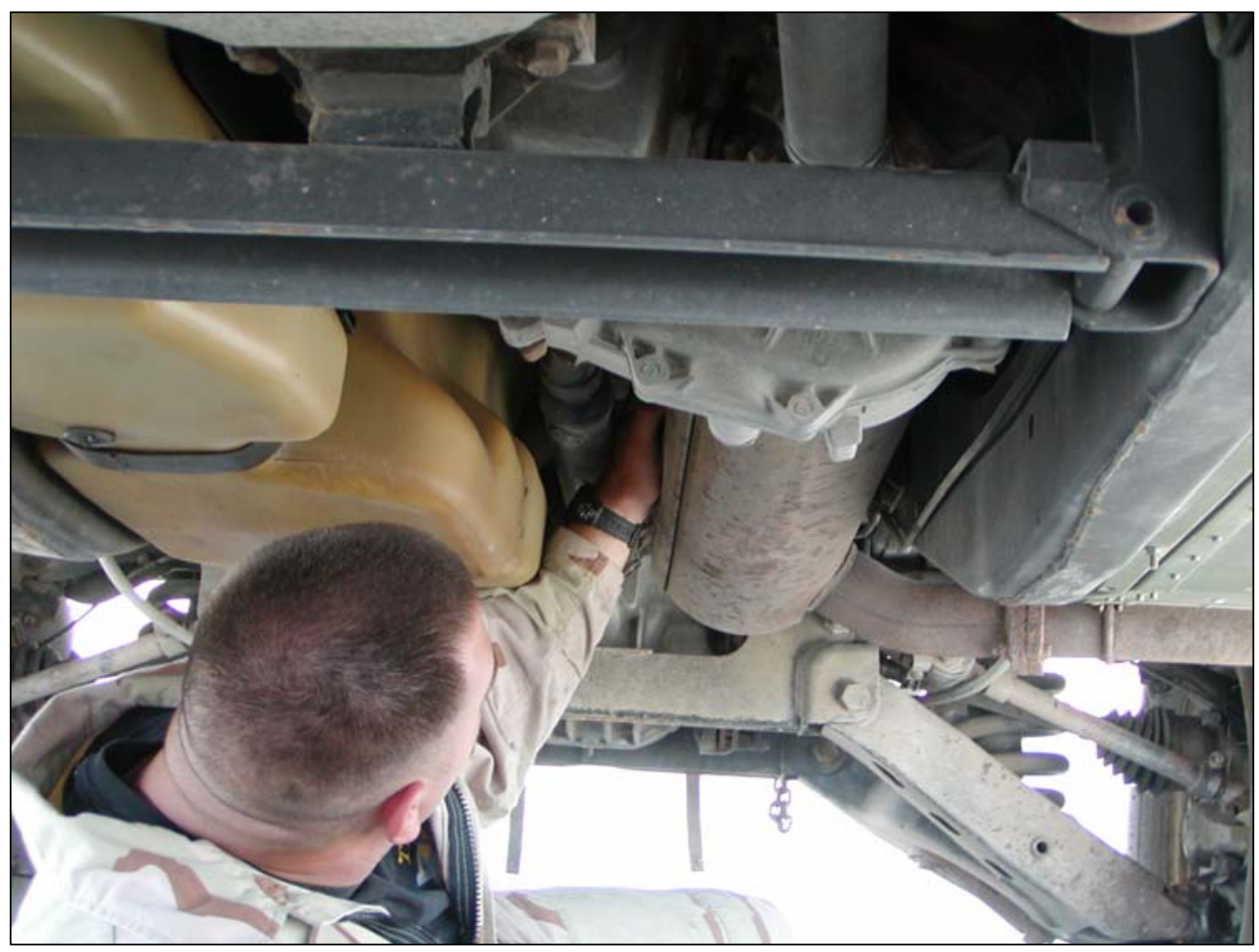

Figure 16. Inspection of vehicles.

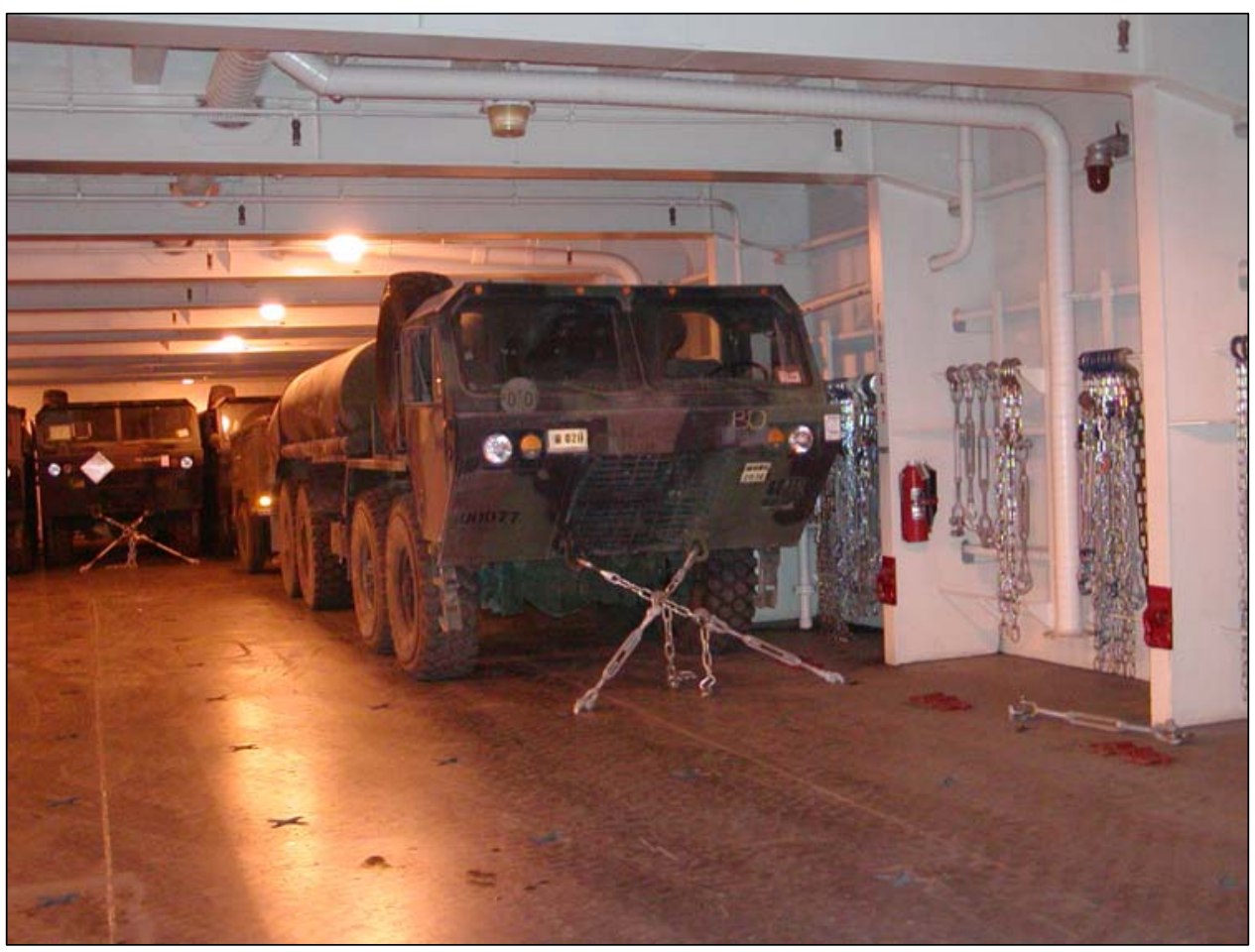

Figure 17. Vehicles loaded on ship for transport. 


\section{Ali al Salem Air Base, Kuwait (August 2004)}

This airfield was not fully operational as an APOD. Embarkation and debarkation of military personnel were still being processed at other locations in Kuwait. This air base had extensive transport operations for C-130's. Material and equipment from Afghanistan, Iraq, and throughout Kuwait passed through this facility. There was no designated area to clean equipment and if conducted it was on an ad hoc basis. Material and equipment were stored in areas adjacent to the flight line and were not strictly monitored. Some of the C-130 flights transported equipment and materials directly outside the CENTCOM Area of Operations (AO). The operations personnel seemed unaware of the requirements to prevent the movement of soil or plant material.

\section{Analysis of cleaning times and cost}

The area of the world with the largest volume for movement of military personnel, equipment, and materials is the CENTCOM AO, where Operation Iraqi Freedom has generated mobilization and deployment of a significant part of the U.S. Force. Table 3 illustrates the level of personnel and equipment shipped out of Kuwait over a 9-month period.

Table 3. Shipments from Kuwait, Nov 2003-Jul 2004.

\begin{tabular}{|l|r|}
\hline Personnel & 228,393 \\
\hline Vehicles & 65,541 \\
\hline Conexes & 7,385 \\
\hline Containers & 9,857 \\
\hline Packages & 275,915 \\
\hline
\end{tabular}

The number of vehicles processed for shipment peaked at 24,516 in March 2004 as shown in Figure 18. 


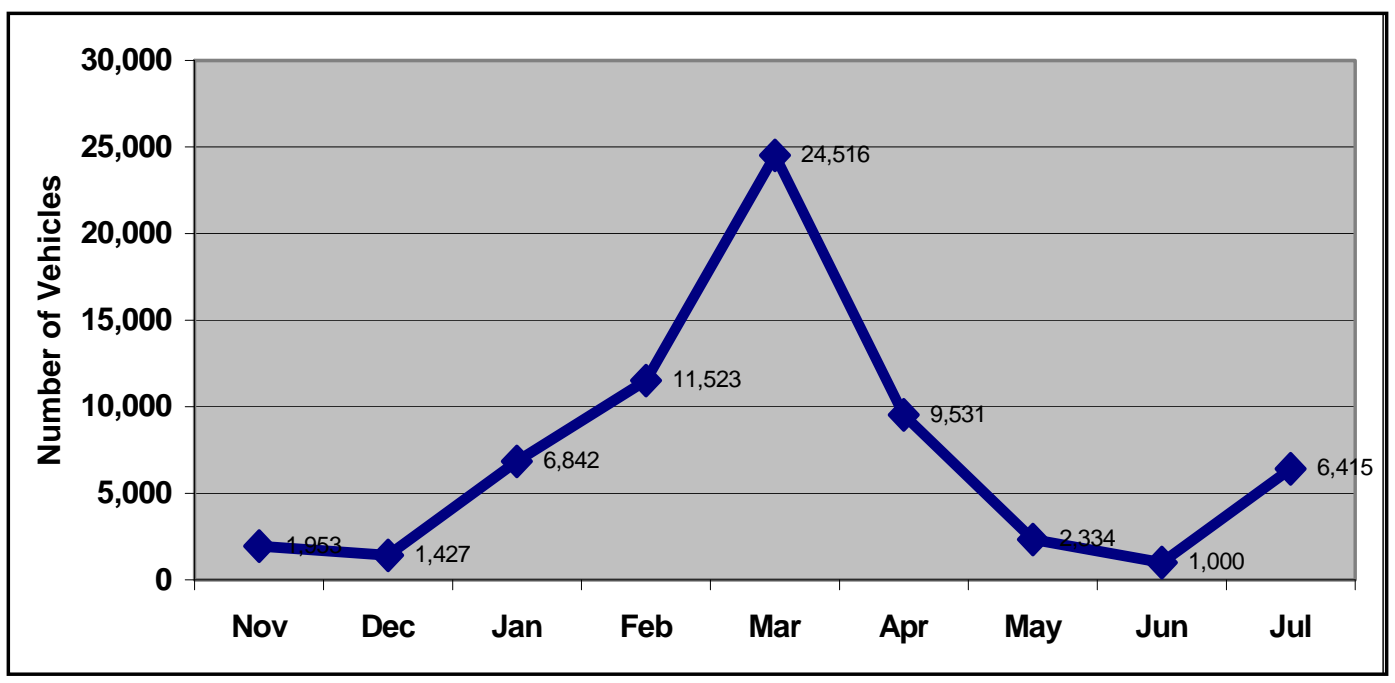

Figure 18. Vehicles processed in Kuwait for movement by month.

The cleaning and inspection process in Kuwait continues $24 \mathrm{hr}$ per day, 7 days per week, when needed, in this wartime environment. The 886th Expeditionary Security Forces Squadron (ESFS) and the 887th ESFS, who were the current Air Force groups conducting customs clearance operations in Kuwait at the time of the team's visit, appeared to be well informed and were meeting the requirement in an outstanding fashion. Their mission with respect to customs operations was to pre-clear personnel and equipment returning to the United States from Kuwait and Iraq. An excerpt from the 886th's SOP is included with this report as Appendix B. Their tasks include:

- Pre-clearing redeploying, recreation and relaxation (R\&R), and emergency leave personnel (PAX operations)

- Cleaning and pre-clearing vehicles, equipment, and conexes (wash rack and redeployment assembly area (RAA) operations)

o Vehicle owners are responsible for cleaning their own vehicles.

o All wash rack leaders are briefed on wash rack use and customs inspections

o Pre-designated liaisons are established and coordinate with Customs Border Clearance Agents (CBCAs) for inspections

- All vehicles are thoroughly washed

o A thorough inspection looking for agriculture, contraband, and prohibited items is conducted of the interior and exterior of the vehicle

o When inspections are complete, DD Forms 2855 are affixed to the vehicles, and the vehicles are convoyed by CBCA to the sterile lot

- Maintaining sterility/ entry control to the sterile yards 
o Sterile lot entry is controlled by a CBCA

o 100 percent of personnel entering the sterile lot are screened for contraband

o Customs personnel stage vehicles while waiting for the call to move forward to the port of debarkation

o Sterile lot CBCAs coordinate with movement control for convoy actions

- Escorting passengers and equipment to APOD or SPOD. Vehicle escorts are conducted by certified CBCAs for move to port of debarkation to maintain sterility

The cleaning time for different items varies depending on the size, use, and configuration of the vehicle. Figure 19 illustrates the range of cleaning times for common pieces of Army equipment. The 886th and 887th ESFS estimate a minimum of $4 \mathrm{hr}$ and a maximum of $24 \mathrm{hr}$ per vehicle. With the volume of vehicles and the labor involved for each, the DoD spends significant resources to guard against the transport of invasive species and other nuisance materials from one country to another. To illustrate this significance, the data shown in Figure 18 were combined with the cleaning times shown in Figure 19, and the assumptions described in Table 3 were used to roughly estimate the time invested in cleaning vehicles in Kuwait over the 9-month period (Table 4 and Figure 20).

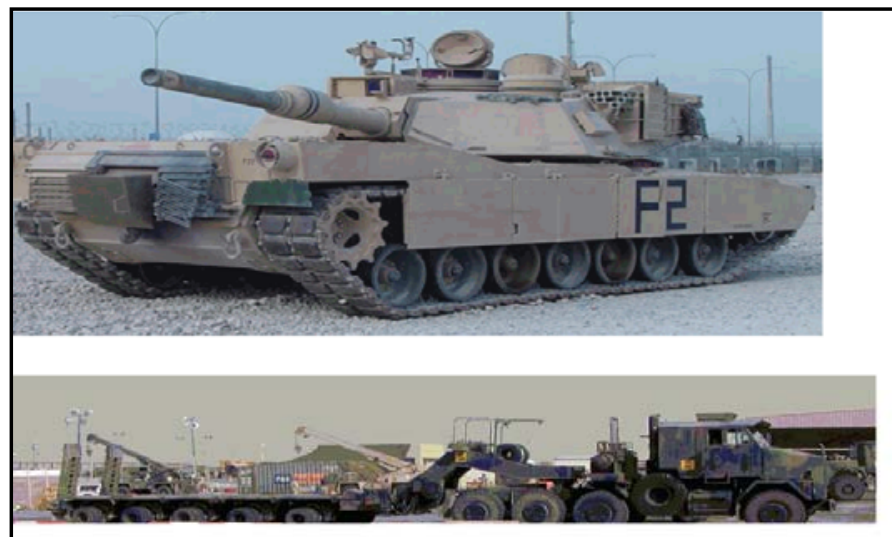

Cleaning Time $=14$ to $24 \mathrm{hr}$

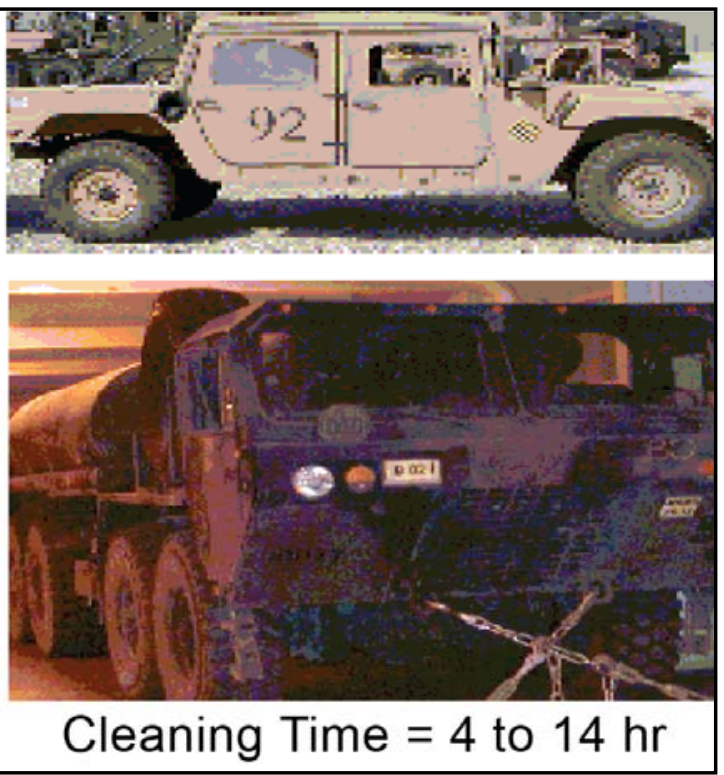

Figure 19. Cleaning times for representative vehicles (data from 886th and 887th ESFS). 
Table 4. Assumptions on numbers of vehicles cleaned by type.

One third of the total vehicles are larger (tanks) and require a minimum of $14 \mathrm{hr}$ each on station to clean

Two thirds of total vehicles are smaller high mobility multipurpose wheeled vehicles (HMMWVs) and require a minimum of $4 \mathrm{hr}$ each on station to clean

No. Vehicles/Month $\times$ Cleaning Time Each $=$ Total Cleaning Time/Month

Table 5. Estimated cleaning time for vehicles moving from Kuwait.

\begin{tabular}{|l|r|r|r|r|r|r|}
\hline & $\begin{array}{l}\text { Total } \\
\text { Vehicles } \\
\text { (All } \\
\text { Sizes) }\end{array}$ & $\begin{array}{l}\text { No. Larger } \\
\text { Vehicles } \\
(1 / 3 \times \text { Total) }\end{array}$ & $\begin{array}{l}\text { Larger } \\
\text { Vehicle } \\
\text { Clean Time } \\
\text { @ 14 hr } \\
\text { Each, hr }\end{array}$ & $\begin{array}{l}\text { No. Smaller } \\
\text { Vehicles } \\
(2 / 3 \times \text { Total) }\end{array}$ & $\begin{array}{l}\text { Smaller } \\
\text { Vehicle } \\
\text { Clean } \\
\text { Time @ } \\
\text { hr Each, }\end{array}$ & $\begin{array}{l}\text { Total } \\
\text { Vehicle } \\
\text { Cleaning } \\
\text { Time, hr }\end{array}$ \\
\hline Nov & 1,953 & 651 & 9,114 & 1,302 & 5,208 & 14,322 \\
\hline Dec & 1,427 & 476 & 6,659 & 951 & 3,805 & 10,465 \\
\hline Jan & 6,842 & 2,281 & 31,929 & 4,561 & 18,245 & 50,175 \\
\hline Feb & 11,523 & 3,841 & 53,774 & 7,682 & 30,728 & 84,502 \\
\hline Mar & 24,516 & 8,172 & 114,408 & 16,344 & 65,376 & 179,784 \\
\hline Apr & 9,531 & 3,177 & 44,478 & 6,354 & 25,416 & 69,894 \\
\hline May & 2,334 & 778 & 10,892 & 1,556 & 6,224 & 17,116 \\
\hline Jun & 1,000 & 333 & 4,667 & 667 & 2,667 & 7,333 \\
\hline Jul & 6,415 & 2,138 & 29,937 & 4,277 & 17,107 & 47,043 \\
\hline $\begin{array}{l}\text { Total } \\
\text { (9 Months) }\end{array}$ & 65,541 & 21,847 & 305,858 & 43,694 & 174,776 & 480,634 \\
\hline
\end{tabular}

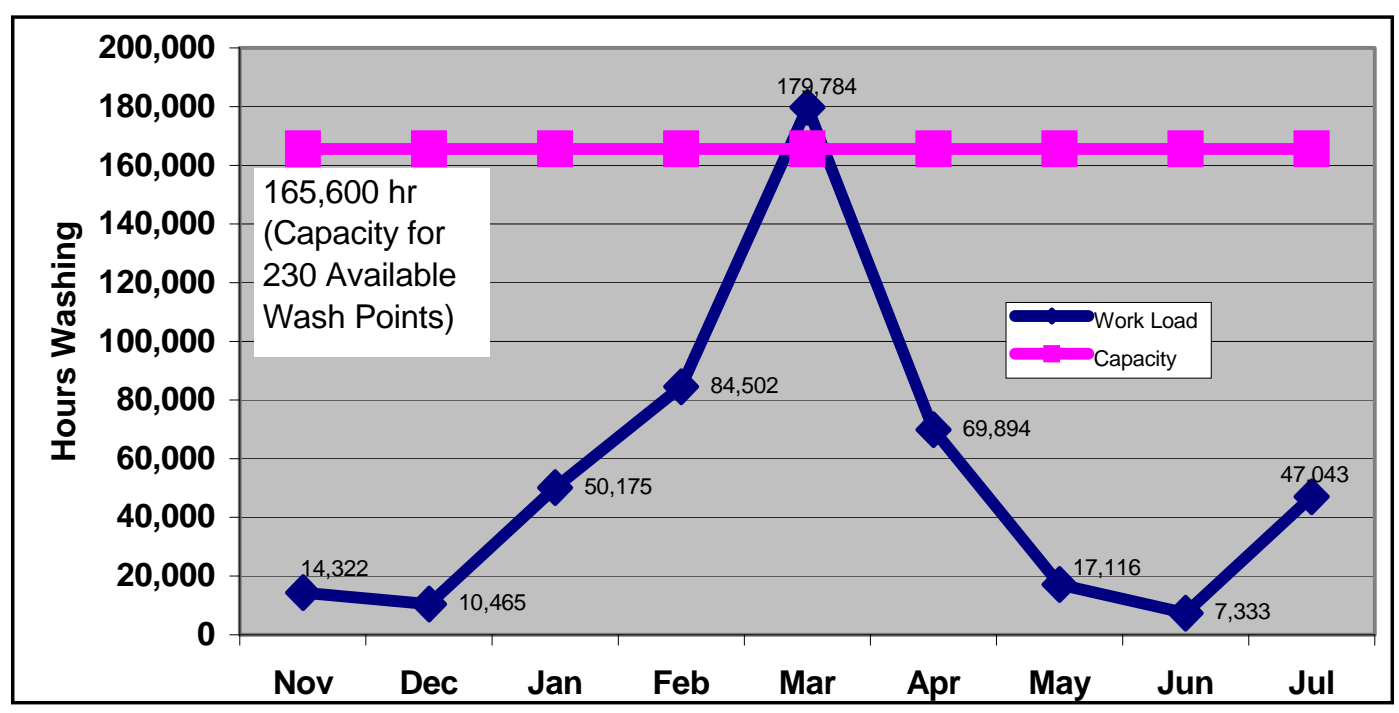

Figure 20. Cleaning hours by month compared to available cleaning capacity at Kuwait. 
The available capacity at the Kuwait facility is $165,600 \mathrm{hr}$ if all 230 available cleaning stations are operated $24 \mathrm{hr}$ per day. Figure 20 shows that the facility was operating at near capacity in March 2004 based on the data and assumptions used in this report.

To illustrate the financial impact of these operations, labor costs alone are estimated in Table 6, which shows that for the 9-month period the vehicle cleaning process costs on the order of \$5-10 million. Added to this is the cost for the inspection force, conservatively estimated at about \$6 million.

Table 6. Estimated cost for vehicle cleaning in Kuwait.

\begin{tabular}{|c|c|c|c|}
\hline \multicolumn{4}{|c|}{ (Assume labor cost of $\$ 5-10 / h r$ and 2 persons per vehicle) } \\
\hline Month & $\begin{array}{l}\text { Total Vehicle Cleaning } \\
\text { Time, hr }\end{array}$ & $\begin{array}{l}\text { Labor Cost, } 2 \text { Pers @ } \\
\$ 5 / \mathrm{hr}\end{array}$ & $\begin{array}{l}\text { Labor Cost, } 2 \text { Pers @ } \\
\$ 10 / \mathrm{hr}\end{array}$ \\
\hline Nov & 14,322 & $\$ 143,220$ & $\$ 286,440$ \\
\hline Dec & 10,465 & $\$ 104,650$ & $\$ 209,300$ \\
\hline Jan & 50,175 & $\$ 501,750$ & $\$ 1,003,500$ \\
\hline Feb & 84,502 & $\$ 845,020$ & $\$ 1,690,040$ \\
\hline Mar & 179,784 & $\$ 1,797,840$ & $\$ 3,595,680$ \\
\hline Apr & 69,894 & $\$ 698,940$ & $\$ 1,397,880$ \\
\hline May & 17,116 & $\$ 171,160$ & $\$ 342,320$ \\
\hline Jun & 7,333 & $\$ 73,330$ & $\$ 146,660$ \\
\hline Jul & 47,043 & $\$ 470,430$ & $\$ 940,860$ \\
\hline Total (9 months) & 480,634 & $\$ 4,806,340$ & $\$ 9,612,680$ \\
\hline
\end{tabular}




\section{Discussion}

\section{Europe (EUCOM area)}

EUCOM has well-developed protocols for dealing with invasive species. Operations at a moderate activity level related to invasive species are conducted at 88 locations. The cleaning programs in EUCOM focus on the key problems from the particular region where cleaning is being conducted. For example, nematodes are problematic in the United Kingdom, France, and The Netherlands, while snails are a major problem in Italy, Spain, and Turkey. Inspectors key into these problems when conducting inspections but are also aware of other potential invasive species. EUCOM's program has benefited from the permanent presence of USDA personnel to assist with various issues and from its own annual training program for personnel involved in the program.

In Europe the storage areas for equipment were well maintained; however, the equipment remained in these areas for extended periods of time, often years. This makes the equipment more susceptible to reinfestations of invasive species. In Italy, for example, even though equipment was cleaned prior to being placed in the storage area, snails reinfested the equipment in a relatively short period of time. Even when housed in protective cases, there was a high probability that snails would become attached to the equipment. When dealing with organisms such as snails, if equipment is not loaded on transports rapidly, the likelihood of reinfestation becomes almost a certainty. This means that every piece of equipment will have to be cleaned and reexamined to ensure removal of organisms.

Inspections of the storage areas in Italy were conducted in 2002 prior to the increase in operations tempo. Livorno site personnel indicated that dirty equipment received at this depot from the first Gulf War was cleaned locally. During inspections conducted in Germany during 2004, Air Force personnel discussed the problem of washing equipment that arrives via aircraft that is dirty and is being transferred to other aircraft. Previously, personnel would clean the dirty equipment; however, the German Government has protested because the air base had no way to contain either the material removed or the water that was used for washing. The current procedure would be to send it to the unit in-country or to pass it through to its next destination. Nations in the EUCOM area are developing more rigid 
policies in dealing with U.S. military equipment potentially contaminated with invasive species.

Invasive species are changing or modifying the movement operations of the military in EUCOM. In a recent briefing on the invasive species issue, the Navy Region Europe (2006) raised a concern about their wash down facilities in Rota, Spain, where Marine Expeditionary Force equipment is cleaned after operations in Southwest Asia and Africa. Without adequate facilities to contain or decontaminate vehicle wash water, there is a potential for release of invasive species or contaminants onto land or into waters of Spain. Anyone causing actual damage to the biological balance in Spain through the release of invasive species may be in violation of Spanish law. Executive Order 13112 (The White House 1999) may also apply if there is or likely to be harm due to invasive species in the United States or elsewhere.

The identification of North American snails (Figure C8) on material being shipped back from Europe also raises other questions. How careful are we when we deploy from CONUS to ensure that we are not moving native North American species or known invasive species to other regions of the world? This pathway is one that has received little attention even though the U.S. Transportation Command (TRANSCOM) regulation (DoD 2006) does make a reference to this situation. Early messages from CENTCOM in 2004 (Figures C21 and C22) indicated that they thought they did not have to clean equipment that was returning to EUCOM-just equipment going to the United States. The responsibility of not moving contaminated equipment or personnel belongs to the unit commander; however, the commander does not have trained personnel such as the USDA inspectors to support and ensure his equipment is free from invasive species.

\section{Southwest Asia (CENTCOM area)}

The CENTCOM AO with the greatest throughput did not have a USDA representative overseeing operations onsite at the time of the onsite review. In addition, in September 2004 the 430 Air Force personnel conducting these operations were scheduled to be replaced by a new group of Air Force inspectors who had not received any training from USDA personnel. Every 6 months thereafter personnel were scheduled to rotate with the Navy and/ or Air Force providing the replacements. CENTCOM's plan called for on-the-job training of the replacement personnel by the outgoing force. 
The Air Force group conducting inspections in August 2004 appeared to be well informed and was meeting the requirement in an outstanding fashion. The responsibility to pass on USDA requirements should be shared by the USDA, as well as the onsite inspectors. In addition, the USDA stated that the equipment currently being transported (August 2004) did not have a pre-cleared status since there was no USDA individual in-country to oversee the operations. In Kuwait the team found that equipment being prepared for shipment out of country via the SPOD was cleaned and stored according to USDA guidelines. Once equipment was cleaned and placed into a secure holding area it remained relatively free of invasive species. The major concern noted was that sand or wind-blown dust would cover the equipment when left in the holding for long durations. This material is generally easy to remove during the final rinse prior to loading the equipment onto the cargo ship.

The cleaning and storage of equipment for transport through the APOD was not as regulated. It appears that the APODs have only minimal cleaning protocols or capability. If equipment arrives dirty, it may not be cleaned to meet USDA standards. This often presents a problem. The material being transported via aircraft is high priority equipment that needs to be moved to another location quickly. Often the crew will allow dirty equipment onto the aircraft so the mission can be completed. Reduced available ground time may also be caused by weather conditions. During the hot months in CENTCOM, aircraft such as the C-17 will land and not turn off its engines to avoid restarting problems in the heat. While this aircraft is on the ground, running decisions have to be made on whether to take critical cargo or not. This increased tempo often causes personnel to overlook problems with equipment. Once the equipment is in transit, it then becomes the problem of the port of debarkation on what to do with dirty equipment. As indicated previously, this situation has occurred with CENTCOM shipments that have arrived in Germany.

It should also be noted that equipment arriving into Kuwait is not inspected. In discussions with personnel at the SPOD and the APOD, no one realized that they should be examining incoming equipment. The TRANSCOM regulation (DoD 2006) states "It is DoD policy that equal vigilance will be exercised in preventing the export of agricultural pests to our foreign host nations." The regulation does not give inspection protocols or procedures and the movement of material and equipment between foreign countries is not under the purview of the USDA so it is 
solely the responsibility of the military and the host nation personnel to prevent introductions.

\section{General discussion}

Invasive species have gained attention because of the problems they cause, including habitat disruption, impacts on biological diversity, damage to agriculture, and health issues. The question is then raised, how can research prevent these species from causing problems? The best approach is to eliminate the pathway or conduit that allows the invasive species to move freely. Any organism moved from its native range to a new location can become an invasive species, so every organism is a potential invasive species.

Ports of embarkation and debarkation act as conduits for the movement of invasive species. They can also act as choke points to restrict the movement of invasive species. By controlling these conduits/ pathways, personnel can regulate the movement of invasive species. It has become quite clear that the rule should be that nothing should be shipped when it is dirty. Inspections conducted during this project revealed that, in most situations at SPODs, cargo being loaded onto ships was clean and did not contain invasive species. The main area of concern in this pathway is cleaning equipment and cargo prior to entering into the staging area or sterile lot. Care must be taken to prevent the reinfestation of the material in these areas. This may be a more significant problem depending on the region of the world where the material is being stored.

Cargo being loaded onto aircraft presents a different problem. Because of the limited carrying capacity of the aircraft and the reduced storage area, many personnel feel it is easy to preclude the movement of invasive species. In many situations this is correct; the crew chief can easily prevent dirty or contaminated equipment from entering the transport. However, during times of high tempo operations, scrutiny of cargo being loaded is often reduced.

Each theater appears to operate independently when dealing with USDA inspectors. Some have a regulated approach like EUCOM. Others like CENTCOM are still developing their procedures. A more regimented policy that is uniform across theaters should be established. 
One major aspect that was not anticipated was the extensive amount of time and funds being devoted to the process of stopping the movement of invasive species. Significant resources need to be allocated to the cleaning and inspection process. In theaters where the operations tempo is high, this could amount to significant portions of a unit's resources. The lack of general awareness of the magnitude of these efforts and expenses is a significant problem. Unit commanders often do not allocate adequate resources for these missions, which causes extensive delays and may alter redeployment operations. In depot operations in EUCOM, no special funding was available to reclean equipment that had been stored. Funds to address these requirements were taken out of the operational budget of the depot. If these requests are minimal then they can be absorbed; however, when a large amount of equipment is needed or the infestation of invasive species is extensive, significant problems arise in being able to meet the requests. Also, the team only calculated the time and cost associated with the cleaning of vehicles, and did not examine the time and cost of cleaning containers, aircraft, and personal equipment. If these other aspects are considered, the cost would more than double.

\section{DoD roles and responsibilities}

TRANSCOM is DoD's executive agent in handling the movement of all military personnel and equipment and should be the focal point of the DoD response to mitigate the movement of invasive species and contaminants. TRANSCOM's role should be to facilitate coordination with other federal agencies that have regulatory requirements that need to be met prior to the introduction of personnel and equipment into the United States, including the USDA, the U.S. Department of Homeland Security (USDHS), and the U.S. Fish and Wildlife Service. These considerations may have different impacts in the various theaters where DoD operates. Having TRANSCOM initiate the coordination process between the agencies and the theater will promote a better understanding of the implications that the agency requirements will have on the movement of personnel and materials out of the theater.

In exercising this responsibility TRANSCOM should provide the framework and structure to have the USDA and USDHS coordinate with the respective theater staffs. This coordinating process will allow the various organizations to understand the requirements for retrograde operations. After these foundational steps occur, operational personnel from the organizations can begin to formulate a process for retrograde operations. 
One key aspect that should be identified early is that military inspectors need to be trained by USDA and USDHS personnel on the agencies' standards for the introduction of personnel and equipment entering the United States. Theater commanders and unit commanders may expand on these requirement levels but they cannot reduce the levels since these are federal requirements mandated by the agencies.

The TRANSCOM regulation (DoD 2006) requires that units meet the standards of the country they are entering. The information is often very limited or non-existent. Meeting standards becomes a unit commander's responsibility. Movement of equipment between theaters is not covered under the USDA standards, although commanders are advised to use these standards.

The DoD Military Customs and Border (Pre-Departure) Clearance/ Inspection Program uses guidance and instructions provided by the USDA to ensure that its cleaning operations will meet the standards for introducing personnel and equipment into the United States. The pre-clearance program allows better utilization of resources because cleaning is conducted OCONUS where organisms are native and would not be a pollutant. If the pre-clearance programs were not in place, dirty equipment would be identified at the U.S. port of debarkation and would have to be cleaned. Organisms that were removed would have to be destroyed. The cleaning water would have to be processed to ensure that no contamination occurred in the United States.

The Armed Forces Pest Management Board Technical Guide No. 31 Retrograde Washdowns: Cleaning and Inspection Procedures (Armed Forces Pest Management Board 2004) is the primary published reference available to the U.S. military to guide clearance procedures. A copy of this guide is viewable on the Internet at http:/ / www.afpmb.org/ pubs/ tims/ tg31/tg31.pdf. DoD Directive 4500.9-R, Defense Transportation Regulation, Part V, outlines DoD's Military Customs Border and Clearance/ Inspection Program authority with USDA's regulations (DoD 2006) (http:// www.transcom.mil/j5/pt/dtr.cfm). 


\section{Conclusions and Recommendations}

\section{Conclusions}

The following conclusions can be drawn:

- Invasive species can be controlled by management of the transportation pathway.

- DoD expends significant resources in preventing the movement of invasive species.

- Generally the military has an excellent program for cleaning and inspecting equipment returning to CONUS.

- Some military equipment is not adequately clean when it is transported.

- Unit commanders are responsible for the movement of their personnel and equipment and the prevention of invasive species movement.

- SPODs and APODs act as a pathway for the transport of invasive species.

- Cleaning of military equipment moving through airports becomes more problematic than movement through seaports. These problems are due to the shorter time frame for air transport, the unavailability of cleaning equipment and water in remote airports of embarkation, and limited area available for operations.

- Operational considerations do not always allow for cleaning time, particularly where aircraft are landing in a hostile or climate-restricted zone.

- The USDA has a designated staff position for an inspector in EUCOM. Locating this representative with the EUCOM staff has proven its value both to USDA and EUCOM.

- The USDA does not have a designated staff position in CENTCOM.

- DoD needs to ensure that U.S. deployments from CONUS locations to other nations or territories are not a conduit for the global spread of invasive species.

- As the invasive species problem escalates, DoD will be faced with additional responsibilities. DoD will need to ensure that the shipment of personnel and equipment between theaters is not contaminated with invasive species. 


\section{Recommendations}

The following recommendations are made:

- Develop a standardized procedure at the TRANSCOM level to coordinate USDA involvement within all theaters.

- Have TRANSCOM develop standards and policies that address, in detail, the cleaning and inspection requirements for the movement of personnel and equipment between theaters and deploying from CONUS. These standards and policies must receive adequate staffing, funding, training, and enforcement to minimize transport of invasive species.

- Conduct annual reviews of procedures.

- Identify a military organization, such as the Armed Forces Pest Management Board, that can assist in ensuring the inspection process is followed and that can provide oversight and technical support for the DoD.

- Direct an outside review of existing and new procedures from academia and key host nations.

- Understand that islands and other isolated geographical locations may require special evaluations when moving equipment and personnel into and out of these areas.

- Ensure that ports of debarkation have the capability to neutralize invasive species and meet the in-country laws and regulations. 


\section{References}

Armed Forces Pest Management Board. 2004. Retrograde washdowns: Cleaning and inspection procedures. Technical Guide No. 31. Washington, DC: Defense Pest Management Information Analysis Center.

http:// www.afpmb.org/ pubs/ tims/tg31/ tg31.pdf

Australia Quarantine and Inspection Service. 2000. Evaluation of the quarantine risks associated with military and humanitarian movements between East Timor and Australia. Northern Australia Quarantine Strategy. Canberra ACT 2601, Australia: Australian Quarantine and Inspection Service. http:// www.affa.gov.au/corporate_docs/publications/word/market_access/bi osecurity/animal/ etimorrisk.doc

Bolton, H. C. 1999. Personal communication. U.S. Navy, Armed Forces Pest Management Board.

Department of Defense. 2006. Defense Transportation Regulation, Part V, Department of Defense Customs and Border Clearance Policies and Procedures. DoD Regulation 4500.9-R. Washington, DC: Department of Defense. http:// www.transcom.mil/j5/pt/dtr.cfm

Manning, W. L. 2004. Personal communication. U.S. European Command.

National Invasive Species Council. 2001. Meeting the invasive species challenge: National invasive species management plan. Washington, DC: National Invasive Species Council.

Navy Region Europe. 2006. Personal communication. Invasive species issue related to tactical vehicle washing briefing package.

Pimentel, D., R. Zuniga, and D. Morrison. 2005. Update on the environmental and economic costs associated with alien-invasive species in the United States. Ecological Economics 52:273-288.

Pomerinke, M. 1999. Personal communication. Headquarters, U.S. Air Force Europe.

Rivera, D. 2001. Personal communication. U.S. Department of Agriculture, Animal Plant Health Inspection Service.

Solsa, E. 2004. Personal communication. U.S. Department of Agriculture, Animal Plant Health Inspection Service.

The White House. 1999. Invasive species. Executive Order 13112 of February 3, 1999. Washington, DC. 


\section{Appendix A: Laws, Rules, and Regulations Governing the Department of Defense in Control of Invasive Species}

\section{Federal Laws}

The National Invasive Species Council (2001) identified and briefly described as follows statutes that in some way address the invasive species issue and that are relevant to the Department of Defense (DoD).

\section{Plant Protection Act}

- 7 U.S.C. 7701 et seq.

- Consolidated the authorities of the Plant Quarantine Act, Federal Plant Pest Act, Federal Noxious Weed Act, and other plant-related statutes.

- Authorizes U.S. Department of Agriculture (USDA) to prohibit or restrict the importation or interstate movement of any plant, plant product, biological control organism, noxious weed, article or means of conveyance if necessary to prevent the introduction into the United States, or the dissemination within the United States of a plant pest or noxious weed.

\section{Federal Seed Act}

- 7 U.S.C. 1581 et seq.

- Requires accurate labeling and purity standards for seeds in commerce, and prohibits the importation and movement of adulterated or misbranded seeds.

- Authorizes the USDA to regulate the importation and movement of field crop, pasture and forage, or vegetable seed that may contain noxious weed seeds.

\section{Animal Quarantine Laws}

- 21 U.S. 101-135b and 19 U.S.C. 1306

- Authorizes USDA to promulgate regulations and take measures to prevent the introduction and dissemination of communicable diseases and pests of livestock and poultry. 
- Authorizes USDA to seize, quarantine, and dispose of animals, animal products, or other material that can harbor disease or pests of livestock or poultry that are moved in interstate or foreign commerce.

\section{Virus-Serum-Toxin Act}

- 21 U.S.C. 151 et seq.

- Authorizes USDA to regulated veterinary biological products that are intended for use in the treatment of diseases of animals.

\section{Animal Damage Control Act of $\mathbf{1 9 3 1}$ as amended in the Agricultural Appropriations Act of 2001}

- Provides USDA the general authority under which the Animal Plant Health Inspection Service (APHIS) Wildlife Services program functions.

- Primary program for research and control on the brown tree snake that has devastated bird populations on Guam.

\section{Organic Administration Act}

- 16 U.S. 551

- Protects National Forests from destruction by fire and depredations.

\section{Multiple-Use Sustained-Yield Act of 1960}

- 16 U.S.C. $528-531$

- Provides that the National Forests are established and shall be administered for outdoor recreation, range, timber, watershed, and wildlife and fish purposes.

Forest and Rangeland Renewable Resources Planning Act of 1974, as amended by National Forest Management Act

- 16 U.S.C. 1604

- Provides that forest plans establish forest-wide and area-specific management direction and may include management direction relating to the control of invasive species.

\section{Federal Noxious Weed Act of 1974}

- 7 U.S.C. 2814 
- Requires federal land management agencies to develop and establish a management program for control of undesirable plants that are classified under state or federal law as undesirable, noxious, harmful, injurious, or poisonous on federal lands under the agency's jurisdiction.

\section{Nonindigenous Aquatic Nuisance Prevention and Control Act}

- 16 U.S.C. $4701-4741$

- Seeks to prevent and control infestations of the coastal inland waters of the United States by zebra mussel and other nonindigenous aquatic nuisance species.

\section{National Invasive Species Act of 1996 (Public Law 104-332)}

- 16 U.S.C. 4701 et seq.

- "An Act to provide for ballast water management to prevent the introduction and spread of nonindigenous species into the waters of the United States and for other purposes."

\section{The Lacey Act}

- 18 U.S.C. 42

- Administered by the U.S. Fish and Wildlife Service.

- Prohibits importation into the United States certain categories of animal species determined to be injurious to human beings; to the interests of agriculture, horticulture, or forestry; or to wildlife or the wildlife resources of the United States.

\section{Endangered Species Act}

- 16 U.S.C. 1531 et seq.

- Relates effect of invasive species on listed endangered species.

\section{National Environmental Policy Act}

- Federal agencies must address impact of invasive species on their actions. 


\section{Executive Order 13112 of February 3, 1999, Invasive Species}

\section{Purpose}

- To prevent the introduction of invasive species and provide for their control and to minimize the economic, ecological, and human health impacts that invasive species cause.

\section{Federal agency duties}

- Each federal agency whose actions may affect the status of invasive species shall, to the extent practicable and permitted by law, identify such actions subject to the availability of appropriations, and within Administration budgetary limits, use relevant programs and authorities to:

(1) prevent the introduction of invasive species;

(2) detect and respond rapidly to and control populations of such species in a cost-effective and environmentally sound manner;

(3) monitor invasive species populations accurately and reliably;

(4) provide for restoration of native species and habitat conditions in ecosystems that have been invaded;

(5) conduct research on invasive species and develop technologies to prevent introduction and provide for environmentally sound control of invasive species; and

(6) promote public education on invasive species and the means to address them; and not authorize, fund, or carry out actions that it believes are likely to cause or promote the introduction or spread of invasive species in the United States or elsewhere unless, pursuant to guidelines that it has prescribed, the agency has determined and made public its determination that the benefits of such actions clearly outweigh the potential harm caused by invasive species; and that all feasible and prudent measures to minimize risk of harm will be taken in conjunction with the actions.

\section{DoD Regulation}

Compliance with federal statutes by the DoD is covered primarily in DoD Regulation 4500.9-R, Defense Transportation Regulation (DTR), Part V, Department of Defense Customs and Border Clearance Policies and 
Procedures. http:/ / www.transcom.mil/j5/pt/ dtr.cfm. Highlights of the requirements of the DTR are as follows:

\section{Policy}

- "It is the policy of the DoD that all organizations and personnel involved in the movement of DoD-sponsored cargo, personal property, and accompanied baggage will take those steps necessary to prevent the spread of agricultural pests from one location to another. This includes movement not only across national borders, but any movement that has the potential to introduce invasive species to a new area. It includes shipments from DoD installations and vendor locations by both military and commercial carriers" (DoD 4500.9-R, DTR Part V, Chapter 505).

- It is DoD policy that equal vigilance will be exercised in preventing the export of agricultural pests to foreign host nations. Generally, the same responsibilities of DoD activities for the prevention of agricultural pest movements apply to export shipments from the United States to foreign countries as well as on imports to the United States (clean, free of soil and pest infestations). Specific country requirements are listed under the applicable country.

\section{Roles and Responsibilities}

- DoD 4500.9-R, DTR, Part III, Mobility, references Part 5 and requires compliance, requires washdown.

- DoD 4500.9-R, DTR, Part V, Section B Chapter 505, addresses prevention of introduction of pests into/ out of United States.

- Deputy Under Secretary of Defense (Environment and Safety) develops technical guidance and recommendations.

- USDA APHIS trains personnel for inspection and has final authority on pest risk status of material.

- Unit commanders ensure DTR requirements are met and procedures are followed to prevent agricultural pests from entering the United States.

- Port and transportation commanders will not allow movement of cargo from facilities unless apparently free of soil, pest infestation, and prohibited agricultural items.

- Armed Forces Pest Management Board recommends policy, provides guidance, and coordinates information exchange. 
- DoD 4500.9-R, DTR, Part V, Section B, Chapters 510-514, provide country-specific requirements for customs/ agricultural pre-clearance. 


\section{Appendix B: 886 Expeditionary Security Forces Group (ESFG) Standard Operating Procedures}

The purpose of this SOP is to provide command policy, procedures, references to authorities, and standardize customs pre-clearance inspections of vehicles, containers, aircraft, and equipment.

\section{Contents}

\section{Chapter 1-General Information}

1.1. References

1.2. Responsibilities

1.3. Purpose

1.4. Policy

\section{Chapter 2-CBCA Duty Description}

2.1. Duty Description

2.2. Authority

2.3. No Authority

Chapter 3-PAX Pre-Clearing Procedures

3.1. Overview

3.2. Requirements

3.3. Physical Requirements for Terminal Operations

3.4. Requirements for Customs Brief

3.5. Examination

3.6. Places of Concealment

3.7. Enforcement Actions

3.8. Personnel Searches

3.9. Sterile Area

3.10. Baggage Detail

3.11. Escort to Aircraft

3.12. Aircrew

Chapter 4-Container Pre-Clearance Procedures

4.1. Overview 
4.2. Clearing Unit's Requirements

4.3. CBCA Requirements for Pre-Clearance

4.4. Examination

4.5. Enforcement Action

\section{Chapter 5-Vehicle Pre-Clearance Procedures}

5.1. Overview

5.2. Clearing Unit's Requirements

5.3. CBCA Requirements for Pre-Clearance

5.4. Requirements for Secondary Cargo

5.5. Requirements for Customs Brief

5.6. Enforcement Action

Chapter 6-Aviation Procedures

6.1. Overview

6.2. Clearing Unit's Requirements

6.3. CBCA Requirements for Pre-Clearance

6.4. Requirements for Customs Brief

6.5. Enforcement Actions

\section{Chapter 7-Pallet Pre-Clearance Procedures}

7.1. Overview

7.2. Clearing Unit Requirements

7.3. CBCA Requirements for Pre-Clearance

7.4. Examination

7.5. Enforcement Actions

\section{Chapter 8--- Sterile Lot Procedures}

8.1. Procedures for Accepting Vehicles into Sterile Lot

8.2. Procedures for Releasing Vehicles from Sterile Lot

8.3. Reporting Instructions

8.4. Procedures for Persons Entering the Sterile Lot

\section{Attachment 1-Glossary of Terms (Omitted from this copy)}

Attachment 2-Prohibited and Restricted Items (Omitted from this copy)

Attachment 3-CBCA Field Guide (Omitted from this copy) 
Attachment 4-UXO Procedures (Omitted from this copy)

Attachment 5-Areas to Check on Vehicles (Included in this copy) Attachment 6-Inspectable Areas on Aircraft (Included in this copy)

Attachment 7-Handling and Storage of Seized Contraband (Omitted from this copy)

Attachment 8-Sample Customs Brief (Omitted from this copy)

Attachment 9-Red Lining Procedures (Omitted from this copy)

Attachment 10-Blank \& Sample Forms (Omitted from this copy)

Attachment 11---Custom Stamp Control (Omitted from this copy)

Attachment 12---Custom Pre-Clearance Scheduling Procedures (Omitted from this copy) 


\section{Chapter 1}

\section{GENERAL INFORMATION}

1.1. REFERENCES: The following references direct policy and procedures that govern the establishment of Military Customs Inspection Programs (MCIP) for all DoD personnel and cargo being returned to CONUS from locations outside the Customs territory of the United States (CTUS).

1.1.1. DoD Reg. 4500.9-R, Mar. 03, Defense Transportation Regulation Part V.

1.1.2. AR190-41, Mar 94, Customs Law Enforcement.

1.1.3. AR 700-93, May 80, Processing and shipping DoD sponsored retrograde material destined for shipment to the United States, its territories, trusts, and possessions.

1.1.4. J oint Memorandum between DoD, US Customs Service, and the US Department of Agriculture.

1.1.5. CENTCOM Reg. 600-10, Military Customs Inspection Program. (Currently under revision. . revision draft is dtd 14 Mar 2004). Un-revised version dtd 5 May 89.

1.1.6. Armed Forces Pest Management Board Technical Information Memorandum (TIM) No. 31 (Contingency Retrograde Washdowns Cleaning \& Inspection Procedures)

1.1.7. General Order Number 1A

1.1.8. CENTCOM FRAGO 09-528 (War Souvenirs)

1.1.9. COMCFLCC FRAGO 98 to COMCFLCC OPORD 03-036 (War Souvenirs)

\subsection{RESPONSIBILITIES:}

1.2.1. 886 ESFG/ S-3 (Operations) Responsibilities: 
1.2.1.1. Develop policy and procedures for customs pre-clearance inspections of personnel, vehicles, containers, aircraft, and equipment.

1.2.1.2. Research references and interface with personnel from the 377 PMO, CFLCC PMO, US Customs, and USDA in order to provide guidance for customs pre-clearance operations.

1.2.1.3. Oversee and standardize the customs pre-clearance process.

1.2.1.3.1. Approve sites selected by subordinate units for pre-clearance operations and ensure it meets the standards as outlined in the various customs regulations, policy letters, and Standard Operating Procedures (SOP).

1.2.1.3.2. Conduct quality control visits to ensure military Customs/ Border Clearance Agents (CBCA) are performing their duties as outlined in customs regulations, policy letters, and SOPs.

1.2.1.4. Act as the central point of contact for customs pre-clearance operations.

1.2.1.5. Task subordinate units to effectively accomplish customs preclearance missions.

1.2.1.6. Coordinate with the 377 and CFLCC PMO to effect policy and/ or procedural changes.

1.2.1.7. Develop procedures to ensure custom stamp control. (See Atch \#11)

1.2.1.8. Determine training requirements and downward direct to ensure consistency.

1.2.2. Unit Commander Responsibilities:

1.2.2.1. Ensure compliance with this SOP, customs related FRAGOs, and the referenced regulations and directives.

1.2.2.2. Develop site/ mission specific SOPs using Group policies and procedures. 
1.2.2.3. Develop work/ rest schedules to ensure CBCAs are effectively utilized to meet mission requirements.

1.2.2.3.1. During the winter months, 1 Oct - $30 \mathrm{Apr}$, the standard work cycle is a 6\&112-hour workweek.

1.2.2.3.2. During the summer months, 1 May - 30 Sep, the standard work cycle is a 6\&18-hour workweek (for outdoor posts). Due to increased operations tempo, units may have to continue in 12-hour shifts. Commanders should ensure adequate work/ rest schedule, regardless.

1.2.2.3.3. Unit commanders may reduce the work-to-rest ratio, if mission taskings permit; however, unit commanders must ensure all personnel have at least one day off per 7-day cycle.

1.2.2.4. Ensure a minimum of one $\mathrm{CBCA}$ is posted for every ten occupied wash points.

1.2.2.5. Conduct site visits to ensure each customs pre-clearance site/ location meets the standards as outlined in the various customs regulations, policy letters, and SOPs.

1.2.2.6. Conduct quality control visits to ensure the CBCAs are performing their duties as outlined in customs regulations, policy letters, and SOPs.

1.2.2.7. Determine logistical requirements based on mission taskings and submit requirements through the $886 \mathrm{ESFG} / \mathrm{S}-4$.

1.2.2.8. Coordinate any customs pre-clearance policy and/ or procedural changes through the 886 ESFG/ S-3.

1.2.2.9. Control and safeguard custom stamps. (See Atch 11)

1.3. PURPOSE: The purpose of the Customs / Border Clearance Agent program is to:

1.3.1. Eliminate the flow of Restricted/Prohibited Articles (agricultural pests, environmental hazards, controlled substances, and contraband) into the Customs Territory of the United States (CTUS) through 
DoD channels by conducting inspections and/ or examinations of all DoD cargo, equipment, aircraft, vehicles, and personnel.

1.3.2. Minimize inconvenience to DoD personnel and delays in movement of DoD cargo and aircraft/ ships caused by the enforcement of US border clearance regulations at ports of entry.

1.3.3. Provide full cooperation and assistance to the US Customs Service (USCS), US Department of Agriculture (USDA), and other government agencies in enforcing US border clearance regulations at port of entry.

\subsection{POLICY:}

14.1. The goal of this document is to outline the procedures for Customs/ Border Clearance Agents (CBCA) to follow when inspecting/ examining cargo and personnel prior to returning to the CTUS. Adherence to these procedures will ensure that no restricted or prohibited articles will enter the CTUS.

\subsubsection{The Department of Defense requires all DoD sponsored cargo will be examined within the overseas area at the point of origin, prior to ship- ment of cargo to the CTUS. A request for waiver must be submitted in writing IAW procedures outlined in DoD reg. 4500.9-R, Mar. 03. Devia- tions from established standards will not be authorized without the approved waiver.}

1.4.4. The Federal Government, through the Plant Pest Act (Public Law 8536) prohibits the introduction of any animal, plant, or material (e.g., soil), considered harmful to US agriculture. Accordingly, DoD cargo returning to CONUS is subject to wash down operations or other cleaning as necessary to ensure proper cleanliness prior to entry into the CTUS. Soil (which can harbor fungi, bacteria, viruses, insects, snails, weeds, etc.) is the number one high-risk substance of concern to USDA and must be removed.

1.4.5. All DoD cargo returning to CONUS must be thoroughly examined by a CBCA to ensure USDA/ USCS standards are met. Once standards are obtained, a DD form 2855 (Military Customs Inspection Label) will be affixed to each piece of equipment, pallet, or container and stamped validating Customs pre-clearance. Cargo entering the CTUS without a 
validated DD Form 2855 will be impounded or turned away at the APOD/ SPOD by USDA/ USCS officials.

1.4.6. Each site has unique challenges to ensure proper inspections/ examinations. Therefore, commanders of Customs inspection site or task force should use this SOP as a guide for developing their own local SOP. 


\section{Chapter 2}

\section{DUTY DESCRIPTIONS}

2.1CBCA: By agreement with appropriate military commands, the US Customs Service will designate specifically assigned military personnel to act as Customs Inspectors at certain military installations. These personnel will be assigned on orders designating them as Customs/ Border Clearance Agents (CBCAs). These orders authorize the individual to perform the duties of a Customs Officer; the scope of these duties will be provided on the form and may vary from facility to facility. Those persons so designated will be responsible for the enforcement of the regulations of the US Customs Services and other related Government Agencies. This may require the inspection of military aircraft, baggage (accompanied and unaccompanied), personnel, and cargo.

\subsection{CBCAs have the authority to inspect:}

2.2.1. US military and civilian aircraft and ships

2.2.2. US military and civilian crew

2.2.3. All US military personnel (Reserve, National Guard, and Active Duty) and DoD-sponsored personnel (includes US retired, dependents, DoD civilians, etc.)

\subsubsection{DoD cargo and vehicles}

2.3. In order to perform these duties, the CBCA has the full range of Customs Authority EXCEPT, under CUSTOMS AUTHORITY, the CBCA MAY NOT:

2.3.1. Assess or collect duties, taxes, or fees.

2.3.2. Search persons

2.3.3. Use detector dogs on persons 


\section{Chapter 3}

\section{PASSENGER PROCEDURES}

3.1. Overview: Passengers (PAX) utilizing DoD owned or controlled air transportation to enter the CTUS will be inspected/ examined as appropriate prior to entering the aircraft. In Kuwait, 100 percent of all items will be examined-IAW TAB B to Appendix 3 of the CFLCC Operations

SOP. The actual physical setup will vary from site to site, but several basic requirements must be met.

\subsection{Requirements:}

3.2.1. Passengers should arrive 8 hours prior to departure.

3.2.2. Every passenger should receive a Customs Brief, to include an Amnesty Brief.

3.2.3. Every passenger must complete the Individual Declaration Form, $\mathrm{CF}$ 6059B.

3.2.4. Baggage is checked by Military Working Dog Teams for explosives and narcotics. (When available).

3.2.5. Passengers must individually go through an Amnesty Box area.

3.2.6. Passengers enter the examination area and turn in their CF 6059B. The CBCA will then examine/inspect the passenger's bags.

3.2.7. The passengers are then directed to a repacking area.

3.2.8. Passengers then proceed to a sterile area where they will remain until called to their flight. If any passenger leaves the sterile area without authorization, they will be re-examined.

3.2.9. Passengers will be escorted to their flight by a certified CBCA.

\subsection{Physical Requirements for Terminal Operations:}


3.3.1. Briefing area with Restricted/Prohibited Articles signs clearly posted.

3.3.2. Amnesty boxes located so that disposal is in a discreet manner.

3.3.3. Inspection/ examination and repacking area.

3.3.4. Sterile area with latrines and water points.

3.3.5. Designated smoking area within sterile area if possible.

3.4. Requirements for Customs Brief: Prior to any actions by the CBCAs, all passengers will receive a Customs Brief explaining prohibited/restricted items and the pre-clearance process that is about to occur.

3.4.1. Prior to the briefing, have the Troop or Chalk Commander call roll from the flight manifest to ensure everyone is present. If the group is too large for the briefing area, brief them in smaller groups.

3.4.2. Ensure all passengers receive a blank $\mathrm{CF}$ 6059B.

3.4.3. Explain how to complete the CF 6059B.

3.4.4. Explain the examination process to include: Amnesty, examination and sterile areas.

3.4.5. Explain prohibited/ restricted articles, and potential consequences of being caught with contraband.

3.4.6. Tell them that if anyone has explosive devices, UXOs, or ammunition to place it next to the Amnesty Box and tell someone it's there. They will still have amnesty.

3.4.7. Check for any questions.

3.4.8. Front load the Troop Commander and the baggage detail.

3.5. Examination: Violations, both petty and serious, may occur because of a misunderstanding of Customs laws. Accordingly, before you inspect 
any baggage you must satisfy yourself that the person clearly understands what is expected and that you have given them every opportunity to properly declare objects acquired abroad. Some questions you may wish to ask include the following:

3.5.1. "Did you receive a briefing on what we are looking for today?"

3.5.2. "Did you have an opportunity to take advantage of the amnesty area?"

3.5.3. "Have you declared all articles that you purchased or acquired in any other manner during this trip?"

3.5.4. "Have you included all clothing and jewelry which you acquired abroad regardless of whether it has or has not been worn?"

3.5.5. "Are you carrying any articles for other persons?" (Mail, letters, gifts etc.)

3.5.6. "Have you included in your exemption purchases made for friends or relatives not intended as gifts?”

3.5.7. "Do you have any meat or animal products, fruits, vegetables, plants, plant products, soil, live insects, cultures, snails, birds, or other animals?"

3.5.8. "Have you declared everything acquired on base/ post facilities while overseas?"

3.5.9. "Are you carrying over $\$ 10,000$ in coin, currency, traveler's checks, money orders, or negotiable instruments?"

Note: During questioning, make a mental note of any inconsistencies or evasions in the answers given. An additional warning regarding their declaration may be given, when deemed appropriate, in language similar to the following:

"If you have failed to declare any article, or have declared any improper value you may change your declaration to correct for these errors before the inspection of your baggage. I must advise you that if inspection reveals any articles, which were not declared, or the values, which you have 
declared, are found to be false, you will not be allowed to change the information given in your declaration. Undeclared, undervalued articles and any prohibited/ restricted articles are subject to seizure and forfeiture. In addition, you may be liable for a substantial penalty or subject to UCMJ action."

When an individual advises you before inspection that certain articles have not been properly declared, you may permit them to amend their declaration.

How detailed an examination varies with the passenger being examined. Closely observe the passenger's demeanor and the manner in which they answer your questions. A seemingly insignificant occurrence or chance remark may indicate that a more intensive examination is warranted. Evasive answers, reluctance to answer questions, not wanting to open containers, naming of superior officers for the purpose of intimidation, offering of gratuities, and other such actions are sufficient cause for you to be alert to the possibility of finding prohibited/ restricted articles and/ or contraband.

Always work systematically to avoid missing an area. When inspecting suitcases, be alert to the possibility of false bottoms or other secret compartments.

\subsection{Places of Concealment:}

3.6.1. Trunks and other containers used for the transportation of passenger's personal effects afford many opportunities for concealment of contraband. Undeclared items have been found hidden in clothing, among toilet articles, in soiled clothing, and in various wrapped packages often found in such baggage. Observe whether a passenger shows unusual interest in the examination of a particular piece of baggage. All baggage should be opened in order to expose the contents, and carefully scrutinized to discover any concealed contraband.

3.6.2. Small valuable objects and narcotic drugs in the form of powders, crystals, capsules or tablets may be readily secreted inside hatbands and sweatbands of hats. Objects also may be hidden under collars and lapels of shirts; sewed into pockets, linings, and seams of garments; under armpits and in various body crevices; in waistbands and cuffs of trousers; in shoes 
and stockings; under bandages; in the crook of the elbow; between the shoulder bag hung around the neck or elsewhere about the body; and in women's handbags and vanity cases. If you have reason to believe that a passenger is concealing objects on their person, notify the NCOIC or OIC to arrange for a personal search.

3.7. Enforcement Actions: There are three basic types of violations: petty, serious, and agricultural. Listed below are examples of each type of violation, and what actions to take upon discovery of the violation.

\subsubsection{Petty Violations:}

3.7.1. 1. Pornographic magazines

3.7.1.2. A small quantity of an unauthorized war trophy

\subsubsection{Ammunition.}

\subsubsection{A few Cuban cigars.}

\subsubsection{Water pipe.}

3.7.1.6. Articles inadvertently not declared.

Action: For petty violations, seize article and explain to the passenger why the article is prohibited. Have the passenger update declaration, if necessary. Annotate findings on appropriate form.

\subsubsection{Serious Violations:}

3.7.2.1. Belligerent or excessively uncooperative subject.

3.7.2.2. Threatens CBCA with bodily harm.

3.7.2.3. Physically prevents CBCA from examining an object or container.

3.7.2.4. Attempts to bribe CBCA to allow prohibited or restricted item to pass. 
3.7.2.5. Any explosives or UXOs.

3.7.2.6. Any weapons (firearm).

3.7.2.7. Any narcotics or controlled substances.

3.7.2.8. Large quantities of undeclared merchandise.

3.7.2.9. A willful violation. (The intentional concealment of prohibited, restricted, or contraband items is a willful violation.)

\section{Action:}

Detain the passenger (Use handcuffs only if necessary).

Contact Group TOC at DSN 825-1440 or cell 968-1908, and request presence of either CID (Army) or NCIS (Navy or Marine).

Seize evidence on DA Form 4137, Evidence/ Property Custody Document to start chain of custody.

Prepare DA Form 2823, Sworn Statement. CID/ NCIS will conduct investigation to include preparing the DA Form 3881, Rights Warning

Procedure/ Waiver Certificate and apprehending subject.

If CID/NCIS do not respond, then CBCA's at the scene will conduct the investigation.

Apprehend subject.

Complete DA Form 3881, Rights Warning Procedures/Waiver Certificate.

Complete DA form 3975, Military Police Report.

Release subject to unit commander on DD Form 629, Receipt for Prisoner or Detained Person.

3.7.3. Agricultural Violations:

3.7.3.1. Soil or sand present. 


\subsubsection{Unauthorized food.}

3.7.3.3. Article with uncertified stuffing

3.7.3.4. Any agriculturally prohibited items.

Actions: If item is dirty, have the passenger clean item. Otherwise seize prohibited article and explain reason for seizure. All agricultural violations will be corrected on the spot.

\subsection{Personal Searches:}

3.8.1. During the course of a passenger's baggage examination circumstances may indicate the need for a personal search of the declarant. These circumstances may include the detection of a suspected controlled substance in the baggage or the wear of excessively bulky clothing.

3.8.2. Under no circumstances will the CBCA search an individual under Customs Authority.

Note: While it's true CBCAs cannot search individuals or use MWDs to search individuals under Customs authority, they may, however, search individuals or use MWDs to search individuals, if the situation warrants, and the CBCA has military authority to do so.

3.8.3. The CBCA will contact the OIC or NCOIC who will determine if a search is required. If so, they will contact the 886 ESFG TOC at DSN 8251440 or cell 968-1908. Personal searches will occur out of public view.

\subsection{Sterile Area:}

3.9.1. Once examined, the passenger moves into the sterile area. No one may leave the sterile area.

3.9.2. Those inside the sterile area may not come in contact with those outside the sterile area.

3.9.3. The sterile area should be equipped with latrines and supplied with water. MREs or meals should be provided if necessary. 
3.9.4. The sterile area needs to be controlled by a CBCA until passengers depart for the aircraft.

3.9.5. Observe occupants in the sterile area to ensure contraband isn't introduced into the sterile area.

3.9.6. Anyone who leaves the sterile area needs to be re-examined and a new declaration completed.

3.9.7. After all passengers have been examined hand over stamped Customs Declarations to the Troop Commander. Verify that the correct number of declarations is present. If incorrect number is present, check against the manifest to identify who is missing a declaration. Direct the Troop Commander to present declarations to the Customs Official at the port of entry to the CTUS.

3.9.8. Ensure departing passengers police the sterile area of all trash and leave the area in good order.

3.10. Baggage Detail:

3.10.1. The baggage detail must be under constant observation by a CBCA.

3.10.2. The aircraft cargo area must be searched for cleanliness and/ or presence of contraband prior to loading of baggage. - this requirement pending clarification.

3.10.3. The baggage detail must bring their hand carried luggage with them, as they will usually not return to the sterile area.

3.11. Escorting Passengers to Aircraft:

3.11.1. Airfield operations will notify the CBCAs when they are prepared for the passengers to move to the aircraft.

3.11.2. A CBCA will remain with the passengers until they have boarded the aircraft and the aircraft has departed. For passenger movements from the APOD at Camp Doha, two CBCAs will accompany the passenger escort detail-one in the lead vehicle and one in the trail vehicle. 
3.12. Aircrew: Aircrews for all military and military controlled-aircraft must be pre-cleared for Customs, provided that the aircrew will be flying directly to CTUS. If the crew will be changed out enroute, customs preclearance would be irrelevant. If the aircrew will be cleared, follow the below steps.

3.12.1. The flight crew will complete a General Declaration (outward/inward), CF-7507, Agriculture, Customs, Immigration, and Public Health form.

3.12.2. The aircrew will receive a briefing and complete a customs declaration (DD Form 1854, CF 5123, or CF 5129).

3.12.3. Examine bags.

3.12.4. Process expeditiously to avoid delays.

3.12.5. Maintain sterility following examination/inspection.

This requirement is on hold pending further clarification. 


\section{Chapter 4}

\section{CONTAINER PROCEDURES}

4.1. Overview: DoD reg. 4500.9-R requires ALL DoD-sponsored cargo be examined within the overseas area at the point of origin prior to shipment of cargo to CTUS. In keeping with this requirement, the unit preparing for redeployment will arrange to have CBCAs present during the loading of their containers. The CBCAs will examine all cargo (personal and government) to ensure compliance with US Customs laws and agricultural requirements. Following examination, the container will be sealed and a stamped DD Form 2855 affixed to the exterior of the container. Any container not having a DD Form 2855 will not be allowed to enter the SPOE or the APOE. Prior to boarding of the ship or aircraft, the container will receive a final rinse (if needed).

\subsection{Clearing Unit's Requirements:}

4.2.1. Unit schedules the pre-clearance of their containers at least 48hours out (DSN 825-1440, cell 968-1908).

4.2.2. Unit will ensure all equipment is clean prior to inspection.

4.2.3. Prior to arrival of CBCAs, all containers will be unloaded, and the equipment will be staged for inspection. Avoid laying equipment directly on ground. Ideally some sort of hardstand should be available, or else lay plywood or tarps underneath.

4.2.4. All locked/ taped boxes need to be opened and emptied for inspection.

4.2.5. Personal property/ equipment may be included in DoD cargo shipments. However, the owner or responsible party must be present during the inspection and when the gear is palletized/ containerized.

4.2.6. Develop load plan prior to inspection.

4.2.7. Have sufficient personnel present to correct any deficiencies noted, and to ensure efficient loading of containers. Unit should bring brushes and rags. 
4.2.8. Interior of all containers must be swept prior to arrival of CBCAs. Commander will brief troops about prohibited/restricted items prior to inspection.

\subsection{CBCA Requirements for Pre-clearance:}

4.3.1. Once tasked with the specific job by the applicable squadron's controller, the NCOIC will contact unit POC at least $24 \mathrm{hrs}$ prior to appointment to:

\subsubsection{Verify location and number of containers.}

4.3.1.2. Determine number of personal bags and footlockers to be uploaded. Inform POC that the owners/ responsible person of the bags/ footlockers needs to be present for the examination.

4.3.1.3. Confirm that all containers will be downloaded and swept out prior to CBCA arrival.

4.3.1.4. Remind that all locked/ taped boxes must be readily accessible for inspection.

4.3.1.5. Determine if any containers have not been opened and have their original seals intact. Inform POC that these containers need not be opened.

4.3.1.6. Verify personnel have been briefed on prohibited/restricted items.

4.3.2. NCOIC will conduct a Customs Brief prior to starting inspections/ examinations. Be sure to include an Amnesty period.

4.3.3. Containers that have not been opened in theater will be inspected to verify that they have not been opened (the original security seal is still intact; verify against DD Form 2855).

4.3.3.1. A random sample ( 10 percent) of containers will be opened to determine if windblown soil has entered containers through improperly sealed doors. If sample inspection reveals soil contamination, then all containers will be opened and all visible soil will be swept out. This does not necessarily require the containers to be down loaded. 
4.3.3.2. After the integrity and cleanliness of the interior is established, a new security seal will be affixed to the doors (where applicable) and a new DD Form 2855 completed, stamped, and affixed to the door. The new seal \# and container \# will be annotated on the form.

4.3.4. All other containers must be downloaded for examination. The interiors will be swept to remove contamination. Cleanliness will be verified by a CBCA before loading begins.

4.3.5. CBCAs will examine 100 percent of all cargo and personal baggage prior to loading.

4.3.6. Once cargo is cleared for loading, a CBCA will observe the loading of the container to ensure no contraband or unexamined cargo is loaded. Owner/ User of inspected cargo will not depart for lunch or appointments. NOTE: Owner/ User is responsible for loading of items. Under no circumstances will CBCAs assist in loading of items.

4.3.7. All bracing material (plywood, lumber, etc.) will be examined to ensure no signs of insect infestation.

4.3.8. Once a container is loaded and locked, the CBCA will seal and affix a stamped DD Form 2855 to the door above the seal. Be sure to annotate the seal \# and container \# on the DD Form 2855.

4.3.9. Be sure to log the container \#'s and Seal \#'s on the container log sheet.

4.3.10. Log any contraband seized on the contraband inventory sheet. Turn in the completed form to the $886 \mathrm{ESFG} / \mathrm{S} 2$.

NOTE: If the NCOIC determines that the unit being cleared is not prepared for inspection (i.e. equipment dirty, not staged properly, insufficient personnel, etc.), they will explain the problems to the POC to give them the opportunity to correct the problems. If the problems continue, the NCOIC may terminate the inspection and direct the POC to reschedule through the applicable squadron's TOC.

4.3.12. Requirements for Customs Brief: Prior to any actions by the CBCAs, everyone will receive a Customs Brief explaining 
prohibited/restricted items and the pre-clearance process that is about to occur.

4.3.12.1. Prior to briefing ensure everyone is present. If the group is too large for the briefing area, brief them in smaller groups.

4.3.12.2. Explain the inspection/ examination process to include amnesty.

4.3.12.3. Explain prohibited/ restricted articles and the potential consequences of being caught with contraband.

4.3.12.4. Tell them if anyone has explosive devices, UXO's, or ammunition they need to inform an inspector prior to the start of the examination they will still have amnesty.

\subsubsection{Check for any questions.}

4.4. Examination: Violations, both petty and serious, may occur because of a misunderstanding of the Customs laws. Accordingly, before you inspect any baggage you must satisfy yourself the person clearly understands what is expected and has been given every opportunity to properly declare objects acquired abroad. Some questions you may wish to ask include the following:

\subsection{1. "Did you receive a briefing on what we are looking for today?"}

4.4.2. "Did you have an opportunity to take advantage of the amnesty period?"

4.4.3. "Are you carrying any articles for other persons?" (Mail, letters, gifts etc.)

4.4.4. "Do you have any meat or animal products, fruits, vegetables, plants, plant products, soil, live insects, cultures, snails, birds, or other animals?"

4.4.5. "Are you carrying over $\$ 10,000$ in coin, currency, traveler's checks, money orders, or negotiable instruments?" 
4.4.6. During questioning, make a mental note of any inconsistencies or evasions in the answers given.

4.4.7. How detailed an examination varies with the passenger being examined. Closely observe the person's demeanor and the manner in which they answer your questions. A seemingly insignificant occurrence or chance remark may indicate that a more intensive examination is warranted. Evasive answers, reluctance to answer questions, not wanting to open containers, naming of superior officers for the purpose of intimidation, offering of gratuities, and other such actions are sufficient cause for you to be alert to the possibility of finding prohibited/restricted articles. Always work systematically to avoid missing an area. When inspecting suitcases, be alert to the possibility of false bottoms or other secret compartments.

\subsubsection{Places of Concealment:}

4.4.8.1. Trunks and other containers used for the transportation of passengers' personal effects afford many opportunities for concealment of contraband.

4.4.8.2. Undeclared items have been found hidden in clothing, among toilet articles, in soiled clothing, and in various wrapped packages often found in such baggage.

4.4.8.3. Observe whether a person shows unusual interest in the examination of a particular piece of baggage.

4.4.8.4. All baggage should be opened in order to expose the contents, and carefully scrutinized to discover any concealed contraband.

4.4.8.5. Wooden boxes are particularly susceptible to false bottoms/ sides.

\subsection{Enforcement Actions:}

4.5.1. There are three basic types of violations: petty, serious, and agricultural. Listed below are examples of each type of violation and what actions to take upon discovery of the violation.

\subsubsection{Petty Violations:}


4.5.2.1. Pornographic magazines

4.5.2.2. A small quantity of an unauthorized war trophy.

4.5.2.3. Ammunition.

4.5.2.4. A few Cuban cigars.

4.5.2.5. Water pipe

4.5.2.6. Articles inadvertently not declared.

\section{Action:}

- Seize article, and explain the reason why the article is prohibited.

- Annotate findings on appropriate form.

4.5.3. Serious Violations:

4.5.3.1. Belligerent or excessively uncooperative subject.

4.5.3.2. Threatens CBCA with bodily harm.

4.5.3.3. Physically prevents CBCA from examining an object or container.

4.5.3.4. Attempts to bribe CBCA to allow prohibited or restricted item to pass.

4.5.3.5. Any explosives or UXO's.

4.5.3.6. Any weapons. (firearm)

4.5.3.7. Any narcotics or controlled substances.

4.5.3.8. A willful violation (the intentional concealment of prohibited, restricted, or contraband items is a willful violation).

\section{Action:}

- Detain the passenger (Use handcuffs only if necessary). 
- Contact Group TOC at DSN 825-1440 or cell 968-1908, and request presence of either CID (Army) or NCIS (Navy or Marine).

- Seize evidence on DA Form 4137, Evidence/ Property Custody Document to start chain of custody.

- Prepare DA Form 2823, Sworn Statement. CID/ NCIS will conduct investigation to include preparing the DA Form 3881, Rights Warning Procedure/ Waiver Certificate and apprehending subject.

If CID/ NCIS do not respond, then CBCA's at the scene will conduct the investigation.

- Apprehend subject.

- Complete DA Form 3881, Rights Warning Procedures/Waiver Certificate.

- Complete DA form 3975, Military Police Report.

- Release subject to unit commander on DD Form 629, Receipt for Prisoner or Detained Person.

4.5.4. Agricultural Violations:

4.5.4.1. Soil or sand present.

4.5.4.2. Unauthorized food.

4.5.4.3. Article with uncertified stuffing

4.5.4.4. Any agriculturally prohibited items.

4.5.5. Actions:

4.5.5.1. If item is dirty, have the individual clean item.

4.5.5.2. Otherwise seize prohibited article and explain reason for seizure.

\subsubsection{All agricultural violations will be corrected on the spot.}




\section{Chapter 5}

\section{VEHICLE PROCEDURES}

5.1. Overview: $D o D$ reg. $4500.9-R$ requires $A L L$ DoD-sponsored cargo to be examined within the overseas area at the point of origin prior to shipment of cargo to CTUS. In keeping with this requirement, redeploying units are responsible for cleaning their vehicles to USDA standards. A CBCA will inspect all vehicles for Customs and USDA violations. Once cleared the CBCA will affix a 2855 to the inside windshield (upper right corner of driver's side), place a security seal on all lockable compartments, and direct the vehicle to a sterile holding area. When called for, the vehicles will be moved to the SPOE/ APOE where they will receive a final rinse (if needed) and verification of customs pre-clearance.

\subsection{Clearing Unit's Requirements:}

5.2.1. Unit will arrive at wash rack at designated time. Units redeploying from remote areas will need to locate appropriate wash area and sterile area.

5.2.2. Ensure sufficient personnel present to efficiently clean the vehicles.

5.2.3. All locked compartments need to be readily accessible for inspection.

5.2.4. Ensure sufficient personnel remain with vehicle during examination to correct any deficiencies noted.

5.2.5. Ensure no Secondary Loads (equipment inside of MLVANS, ISUs, and etc.,) are in the vehicles. Secondary loads are inspected prior to the wash rack start date. The only inspections of secondary loads allowed on the wash rack are the Basic Issue Items (BII) for the vehicle being inspected. The BII must be secured in a compartment in the vehicle and accessible to CBCA personnel.

5.2.6. Ensure vehicle fuel tanks have between $1 / 2$ and $3 / 4$ of fuel prior to entering the wash rack. Drives will not be permitted to refuel their vehicles once they enter the wash rack. 
5.2.7. Ensure water buffaloes and tankers are empty and have had a "sniff" test-documentation is required to prove the "sniff" test.

5.2.8. Ensure all tarps and bows on 5-ton and $2 \frac{1}{2} 2$-ton trucks are removed due to ship restrictions on height.

5.2.9. Provide/ Arrange for drivers to move vehicles to sterile area, and later to SPOE/APOE.

5.2.10. Commander will brief soldiers about prohibited/ restricted items prior to inspection.

\subsection{CBCA Requirements for Pre-clearance:}

5.3.1. Inspections will be conducted 24-hours a day unless other wise directed by ESFG S-3.

5.3.2. Remind that all locked compartments must be readily accessible for inspection.

5.3.3. Verify that personnel have been briefed on prohibited/ restricted items.

5.3.4. NCOIC will conduct a Customs brief prior to starting inspections/ examinations. Amnesty period is anytime before the vehicle is inspected.

5.3.5. CBCAs will be available at wash rack to provide advice to the unit.

5.3.6. Examine all vehicles to ensure compliance with USDA regulations.

5.3.4.1. Vehicles will have NO soil, sand, vegetable matter, or insect/animal parts. A light dusting is acceptable.

5.3.4.2. Grease is not considered soil/ dirt.

5.3.4.3. Unit will remove all equipment from vehicles, remove any access panels, and open all compartments IAW CBCA instructions prior to the examination being conducted. 
5.3.4.4. See Attachment \#5 for problem areas.

NOTE: It is recommended that CBCAs examining tracked vehicles be trained on the proper procedures for examining tracked vehicles.

5.3.7. Once a vehicle passes examination, the CBCA will place a security seal on all lockable compartments, affix a completed 2855 (annotating the seal \#'s on the form) to the inside of the windshield (upper right corner of driver's side). For track vehicle, place the DD Form 2855 on the left side, above the track, near the front.

5.3.8. All vehicles need to be escorted from inspection area to sterile area.

5.3.9. Be sure to log type of vehicle and bumper \# on the Vehicle Inspection Log sheet.

5.3.10. Log any contraband seized on the contraband inventory sheet. Turn in the form and contraband to the 886 ESFG TOC.

5.3.11. Contact 886 ESFG TOC (DSN 825-1440 or cell 968-1908) upon completion of inspection to report quantity of vehicles cleared.

5.3.12. Vehicles will be moved from the sterile area to the SPOE/APOE, under CBCA escort, when called for at the port. This requirement has been identified, but has not been implemented due to lack of logistical support.

5.3.13. Vehicles will be staged in another sterile area.

5.3.14. Vehicles will receive a final rinse and verification of customs preclearance prior to loading.

5.3.15. If the DD Form 2855 is removed, or if sterility/ cleanliness is compromised at any time, the vehicle must be re-examined and a new DD Form 2855 affixed.

5.4. Requirements for Secondary Cargo: The only secondary cargo allowed to be placed onto a vehicle is the Basic Issue Item (BII) for that vehicle. The BII must be able to be secured in a lockable container on the vehicle. Once the BII has been examined and cleared it must be sealed and have a separate stamped 2855(annotating seal \#s on the form) placed 
above the seal. Record the seal numbers on the Vehicle Inspection Log sheet.

5.5. Requirements for Customs Brief: Prior to any actions by the $\mathrm{CBCAs}$, everyone will receive a customs brief explaining prohibited and restricted items and the pre-clearance process that is about to occur.

5.5.1. Prior to briefing ensure everyone is present. If the group is too large for the briefing area, brief them in smaller groups.

5.5.2. Explain the inspection/ examination process to include amnesty area.

5.5.3. Explain prohibited and restricted articles and potential consequences of being caught with contraband.

5.5.4. Tell them that if anyone has explosive devices or UXO's, they need to inform an inspector prior to the start of the examination. They will still have amnesty.

5.5.5. Check for any questions.

\subsection{Enforcement Actions:}

5.6.1. There are three basic types of violations: petty, serious, and agricultural. Listed below examples of each type of violations, and what actions to take upon discovery of the violation.

5.6.2. Petty Violations:

5.6.2.1. Pornographic magazines

5.6.2.2. A small quantity of an unauthorized war trophy

5.6.2.3. A few Cuban cigars.

5.6.2.4. Ammunition.

5.6.2.5. Water pipe 
5.6.2.6. Articles inadvertently not declared.

Action:

- Seize article, and explain to soldier reason article is prohibited.

- Annotate findings on appropriate form.

5.6.3. Serious Violations:

5.6.3.1. Belligerent or excessively uncooperative subject. Threatens CBCA with bodily harm.

5.6.3.2. Physically prevents CBCA from examining an object or container.

5.6.3.3. Attempts to bribe CBCA to allow prohibited or restricted item to pass.

5.6.3.4. Any explosives or UXO’s.

5.6.3.5. Any weapons. (firearm)

5.6.3.6. Any narcotics or controlled substances.

5.6.3.7. A willful violation. (The intentional concealment of prohibited, restricted, or contraband items is a willful violation.)

\section{Action:}

- Detain individual (Use handcuffs only if necessary).

- Contact 886 ESFG TOC at DSN 825-1440 or cell 968-1908, and request presence of either CID (Army) or NCIS (Navy or Marine).

- Seize evidence on DA 4137 to start chain of custody.

- Prepare DA 2823.

- CID/ NCIS will conduct investigation to include preparing DA Form 3881, and apprehending subject.

- If CID/NCIS do not respond, then CBCAs at the scene will conduct the investigation.

- Apprehend Subject.

- Complete DA 3881.

- Complete DA 3975. 
- Release subject to unit commander on DD 629.

5.6.4. Agricultural Violations:

5.6.4.1. Soil or sand present.

5.6.4.2. Unauthorized food.

5.6.4.3. Article with uncertified stuffing

5.6.4.4. Any agriculturally prohibited items.

\section{Actions:}

- If item is dirty have soldier clean item.

- Otherwise seize prohibited article and explain reason for seizure.

- All agricultural violations will be corrected on the spot. 


\section{Chapter 6}

AVIATION PROCEDURES

6.1. Overview: DoD reg. $4500.9-\mathrm{R}$ requires ALL DoD-sponsored cargo to be examined within the overseas area at the point of origin prior to shipment of cargo to CTUS. In keeping with this requirement, redeploying units are responsible for cleaning their aircraft to USDA standards. A CBCA will inspect all aircraft for Customs and USDA violations. Once cleared, the CBCA will affix a DD Form 2855 to the windshield and place a security seal on all lockable compartments. The aircraft will be flown to the SPOE. CBCAs will observe the aircraft and conduct spot checks while they are prepared for shipment.

\subsection{Clearing Unit's Requirements:}

6.2.1. Unit schedules the pre-clearance of their aircraft at least 48 hours out (DSN 825-1440, cell 968-1908).

6.2.2. Ensure sufficient personnel present to efficiently clean the aircraft.

6.2.3. All lockable and inspectable areas of the aircraft must be readily accessible to the CBCA. (See Attachment 6 for inspectable areas).

6.2.4. Ensure sufficient personnel remain with aircraft during examination to correct any deficiencies noted.

6.2.5. Commander will brief soldiers about prohibited/ restricted items prior to inspection.

\subsection{CBCA Requirements for Pre-clearance:}

6.3.1. NCOIC will contact unit POC at least $24 \mathrm{hrs}$ prior to appointment to:

6.3.1.1. Verify location of heavy wash.

6.3.1.2. Ask quantity and types of aircraft to be cleared.

6.3.1.3. Remind them to have personnel present for inspection and loading. 
6.3.1.4. Remind that all locked compartments and inspectable areas must be readily accessible for inspection.

6.3.1.5. Verify that personnel have been briefed on prohibited/restricted items.

6.3.2. NCOIC will conduct a Customs brief prior to starting inspections/ examinations. Be sure to include an amnesty period.

6.3.3. CBCAs will be available at wash area to provide advice to the unit.

6.3.4. Examine all aircraft to ensure compliance with USDA regulations.

6.3.4.1. Aircraft will have no soil, sand, vegetable matter, or insect/ animal parts. A light dusting is acceptable.

6.3.4.2. Grease is not considered soil/ dirt.

6.3.4.3. Unit will remove all equipment from aircraft, remove any access panels, and open all compartments IAW CBCA instructions prior to the examination being conducted.

6.3.4.4. See Attachment \#6 for inspectable areas.

NOTE: It is recommended that CBCA's examining aircraft be trained on the proper procedures for examining aircraft.

6.3.5. Once an aircraft passes examination, the CBCA will place a security seal on all lockable compartments, and affix a completed DD Form 2855, annotating the seal \#s and aircraft \# on the form, to the windshield; this DD Form 2855 is for the lockable compartments only.

6.3.6. Aircraft will then be flown to the SPOE, where it will be checked for contraband and agricultural violations. Once satisfactorily inspected, the helicopter will be "shrinked wrapped" and a DD Form 2855 will be affixed.

6.3.7. Be sure to log the type of aircraft on aircraft log sheet.

6.3.8. Log any contraband seized on the contraband inventory sheet. Turn in the form and contraband to the 886 ESFG/S2. 
6.3.9. Contact 886 ESFG TOC (825-1440) upon completion of inspection to report quantity of aircraft cleared.

6.3.10. CBCAs will observe the aircraft and conduct spot checks while they are prepared for shipment.

6.3.11. Verification of customs pre-clearance prior to loading.

6.4. Requirements for Customs Brief: Prior to any actions by the CBCA's everyone will receive a customs brief explaining prohibited and restricted items, and the pre-clearance process that is about to occur.

6.4.1. Prior to briefing ensure everyone is present. If the group is too large for the briefing area, brief them in smaller groups.

6.4.2. Explain the inspection/ examination process to include amnesty area.

6.4.3. Explain prohibited and restricted articles, and potential consequences of being caught with contraband.

6.4.4. Tell them that if anyone has explosive devices or UXO's, they need to inform an inspector prior to the start of the examination. They will still have amnesty.

6.4.5. Check for any questions.

\subsection{Enforcement Actions:}

6.5.1. There are three basic types of violations: petty, serious, and agricultural. Listed below examples of each type of violations, and what actions to take upon discovery of the violation.

\subsubsection{Petty Violations:}

\subsubsection{Pornographic magazines}

6.5.2.2. A small quantity of an unauthorized war trophy

\subsubsection{Ammunition.}


6.5.2.4. A few Cuban cigars.

6.5.2.5. Water pipe

6.5.2.6. Articles inadvertently not declared.

\section{Action:}

- Seize article, and explain to soldier reason article is prohibited.

- Annotate findings on appropriate form.

\subsubsection{Serious Violations:}

6.5.3.1. Belligerent or excessively uncooperative subject.

6.5.3.2. Threatens CBCA with bodily harm.

6.5.3.3. Physically prevents CBCA from examining an object or container.

6.5.3.4. Attempts to bribe CBCA to allow prohibited or restricted item to pass.

6.5.3.5. Any explosives or UXOs.

6.5.3.6. Any weapons. (firearm)

6.5.3.7. Any narcotics or controlled substances.

6.5.3.8. A willful violation. (The intentional concealment of prohibited, restricted, or contraband items is a willful violation.)

\section{Action:}

- Detain individual (Use handcuffs only if necessary).

- Contact 886 ESFG TOC at DSN 825-1440 or cell 968-1908, and request presence of either CID (Army) or NIS (Navy or Marine).

- Seize evidence on DA 4137 to start chain of custody.

- Prepare DA 2823.

- CID/ NCIS will conduct investigation to include preparing the 3881, and apprehending subject. 
If CID/ NCIS do not respond, then CBCAs at the scene will conduct the investigation.

- Apprehend Subject.

- Complete DA 3881.

- Complete DA 3975.

- Release subject to unit commander on DD 629.

6.5.4. Agricultural Violations:

6.5.4.1. Soil or sand present.

6.5.4.2. Unauthorized food.

6.5.4.3. Article with uncertified stuffing. Any agriculturally prohibited items.

\section{Actions:}

- If item is dirty, have individual clean item.

- Otherwise seize prohibited article and explain reason for seizure.

- All agricultural violations will be corrected on the spot. 


\section{Chapter 7}

\section{PALLET PROCEDURES}

7.1. Overview: DoD reg. $4500.9-\mathrm{R}$ requires ALL DoD-sponsored cargo to be examined within the overseas area at the point of origin prior to shipment of cargo to CTUS. In keeping with this requirement, the unit preparing for redeployment will arrange to have CBCAs present during the loading of their pallets. The CBCAs will examine all cargo (personal and government) to ensure compliance with US Customs laws and agricultural requirements. Following examination, the pallet will be covered, strapped down with cargo netting. Seals will be placed around the bottom of the netting to indicate tampering.

\subsection{Clearing Unit's Requirements:}

7.2.1. Unit schedules the pre-clearance of their pallets at least 48 hours out (DSN 825-1440, cell 968-1908).

7.2.2. Unit will ensure all equipment is clean prior to inspection.

7.2.3. Prior to arrival of $\mathrm{CBCAs,}$ all pallets will be unloaded, and the equipment will be staged for inspection. Avoid laying equipment directly on ground. Ideally some sort of hardstand should be available, or else lay plywood or tarps underneath.

7.2.4. All locked/taped boxes need to be readily accessible for inspection.

7.2.5. Personal property/ equipment may be included in DoD cargo shipments. However, the owner must be present during the inspection and when their gear is palletized/ containerized.

7.2.6. Develop load plan prior to inspection.

7.2.7. Have sufficient personnel present to correct any deficiencies noted, and to ensure efficient loading of containers. Unit should bring brushes and rags.

7.2.8. Ensure the pallet is clean and serviceable 
7.2.9. Commander will brief troops about prohibited/ restricted items prior to inspection.

\subsection{CBCA Requirements for Pre-clearance:}

7.3.1. NCOIC will contact unit POC at least $24 \mathrm{hrs}$ prior to appointment to:

7.3.1.1. Verify location and number of pallets.

7.3.1.2. Determine number of personal bags and footlockers to be uploaded. Inform POC that the owners of the bags/ footlockers need to be present for the examination.

7.3.1.3. Confirm that all pallets will be clean and serviceable prior to CBCA arrival. Also ensure wrapping material and cargo netting is available.

Wrapping material and cargo netting must be present to ensure the pallets sterility after the inspection.

7.3.1.4. Remind that all locked/taped boxes must be readily accessible for inspection.

7.3.1.6. Verify personnel have been briefed on prohibited/restricted items.

7.3.2. NCOIC will conduct a Customs brief prior to starting inspections/ examinations. Be sure to include an amnesty period.

7.3.3. All other containers must be downloaded for examination. The interiors will be swept to remove contamination. Cleanliness will be verified by a CBCA before loading begins.

7.3.4. CBCAs will examine 100 percent of all cargo and personal baggage prior to loading.

7.3.5. Once cargo is cleared for loading, a CBCA will observe the loading of the pallet to ensure no contraband or unexamined cargo is loaded.

7.3.6. All bracing material (plywood, lumber, etc.) will be examined to ensure no signs of insect infestation. 
7.3.7. The pallet will be wrapped and netted (cargo netting) in a manner to prevent introduction of contraband. Customs seals will be placed along the pallet in a manner to indicate tampering.

7.3.8. Once pallet is loaded and sealed, the CBCA will seal and affix a stamped 2855 on opposite corners of the pallet-2 forms per pallet. Be sure to annotate the seal \# on the 2855.

7.3.9. Be sure to log the Pallet and Seal \#s on the container log sheet.

7.3.10. Log any contraband seized on the contraband inventory sheet. Turn in the form to the 886 ESFG/ S2 TOC.

7.3.11. Contact 886 ESFG TOC (DSN 825-1440, cell 968-1908) upon completion of inspection to report quantity of containers cleared.

NOTE: If the NCOIC determines that the unit being cleared is not prepared for inspection (i.e. equipment dirty, not staged properly, insufficient personnel, etc.), they will explain the problems to the POC to give them the opportunity to correct the problems. If the problems continue the NCOIC may terminate the inspection and direct the POC to reschedule through the 886 ESFG TOC. In addition, if the pallet cannot be sufficiently sealed as to indicate tampering, the POC must find a suitable container.

7.3.12. Requirements for Customs Brief: Prior to any actions by the CBCAs, everyone will receive a customs brief explaining prohibited and restricted items, and the pre-clearance process that is about to occur.

7.3.12.1. Prior to briefing ensure everyone is present. If the group is too large for the briefing area, brief them in smaller groups.

7.3.12.2. Explain the inspection/ examination process to include amnesty area.

7.3.12.3. Explain prohibited and restricted articles and the potential consequences of being caught with contraband.

7.3.12.4. Tell them if anyone has explosive devices or UXO's, they need to inform an inspector prior to the start of the examination - they will still have amnesty. 


\subsubsection{Check for any questions.}

7.4. Examination: Violations, both petty and serious, may occur because of a misunderstanding of the Customs laws. Accordingly, before you inspect any baggage you must satisfy yourself the person clearly understands what is expected and has been given every opportunity to properly declare objects acquired abroad. Some questions you may wish to ask include the following:

7.4.1. “Did you receive a briefing on what we are looking for today?”

7.4.2. "Did you have an opportunity to take advantage of the amnesty period?"

7.4.3. "Are you carrying any articles for other persons?" (Mail, letters, gifts etc.)

7.4.4. "Do you have any meat or animal products, fruits, vegetables, plants, plant products, soil, live insects, cultures, snails, birds, or other animals?"

7.4.5. "Are you carrying over $\$ 10,000$ in coin, currency, traveler's checks, money orders, or negotiable instruments?"

7.4.6. During questioning, make a mental note of any inconsistencies or evasions in the answers given.

7.4.7. How detailed an examination varies with the passenger being examined. Closely observe the person's demeanor and the manner in which they answer your questions. A seemingly insignificant occurrence or chance remark may indicate that a more intensive examination is warranted. Evasive answers, reluctance to answer questions, not wanting to open containers, naming of superior officers for the purpose of intimidation, offering of gratuities, and other such actions are sufficient cause for you to be alert to the possibility of finding prohibited/restricted articles. Always work systematically to avoid missing an area. When inspecting suitcases, be alert to the possibility of false bottoms or other secret compartments.

\subsubsection{Places of Concealment:}


7.4.8.1. Trunks and other containers used for the transportation of passengers' personal effects afford many opportunities for concealment of contraband.

7.4.8.2. Undeclared items have been found hidden in clothing, among toilet articles, in soiled clothing, and in various wrapped packages often found in such baggage.

7.4.8.3. Observe whether a person shows unusual interest in the examination of a particular piece of baggage.

7.4.8.4. All baggage should be opened in order to expose the contents, and carefully scrutinized to discover any concealed contraband.

\subsection{Enforcement Actions:}

7.5.1. There are three basic types of violations: petty, serious, and agricultural. Listed below examples of each type of violations, and what actions to take upon discovery of the violation.

\subsubsection{Petty Violations:}

7.5.2.1. Pornographic magazines

7.5.2.2. A small quantity of an unauthorized war trophy.

7.5.2.3. Ammunition.

7.5.2.4. A few Cuban cigars.

7.5.2.5. Water pipe

7.5.2.6. Articles inadvertently not declared.

Action:

- Seize article, and explain the reason why the article is prohibited.

- Annotate findings on appropriate form. 
7.5.3. Serious Violations:

7.5.3.1. Belligerent or excessively uncooperative subject.

7.5.3.2. Threatens CBCA with bodily harm.

7.5.3.3. Physically prevents CBCA from examining an object or container.

7.5.3.4. Attempts to bribe CBCA to allow prohibited or restricted item to pass.

7.5.3.5. Any explosives or UXO’s.

7.5.3.6. Any weapons. (firearm)

7.5.3.7. Any narcotics or controlled substances.

7.5.3.8. A willful violation. (The intentional concealment of prohibited, restricted, or contraband items is a willful violation.)

Action:

- Detain individual (Use handcuffs only if necessary).

- Contact 886 ESFG TOC at DSN 825-1440 or cell 968-1908, and request presence of either CID (Army) or NCIS (Navy or Marine).

- Seize evidence on DA 4137 to start chain of custody.

- Prepare DA 2823.

- CID/ NCIS will conduct investigation to include preparing the 3881, and apprehending subject.

If CID/NCIS do not respond, then CBCAs at the scene will conduct the investigation.

- Apprehend Subject.

- Complete DA 3881.

- Complete DA 3975.

- Release subject to unit commander on DD 629. 
7.5.4. Agricultural Violations:

7.5.4.1. Soil or sand present.

7.5.4.2. Unauthorized food.

7.5.4.3. Article with uncertified stuffing

7.5.4.4. Any agriculturally prohibited items.

7.5.5. Actions:

7.5.5.1. If item is dirty, have the individual clean item.

7.5.5.2. Otherwise seize prohibited article and explain reason for seizure.

7.5.5.3. All agricultural violations will be corrected on the spot. 


\section{Chapter 8}

\section{STERILE LOT GUIDANCE}

\subsection{Procedures for Accepting Vehicles into Sterile Lots}

8.1.1. CBCAs must inspect all vehicles entering the sterile lot. Ensure that the DD Form 2855 is on all separate items.

8.1.2. Do not allow any vehicle that does not meet Customs or USDA standards into the sterile yard.

8.1.3. All secondary loads must be annotated on the Customs form with seal numbers. U.S. Marine Corps vehicles often have tents and camo systems in the back; make sure description and quantity are included on the Customs form in the vehicle windshield or on the trailer.

8.1.4. All locks on any part of the vehicle or equipment must have a seal. All equipment in any container or compartment of a vehicle must be sealed.

8.1.5. If a deficiency can be easily corrected, have the driver pull the vehicle off to the side and make the corrections; allow other vehicles entering the sterile lot to continue through the inspection/ entry process. Do not hold up or turn away an entire convoy because certain vehicle(s) do not meet standards. Turn around or delay only the vehicle(s) with the discrepancies. Correct deficiencies on the spot, if possible.

8.1.6. Turn dirty vehicles around and send it back to the location it came from. There are no personnel available at sterile lots or the SPOE to clean vehicles and equipment. Do not allow dirty or non-inspected vehicles into the sterile yard.

8.1.7. Ensure driver rolls up all windows before allowing the vehicle to enter.

8.1.8. When convoys arrive at the SPOE/SPOD, the sterile lot CBCA will make contact with CBCA escort and verify the number and type of vehicles/ equipment in the convoy. The CBCA escort will personally account for all vehicles/ equipment as they enter the sterile lot. The 
requirement for escorts from sterile lots to the SPOE/ POD has been identified; however, this policy has not been implemented due to logistical shortfalls.

\subsection{Releasing vehicles from sterile lots}

8.2.1. Check all forms to ensure they are still legible. If there is no form, verify vehicle if vehicle had been pre-cleared and still meets customs/USDA standards and attach a new DD Form 2855. If a vehicle's DD Form 2855 is not legible, re-inspect vehicle and attach a new DD Form 2855. If a seal is present, contact appropriate TOC to verify via seal tracking log. If confirmation is made, attach a new DD Form 2855. If confirmation could not be made, equipment will need to be re-inspected.

8.2.2. Direct dirty vehicles to the local wash rack to be cleaned and reinspected, and then attach a new DD Form 2855 on the inside of the windshield (upper right corner of driver's side).

8.2.3. All secondary loads must be annotated on the Customs form, including seal numbers. US Marine Corps vehicles often have tents and camo systems in the back. Items would have to come out, be inspected, and a DD Form 2855 affixed on the equipment.

8.2.4. Vehicles that have locks on any part of the vehicle or equipment must have a seal. All equipment in any container or compartment of a vehicle must be sealed-- preferably with a lock. Empty compartments on a vehicle do not require a seal; however, they must be empty and clean.

8.2.5. Ensure that the DD Form 2855 is on all separate items. DD Form 1253 s are not authorized and if present, should be removed and replaced with a valid form.

8.3. Reporting Instructions: For any vehicle, container, conex, or other equipment frustrated at the sterile lot, contact the 886 ESFG/ S3 and provide the following information (if on the spot corrections made or if vehicle turned around and sent back to location it came from): From Customs form, get CBCA name, date/ time, and stamp \# and origin. Get vehicle bumper number, equipment description, or container number. Also give a detailed account of the problem. 


\subsection{Personnel Entering the Sterile Area:}

8.4.1. Unit commanders in coordination with respective movement control personnel and/ or contractors will develop procedures to limit access into sterile areas.

8.4.2. All personnel, vehicles, and items must be examined to ensure contraband isn't introduced into the area - this may include a "pat-down" of personnel at the discretion of the CBCA.

8.4.3. If personnel enter without being examined, the sterile lot should be closed until it can be determined whether or not contraband was introduced into the area.

/// signed ///

JAMES P. SEWARD, Maj, USAF 886 ESFG, S-3 


\section{Attachment 5}

Areas to Check on Vehicles

\section{- Engine compartment}

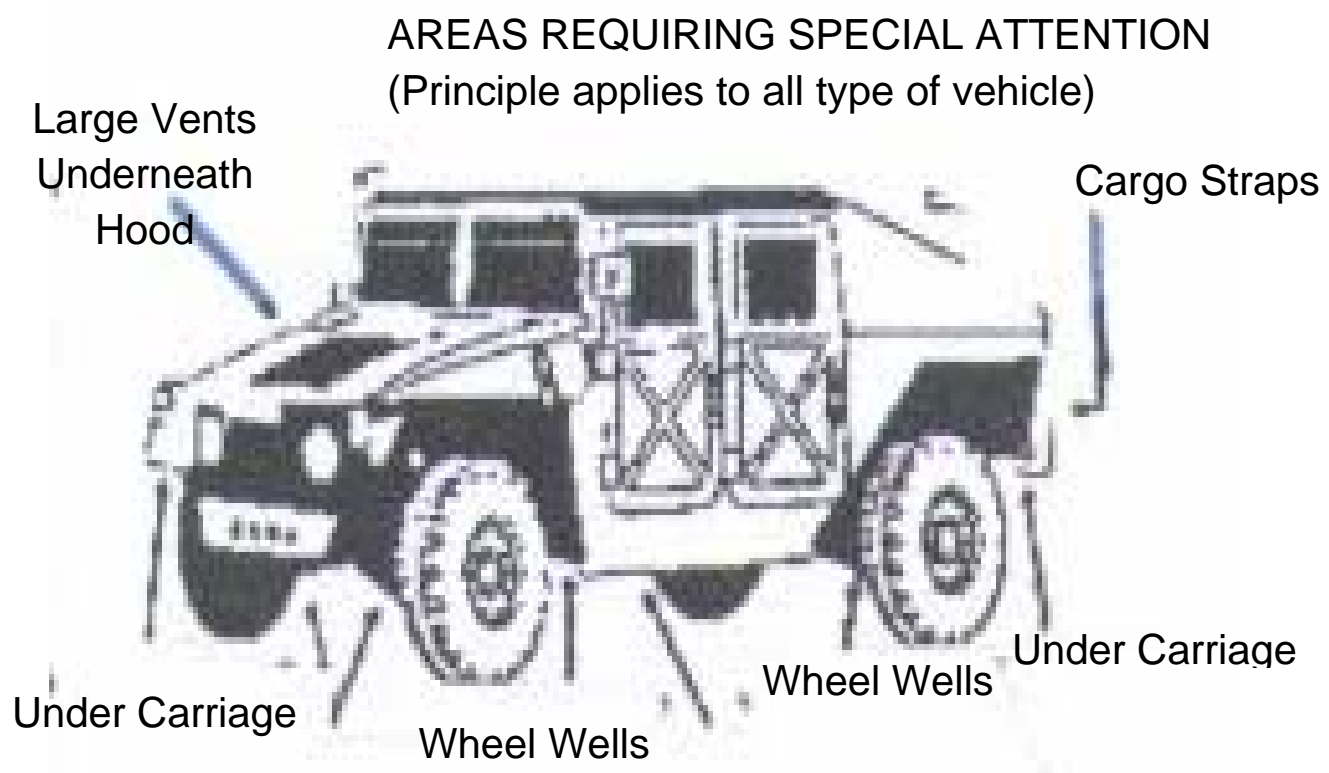

- Exterior

- Hand brake

- Fenders

Exterior

- Under carriage

- Wheel wells

- Axle

- Step

Fenders

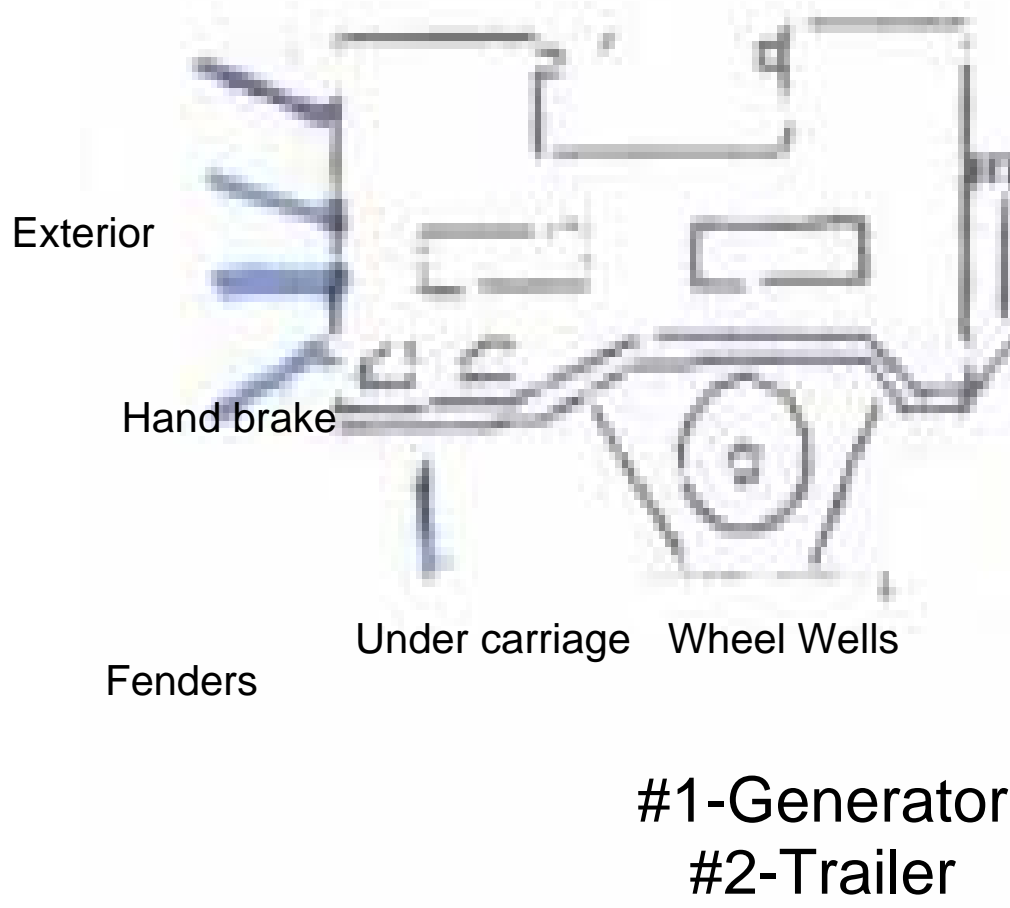

\#2

\#1

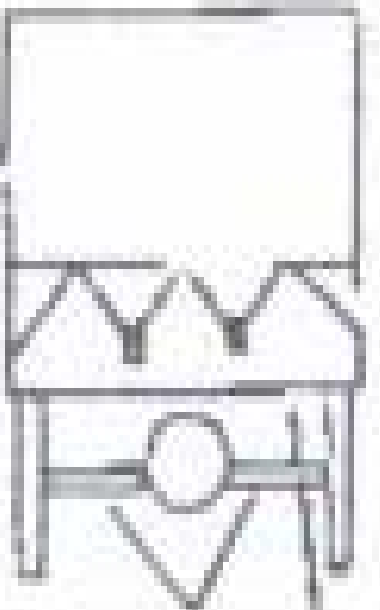

Axle- Under carriage

Underneath Area 


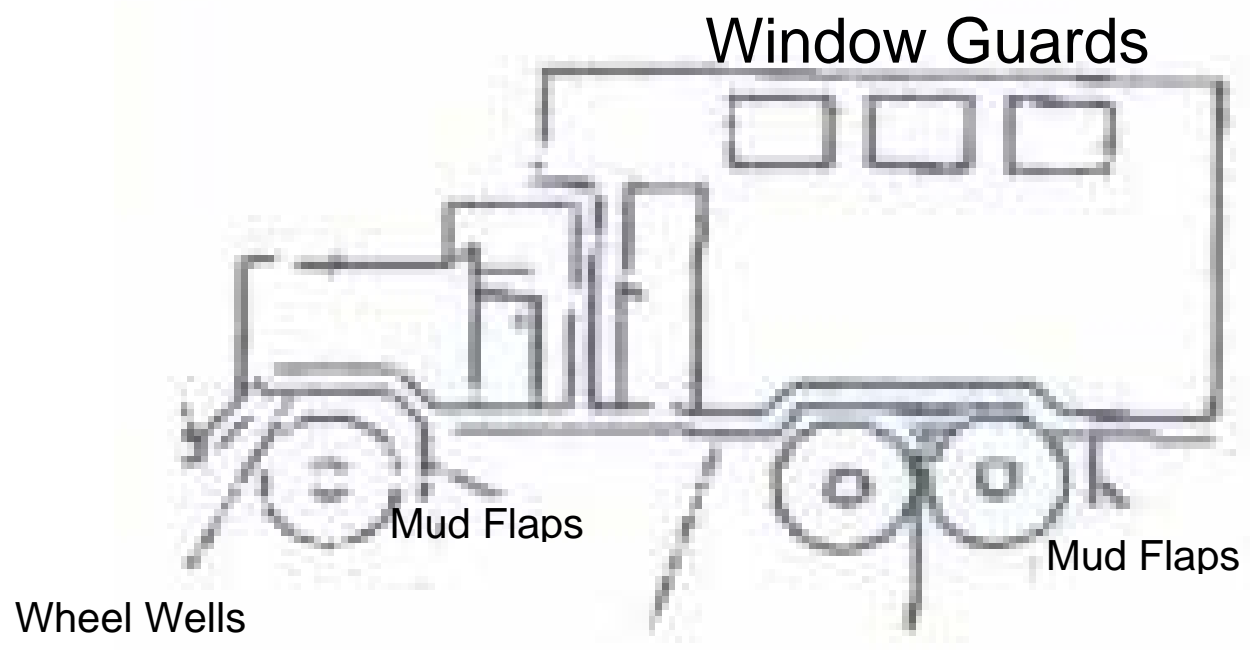

Under Area

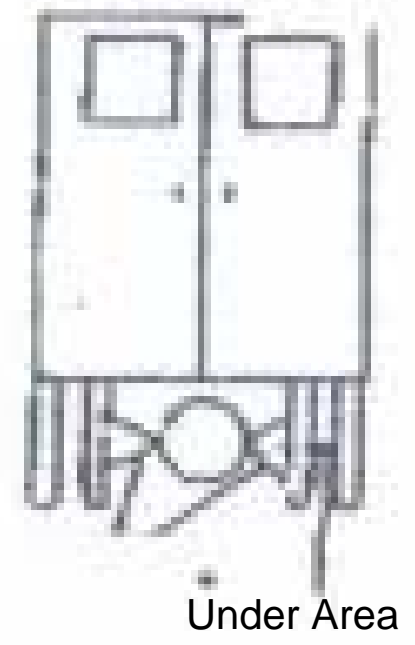

- Wheel wells

- Mud flaps

- Axle

- Drivers compartment 
Areas to Inspect on Tracked Vehicles

- All cargo areas need to be opened

- All deck plates need to be removed from tracks

- NBC tubes/ filters need to be opened/removed for inspection

- All armor skirts need to be opened

- All packs need to be pulled

- Air filters need to be opened/removed for inspection

- Battery boxes need to be opened

- Water barriers on Bradleys need to be unrolled

- Engine compartment opened

- Back door and hatch opened

- Top track guide ready for inspection

- Gas tank covers need to be removed

- Drain plugs need to be removed

- Ammo bay doors need to be opened

- All hatched / cargo areas need to be opened

- Transmission cover plate needs to be removed (M1)

- Rotate turret to inspect subturret

- Inspect/ examine the breech/ barrel 


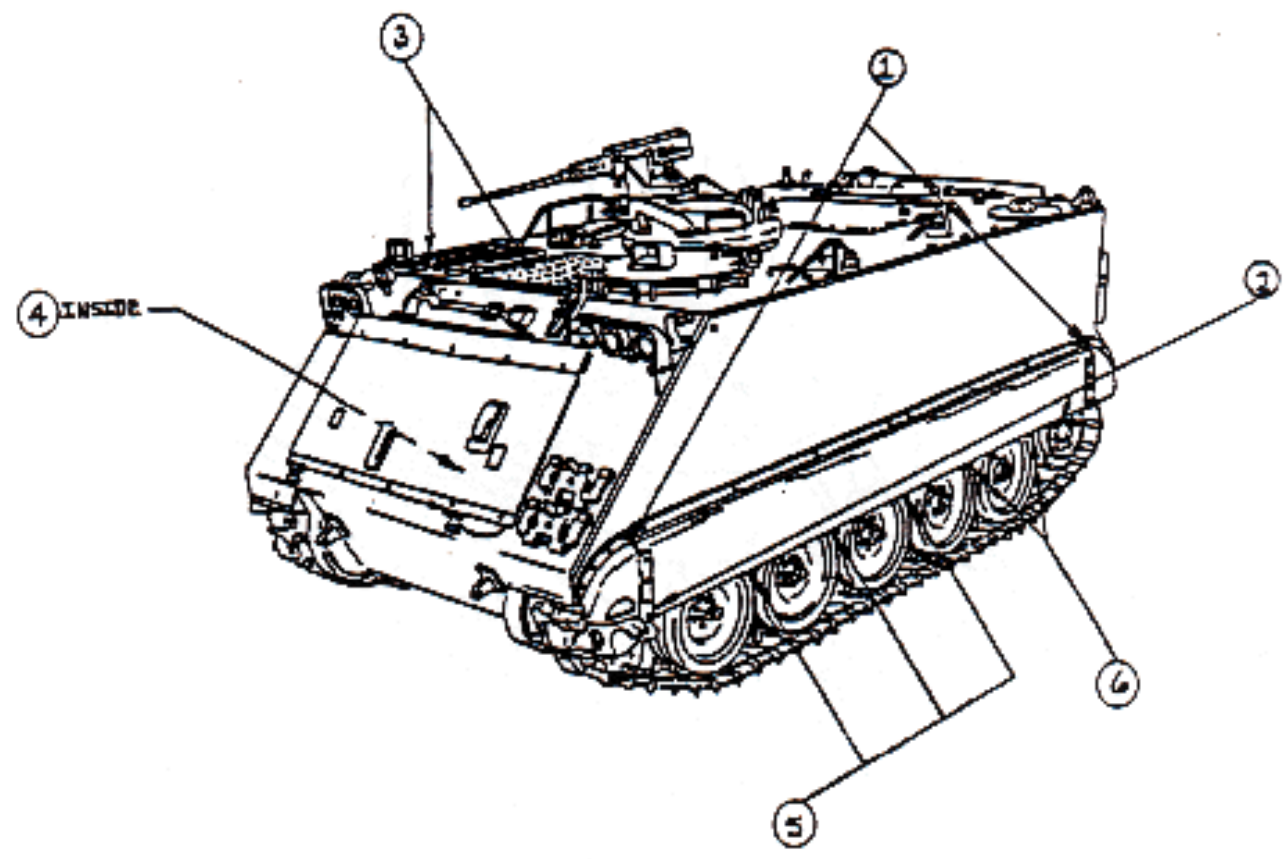

\section{PBOBLEM AREAS}

1. Inside the front and rear fenders, remove fenders for inspection.

2. On top of the track tensioners.

3. Remove twigs and debris from grilts and surrounding areas.

4. Underneath all floor plates inside; remove and leave loose for inspection.

5. The inside edges of all road wheels: from underneath and from the outside also.

6. On top of all axles for the road wheels and end wheels.

NOTE: Tracks are a MAJOR PROBLEM, clean thoroughly. 


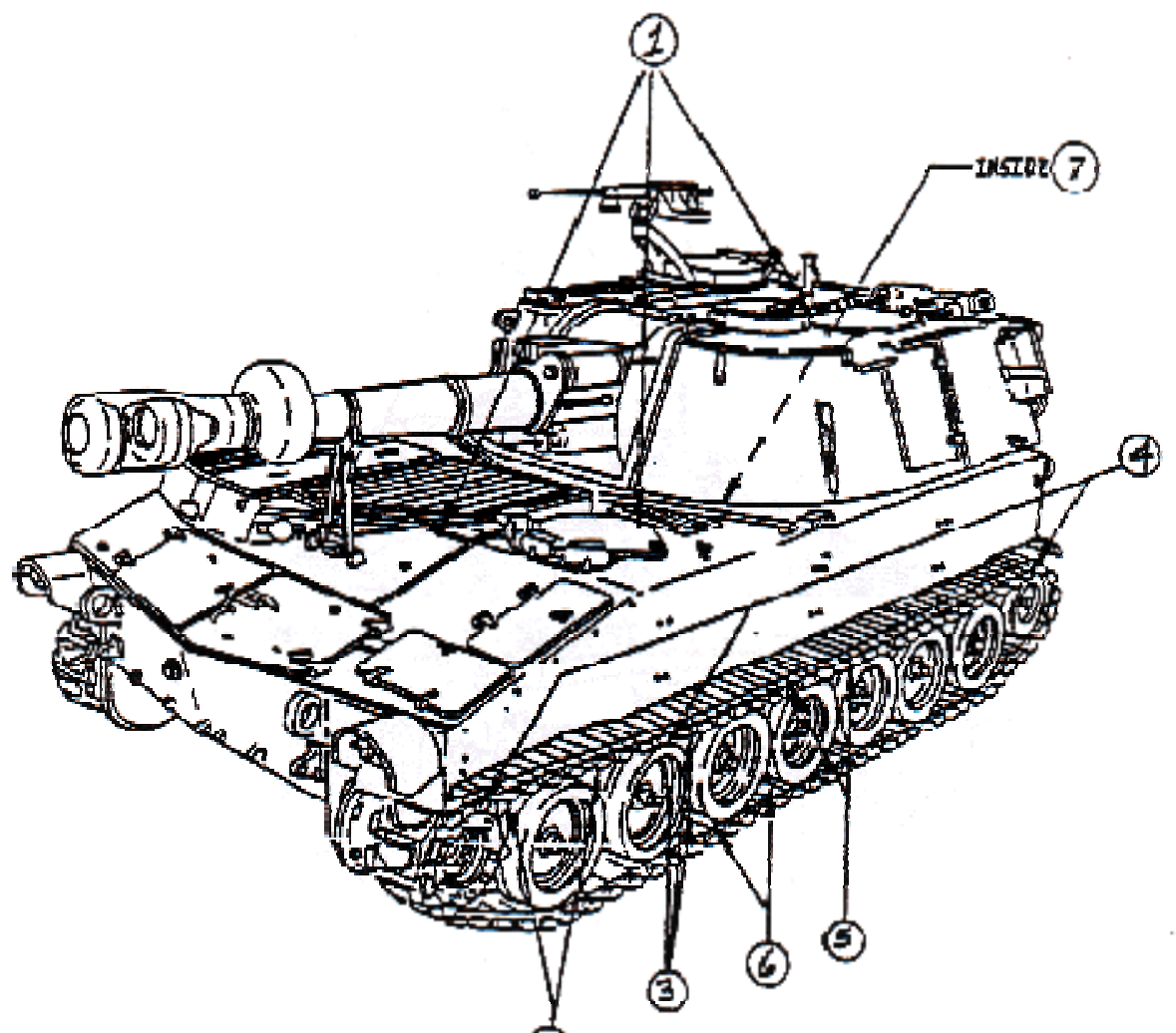

(2)

\section{PROBLEM AREAS}

1. Twigs and debris in the cracks and crevices of the tap surtaces of the tank.

2. On ton of the axies far both tront and rear wheels.

3. On the inside of all road wheels and end wheels; from undemeath and from the autside alco.

4. On top of the axles for all road wheels, and on top of all tensioners.

5. On the support rollers, in the ledges, between the rubber surfaces.

6. On the support rollers, the inside surfaces; from the inside and outside,

7. Inslde the tank, clean the floor, around the driver's footpedals.

NOIt: Tracks are a MAJOR PROBLEM, ciean thoroughiy.

Note: Ensure the breach/barrel is inspected! 


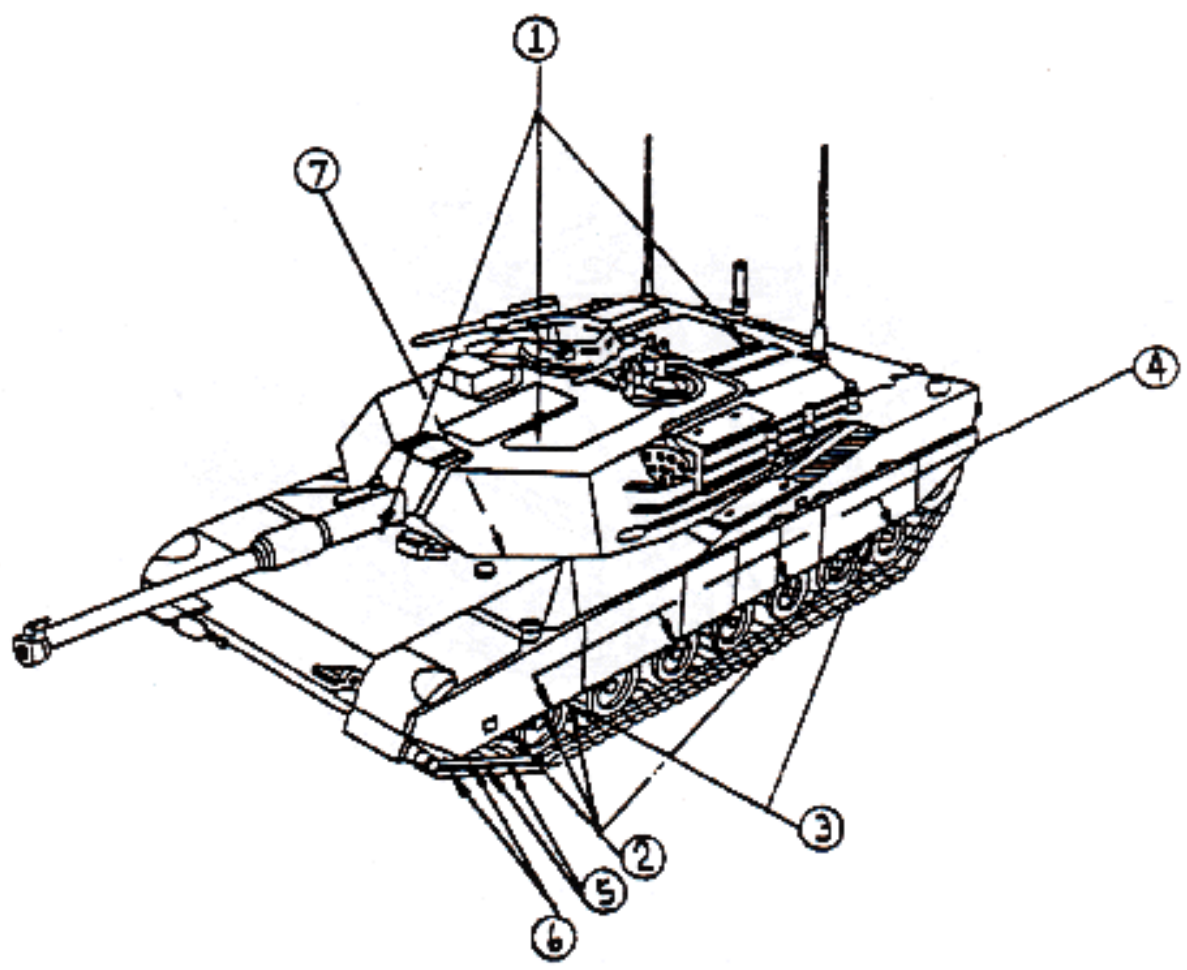

\section{PROBLEM AREAS}

1. Twigs and debris in the cracks and crevices of the top surfaces of the tank.

2. On top of the axies for both front and rear wheeis.

3. On the inside of all road wheels and end wheels; from underneath and from the outside also.

4. On top of the axles for all road wheels, and on top of all tensioners.

5. On the support rollers, in the ledges, between the rubber surfaces.

6. On the support rollers, the inside surtaces; from the inside and outside.

7. Inside the tank, clean the fioor, around the driver's footpedals.

NOTE: Tracks are a MAJOR PROBLEM, clean thoroughly.

\section{Note: Ensure the breach/barrel is inspected!}




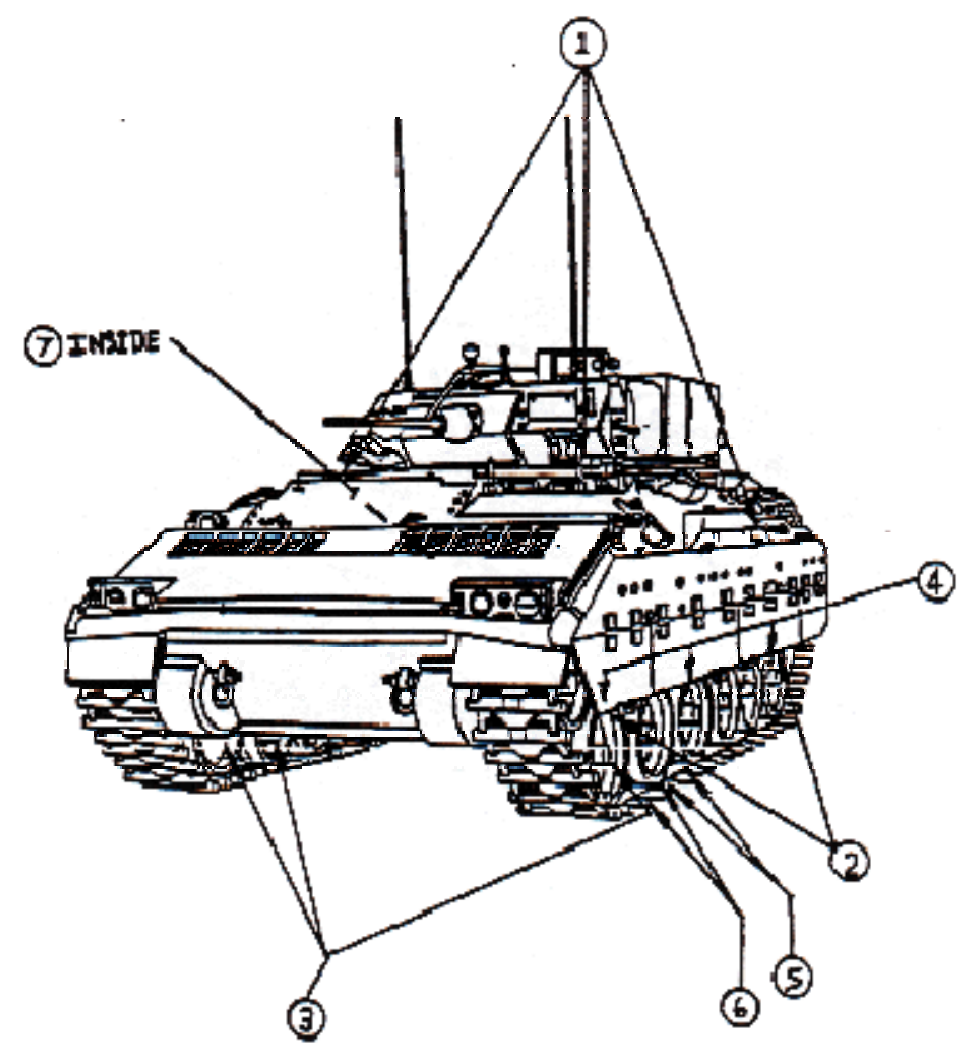

PROBLEM AREAS

1. Twigs and debris in the cracks and crevices of the top surfaces of the tank.

2. On top of the axles for both fron and rear wheels.

3. On the inside of all road wheels and end wheels; from underneath and from the outside also.

4. On top of the axles for all road whegis, and on top of all tensioners.

5. On the support rollers, in the ledges, between the rubber surfaces.

6. On the suppoit rollers, the inside surfaces; from the inside and outside.

7. Inside the tank, clean the floor, around the driver's footpedals.

NOTE: Tracks are a MAJOR PROBLEM, clean thoroughly. 


\section{Attachment 6 \\ Inspectable Areas on Aircraft (Helicopter)}

- Nose compartment opened

- Cockpit area

- Pilot/ Co-Pilot seat cushions removed

- Pilot / Co-Pilot seat wells exposed

- All cabin area sound proofing opened

- Battery area exposed

- Grenade boxes emptied and cleaned

- All seats in cabin removed

- Cargo hook exposed

- Aft side wall sound proofing removed

- Survival kit removed

- Aft cargo compartments emptied and opened

- $\mathrm{R} / \mathrm{H}$ and $\mathrm{L} / \mathrm{H}$ tail cone access panels

- $\quad \mathrm{T} / \mathrm{R}$ and Int. G/ B fairings removed

- All drive shaft covers opened

- Oil compartment opened

- Engine cowlings opened

- Main rotor sliding pylon opened

- All external covers (i.e. fuel, ground power, etc.) opened

All areas IAW:

TM 55-1520-237-23-2 General Aircraft Maintenance

TM 237-10

Operator's Manual

TM 237-PMSI

Preventative Maintenance Service Checks 


\section{Appendix C: Correspondence Relating Agricultural Clearance Incidents Experienced by the Military}




\title{
Military Ocean Terminal at Sunny Point (MOTSU), North Carolina, 1999-2000
}

\author{
INFORMATION PAPER
}

November 1, 1999

SUBJECT: Interception of Snails on Department of Defense Contract Vessel

1. Dr. David Robinson, USDA, APHIS, PPQ, malacologist, (215-299-1175) called to inform the AFPMB of a significant infestation on snails intercepted from the contract ship, the Captain Steven L. Bennett. The USDA, APHIS, PPQ made the interceptions at Wilmington, NC during the week of October 24, 1999.

\section{Findings}

- The ship contained 3000 containers that were packed with ammunition being returned from Europe. Many containers had snails on the exterior of the containers that require immediate quarantine action. No snails have been intercepted, to date, from the cargo within the containers.

- The containers are being inspected one by one because of the degree of infestation

- Snails identified to date by USDA, APHIS, PPQ are consistent with an origin in Italy; some snails also appear to have an origin in Spain. However, the cargo may have had its origin in Germany. Approximately $50 \%$ of the snails are juveniles; this situation complicates identification and causes those snails to be labeled as "actionable" interceptions.

- The USDA, APHIS, PPQ has not yet issued an emergency action order. The involved parties will hold a meeting in Sunnypoint, NC at 1300, November 1, 1999 to discuss the required actions for the infested cargo containers. POC: Mr. George Miller, (910) 3418252.

- The containers will probably need to be fumigated with methyl bromide $(8 \mathrm{lbs} / 1000$ cubic feet at 55 degrees F.) Due to an approaching cold front, the containers may need to be heated to maintain the 55 degree temperature. This will cause additional expense for the fumigation. Thirty containers can be fumigated at one time.

- Despite the need to fumigate the containers, the U.S. Army is unloading the ammunition from the containers and loading new cargo in the containers.

- To complicate the inspection process, snails native to $\mathrm{NC}$ were found on the containers. The snails were intercepted on the containers while still on the ship.

3. Conclusions/Observations

- The preclearance of the cargo was not adequate; the containers were probably not placed in a snail-free zone before being loaded onto the ship. Snails on the exterior of the containers most likely contaminated the exterior of other containers.

- The presence of native NC snails on the cargo containers indicates that the hold of the ship was infested by these snails at some point prior to these interceptions.

Prepared by Captain Herbert T. Bolton, MSC, USN, AFPMB Research Liaison Officer, (352) $374-5900,11 / 01 / 99$

Figure $\mathrm{C} 1$. Information paper reporting snail infestation on military cargo on ships returning from Europe and docked at the Military Ocean Terminal at Sunny Point (MOTSU), North Carolina 


\section{BRIEF HISTORY OF M/V STEVEN L. BENNETT As of November 02, 1999}

The M/V Steven L. Bennett arrived at MOTSU Sunny Point on October 21, 1999. Officer Philip Bcll boarded the ship and cleared the vessel. Upon dcparture, he did a "walk around" on the deck of the ship wherc some military containcrs werc loaded. He intercepted some snails he observed on onc container and submitted them for determination. The ship then started of loading its cargo which consisted of approximately 1402 military containers which had been loaded from various parts of Furope. The two ports of lading were Nordenheim in Germany and Talamari in Italy. The cargo itself had been staged in various countries in Europe including Spain, Kosovo, Italy and England.

We received the determination back on the interception October 25, 1999 and it came back "action". We immediately sent officers back to Sumny Point to do further inspections of the containers. As the off loading of the vessel continued, we found more snails on the containcrs. We talked to the cargo pcople and required them to bring past the inspection station, all containers that had been off loaded during the weckend so we could inspect them also. We eventually inspected all the containcrs from the vessel. We had a total of 129 interceptions of snails with 62 actions so far. The remainder were cither no-action or are still being identified. My staff have put in long hours doing the inspections and have donc a good job. Officer Philip Bell in particular has been on top of the situation and has gone the "extra milc" to ensure a successful operation.

The treatment of these snails and the ship is now being discussed with Port Operations, Methods and myself and a workable plan is being formulated.

Figure C2. Observations of foreign snails on containers on the Motor Vessel Steven L. Bennett in MOTSU, North Carolina (Source: Capt. Herbert T. Bolton, USN) 


\section{UPDATE ON M/V STEVEN L. BENNETT NOVEMBER 02, 1999}

- Please note my first correspondence had November 11 th datc on it, and it should have been November 2.

- Final determinations were received from Dr. Robinson. The final count was 22 non action snails. 107 action or undetermined and considered action. There were a total of 1402 containers on the ship.

- All action and undeterminates are to be fumigated with Methyl Bromide. The cargo management pcople are currently receiving bids on fumigation. All other containers are to be steam cleaned and inspected. The cleaning area is to be salted down after the stcam clcaning is completed. The logistics of this is being worked out by the cargo management people and they will be in contact with us.

- The ship is now is Charleston and Por1 Director George O'Quinn has been contacted and briefed on the operation. Scott Wood of the regional office has been involved to lend his expertise on the treatment of the ship. The recommended treatment of the ship will be to steam clean the sides and floor of the holds as well as the decks and hatch covers. Dr. Robinson belicved that the heat of the steam could kill the snails and also break their attachment from the surface they are attached. to. The emergency order is being written in Charleston since the treatment will be done there.

- No snails have been found inside any containcr. Numcrous containers have been stripped in our presence and none found. All observed pest risk has been on the outside of the containers.

- Dave Reeves of Headquarters and Josic Coolic of Methods have been consulted and given their advice and thoughts concerning this.

Figure C3. Follow-up observations of snails found on the Motor Vessel Steven L. Bennett in MOTSU, North Carolina (Source: Capt. Herbert T. Bolton, USN) 


\title{
REPORT ON M/V STEVEN L. BENNETT
}

\author{
DECEMBER 1, 1999
}

Since the last update concerning this vessel the following actions have occurred:

- We conducted a steam cleaning of the remaining containers which did not appear to have foreign snails during our dock inspections. We enlisted the help of the US Navy Preventative Medicine Unit stationed at Camp Lejeune to assist us with the cleaning. They assisted us for approximately two weeks and we inspected several hundred of the containers. As the operation continued, it became evident that the cleaning was going to require more personnel and time than we were able to commit. The decision was made to go to the staging area where the containers were being held and do a $100 \%$ inspection of the containers. Approximately 70 more containers, which were found to have foreign snails, have been or, are going to be fumigated.

- The ship has undergone steam cleaning in Charleston, SC which was completed on November 30, 1999

- All areas where the containers were staged were treated with $2 \%$ Malathion as per the recommendations of Methods. Salt barriers were put around the perimeter of the staging areas and maintained.

- The following are some to the species that were found on the containers as identified by Dr. David Robinson, Malacologist with APHIS:

Quarantine-significant species:

Prietocella barbara (Linné)

Trochoidea pyramidata (Draparnaud)

Cernuella cisalpina (Rossmässler)

Cernuella virgata ( $\mathrm{Da}$ Costa)

Xerotricha apicina (Draparnaud)

Monacha cartusiana (Muller)

unnamed species of Helicellinae (potentially 3-4 other species)

Theba pisana (Maller)

Species of European oriqin, not quarantine-significant:

Cepaea nemoralis (Linné)

Other snails were found during the $100 \%$ inspection of the containers in the staging areas but the determinations have not come back as of this point. These may or may not be different species than we have already found.

Figure C4. Report of steam cleaning, fumigation, and organism identification-Motor Vessel Steven L. Bennett in MOTSU, North Carolina, p. 1 of 2 (Source: Capt. Herbert T. Bolton, USN) 
- Native snails were found on some of the containers and were of concern to the military. They enlisted our advice on what action to take to prevent these from going overseas with the "Sunny Point" containers when they are loaded back on the Bennett. Methods has offered several treatments which may be effective if proper approval is obtained.

December 6, 1999

- There was a total of 163 containers of the Bennett on which action pests were found. 158 were snails and 5 were Lepidoptera pupae.

- There were 6 gypsy moth egg masses found on the containers. Two of the masses were found on containers also infested with snails. The egg masses were sent in for identification and all were found to be non-viable. Otis Methods Center has expressed as interest in finding out the origin of the containers the eggs masses were on since it may signal a spread of gypsy moth in Europe. This is currently being investigated

Figure C5. Report of steam cleaning, fumigation, and organism identification-Motor Vessel Steven L. Bennett in MOTSU, North Carolina, p. 2 of 2 (Source: Capt. Herbert T. Bolton, USN) 


\section{AUSTRAL RAINBOW}

\section{December 6, 1999}

- M/V Austral Rainbow arrived at MO'ISU, Sunny Point on November 12, 1999. Officer Philip Bell and Port Director Jim Kelley buarded the vessel and conducted a "walk around" survey of the military containers on the deck of the ship. No evidence of snails were found at that time. The ship began its off load of 698 containers on November 13,1999. Out of the first four containers off-loaded, two were found infested with snails. The containers were put back on board and were not off-loaded until November 15, 1999.

- Two teams of two inspectors manned cach container cranc. They conducted a 100 percent inspection of every container which came off the vessel. Seventy two containcrs were found to be infested with action snails. These were quarantined in a holding area and fumigated.

- The following are specics found on the containcrs as identified by Dr. David Robinson, Malacologist with $\Lambda \mathrm{PHIS}$ :

\section{Quarantine-siznificant species}

Ccrnuella virgata

Candidula sp.

Xeropicta krynicki

Helicellinac

Monacha parumcineta

JIelicopsos sp.

Cernuella cisalpina

Monacha sp.

- The Austral Rainbow's holds number 3,5, and 6 were found to be infested with snails after a thorough inspection of all its holds by PPQ officcrs. At the ship owners request, the Rainbow was permitted to sail to Ncw Orlcans, where steam cleaning of the infested holds took place. The Emergency Action Order was issued and signed by all partics. PPQ- New Oleans was notified and sent a copy of the LAO. The cleaning was completed and the ship cleared to load morc cargo.

Figure C6. Observations of foreign snails on containers on the Motor Vessel Austral Rainbow in MOTSU, North Carolina (Source: Capt. Herbert T. Bolton, USN) 


$\begin{array}{llll}\begin{array}{l}\text { United States } \\ \text { Department of }\end{array} & \text { Animal \& } & \text { Plant Protection } & \begin{array}{l}\text { Department of Malacology } \\ \text { Academy of Natural Sciences }\end{array} \\ \text { Agriculture } & \text { Plant Health } & \text { \& Quarantine } & \text { 1900 Benjamin Franklin Pkwy } \\ & \text { Inspection } & & \text { Philadelphia, PA 19103-1195 } \\ & \text { Service } & & \text { Ph.: (215) 299-1170 } \\ & & \text { Fx.: (215) 299-1170 }\end{array}$

Precautionary Survey of MOTSU, 9-12 May 2000

In October and in November, 1999, two transport ships, the Captain Steven L. Bennett, and the Austral Rainbow respectively, carrying containers of military cargo docked at the Military Ocean Terminal at Sunny Point (MOTSU), North Carolina. They were found by PPQ Officers to be heavily infested with a number European and Turkish snail species, over 13 of which are quarantine pests, as well as a number of snails native to North Carolina. Although the infested containers and the ships themselves were treated, there remained a concern that some of the foreign travelling species may have established themselves on the Base.

During May 9 through 12, on behalf of Thomas Chanelli, State Plant Health Director for North Carolina, I surveyed areas at Sunny Point identified by PPQ Officer Tim Stevens as those with highest risk, i.e. where infested containers had been set down or where they had been treated. This included a number of staging pads, North and South Wharf Hard Stands, the Bridge Crane area, the Classification Yard, and the principal staging area known as the "Marl Pit."

Although all areas surveyed provided samples of a number of mollusk species considered native to North Carolina, the Marl Pit yielded in addition populations of four invasive species, all members of the Hygromiidae: Monacha syriaca (Ehrenberg, 1831), Cernuella virgata (Da Costa, 1778), Trochoidea pyramidata (Draparnaud, 1801), and an unidentified Xeropicta sp. All four are considered by PPQ to be of quarantine significance. On May 12, I and two PPQ Officers, Tim Stevens and Sandy Williams were able to delimit the full extent of all four invasives, their distribution being centered in the southeastern portion of the Marl Pit. Although the $C$. virgata (represented by at least two distinct populations, i.e. of different provenances), the T. pyramidata and Xeropicta sp. populations may have been introduced during the latter part of 1999, the population of $M$. syriaca was clearly well-established, was particularly abundant, and showed indications that its establishment predates that of the other three taxa. In fact, it has already spread beyond the confines of the Marl Pit, having encompassed Pad 330, crossed the Battery Lamb Road that leads to the South Wharf, and spread on to the raised embankment on the other side.

Although most of the area encompassed by MOTSU remains relatively inhospitable these invasive species (coniferous forest on a sandy soil), and most of the staging pads covered with hardtop, the Marl Pit provides conditions that are extremely conducive to the establishment of these and other calciphile taxa: the floor of the area consists primarily of a mixture of calcareous earth and crushed shells, this material having been dredged from the Cape Fear River and laid out on throughout the extent of the Marl Pit. This provides these species with the necessary calcium carbonate for their reproduction and continued survival. The vegetation cover, providing a variety of food sources, and abundance of surface features (railroad ties, loose boards, garbage, etc.) that provide cover and humidity for these snails, together generate an environment that will continue to support self-sustaining populations unless they are actively eradicated.

Figure C7. Precautionary survey of a MOTSU staging area indicating the presence of foreign snails and suggesting U.S. snails were transported to foreign ports, p. 1 of 3 (Source: Capt Herbert T. Bolton, USN) 


$\begin{array}{llll}\begin{array}{l}\text { United States } \\ \text { Department of }\end{array} & \begin{array}{l}\text { Animal \& } \\ \text { Plant Health }\end{array} & \begin{array}{l}\text { Plant Protection } \\ \text { \& Quarantine }\end{array} & \begin{array}{l}\text { Department of Malacology } \\ \text { Academy of Natural Sciences }\end{array} \\ \text { Agriculture } & \text { Inspection } & & 1900 \text { Benjamin Franklin Pkwy } \\ & \text { Service } & & \text { Philadelphia, PA 19103-1195 } \\ & & \text { Ph.: (215) 299-1170 } \\ & & \text { Fx.: (215) 299-1170 }\end{array}$

The establishment of these quarantine pests at Sunny Point further increases the possibility that other military bases across the continental United States, to which infested containers of military cargo may have subsequently been sent, may now also harbor populations of these, and possibly other, snail species. Appendix A lists those species intercepted from containers from the two above-mentioned ships.

In addition to the invasive species established in the Marl Pit, a number of interceptions on containers from both Captain Steven L. Bennett and Austral Rainbow consisted of native North Carolina species. The fact that most of these occurred on containers that had not yet been unloaded indicates that the containers were infested prior to the ships crossing the Atlantic to Europe. Most of the interceptions were of Succinea (Calcisuccinea) campestris, which is particularly abundant in the Marl Pit, although other native polygyrids were also encountered. Not only did the presence of these snails result in delays in the processing of these containers, but the potential introduction of these American species to other countries is of concern to the Armed Forces Pest Management Board. The occurrence of Polygyra cereolus among the interceptions, a species whose distribution ranges from Florida to North Carolina but apparently not at Sunny Point may indicate yet another source of infestation.

Figure C8. Precautionary survey of a MOTSU staging area indicating the presence of foreign snails and suggesting U.S. snails were transported to foreign ports, p. 2 of 3 (Source: Capt Herbert T. Bolton, USN) 


$\begin{array}{llll}\begin{array}{l}\text { United States } \\ \text { Department of }\end{array} & \begin{array}{l}\text { Animal \& } \\ \text { Plant Health }\end{array} & \begin{array}{l}\text { Plant Protection } \\ \text { \& Quarantine }\end{array} & \begin{array}{l}\text { Department of Malacology } \\ \text { Academy of Natural Sciences }\end{array} \\ & \text { Inspection } & \text { 1900 Benjamin Franklin Pkwy } \\ \text { Service } & & \text { Philadelphia, PA 19103-1195 } \\ & & \text { Ph.: (215) 299-1170 } \\ & & \text { Fx.: (215) 299-1170 }\end{array}$

Appendix A

Quarantine significant taxa marked by an asterisk (*). Note that most infested containers carried more than one species, i.e. representing multiple interceptions.

Invasive mollusk species intercepted on the Captain Steven L. Bennett (21 October - 24 November 1999):

Origin No. interceptions

CIONELLIDAE

Cionella lubrica (Müller, 1774)

HELICIDAE

Cepaea nemoralis (Linné, 1758)

* Theba pisana (Muller, 1774)

HYGROMIIDAE

* Cermuella cisalpina (Rossmässler, 1837)

* Cernuella virgata (Da Costa, 1778)

Hygromia cinctella (Draparnaud, 1801)

* Monacha cartusiana (Muller, 1774)

* Trochoidea pyramidata (Draparnaud, 180)

- Xerotricha apicina (Lamarck, 1822)

Europe 9

COCHLICELLIDAE

- Prietocella barbara (Linné, 1758)

Germany 2

Italy 1

Italy $\quad 53$

Italy 12

$\begin{array}{ll}\text { Italy } & 1 \\ \text { Italy } & 4\end{array}$

$\begin{array}{lr}\text { Italy } & 4 \\ \text { Italy } & 21\end{array}$

Spain 2

Italy 34

Native mollusk species intercepted on the Captain Steven L. Bennett (21 October - 24 November 1999):

PUPILLIDAE

Pupoides albilabris (C.B. Adams, 1821)

No. interceptions

SUCCINEIDAE

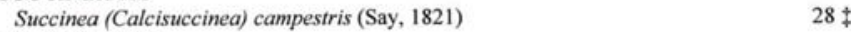

POLYGYRIDAE

Polygyra cereolus (Megerle von Mühlfeld, 1818)

Triodopsis hopetonensis (Shuttleworth, 1852) +2 other unidentified polygyrid spp. $\quad 4$

Invasive mollusk species intercepted on the Austral Rainbow (22 - 24 November 1999):

\begin{tabular}{llc}
\hline $\begin{array}{l}\text { ENIDAE } \\
\text { Euchondrus ledereri (L. Pfeiffer, 1868) }\end{array}$ & Origin & No. interceptions \\
HYGROMIIDAE & Turkey & 5 \\
* Candidula sp. & & \\
* Cermuella virgata (Da Costa, 1778) & Turkey & 6 \\
* Helicopsis sp. & Turkey & 3 \\
* Monacha cf. parumcincta (Menke, 1828) & Turkey & 4 \\
* Xeropicta krynickii (Krynicki, 1833) & Turkey & 8 \\
* unidentified spp. of Helicellinae & Turkey & 9 \\
* unidentified spp. of Trichiinae & Turkey & 3 \\
& Turkey & 5
\end{tabular}

Native mollusk species intercepted on the Austral Rainbow (22 - 24 November 1999):

No. interceptions

SUCCINEIDAE

Succinea (Calcisuccinea) campestris (Say, 1821) $2 \ddagger$

₹ Many other interceptions of this species were made but were not submitted as they identified in the field by PPQ Officers.

Figure C9. Precautionary survey of a MOTSU staging area indicating the presence of foreign snails and suggesting U.S. snails were transported to foreign ports, p. 3 of 3 (Source: Capt Herbert T. Bolton, USN) 


\section{Trapani, Italy, 1999}

\section{MEMORANDUM FOR HQ USAFE/CEVC}

FROM: HQ USAFE/CEVC (Capt. Mark A. Pomerinke, x6382)

SUBJECT: Snail Eradication at Trapani, Italy - 9 Jul 99

1. PURPOSE: This staff assistance visit was in response to the TALCE Operations officer's request for assistance at Trapani, Italy. The request was prompted by the discovery of snails indigenous to Sicily infesting palletized cargo and transport aircraft upon their arrival CONUS. Six C-17s and their cargo were placed in quarantine at Charleston AFB on 6 Jul 99 by USDA/APHIS personal after discovering snails in the aircraft. The aircraft were inspected and released for duty within 24 hours of quarantine, while $233,003 \mathrm{lbs}$ of cargo, including 14 pallets, 2 T2's and 33 pieces of rolling stock were positioned for fumigation. Flights were suspended to Trapani following confirmation that all remaining cargo going CONUS was inspected and certified free from snails.

2. ITINERARY: Upon arrival, I met with Maj. Dougles Cashman (TALCE operations officer). We discussed the actions that he and his team had taken on $7 \mathrm{Jul} 99$ to clean and quarantine the remaining cargo. On $9 \mathrm{Jul} 99 \mathrm{I}$ inspected all of the quarantined cargo along with remaining equipment needing shipment. Following inspection and cleaning of the remaining equipment, I issued letters of clearance for all CONUS bound cargo.

3. SUMMARY OF FINDINGS: Cargo appears to have become infested while being stored in grass off of paved areas. Maj. Cashman and his team stripped down 3 pallets, 2 pieces of rolling stock and 1 loader, cleaning and hand checking all cargo for snails. After ensuring the cargo was free of snails, they positioned the equipment on a dry cement pad and placed a 6 in salt barrier around the equipment. Snails found on un-cleaned pallets were cleaned off with a high-pressure sprayer, while cargo nets were inspected by hand. Quarantine procedures were discussed and put in place for all remaining outbound cargo. Four species of snails, 3 belong to the Helicidae family and 1 un-identified species were collected from pallets. Final identification is still pending.

\section{POSSIBLE SOLUTIONS:}

4.1. PREVENTION: Store supplies and equipment away from snail habitat on paved areas or in warehouses. Insure that equipment placed in snail areas are cleaned and inspected before placing them with snail free equipment.

4.2. CORRECTION/DECONTAMINATION: Remove any snails found on equipment or cargo by cleaning with pressure washers, hand removal, or by chemical treatments. Following treatment cleaned cargo should be placed in a quarantine area to prevent further infestation by snails.

Figure C10. Snail eradication at Trapani, Italy, p. 1 of 3 (Source: Capt Mark A. Pomerinke) 


\section{DISCUSSION:}

5.1. SIGHT SURVAY: Potential indigenous species of concern need to be identified during or immediately following a sight survey. Prior knowledge of the snails would have saved man-hours used for cleaning infested equipment and insured that aircraft and cargo were not quarantined upon arrival in CONUS. Snail control programs need to be established for units deploying to the Mediterranean region. Prior to or shortly after a unit arrives a preventative program should be started. This includes physical and chemical control methods. Physical methods can include burning vegetation, plowing, disking and culti-packing open fields. All physical methods are designed to remove vegetation that snails feed on and live in. Chemical control, such as salt barriers ensures that snails will not migrate onto paved areas, infesting cargo and equipment.

5.2. CONTENUITY: It was learned during conversations with Maj. Cashman that one of the A-10 units deployed at Trapani, had initiated procedures for keeping snails off of their equipment. The unit personal remembered a previous deployment to Turkey and problems encountered with snails. Unfortunately, their procedures and knowledge were not passed on to the other units deployed at Trapani.

Figure C11. Snail eradication at Trapani, Italy, p. 2 of 3 (Source: Capt Mark A. Pomerinke) 


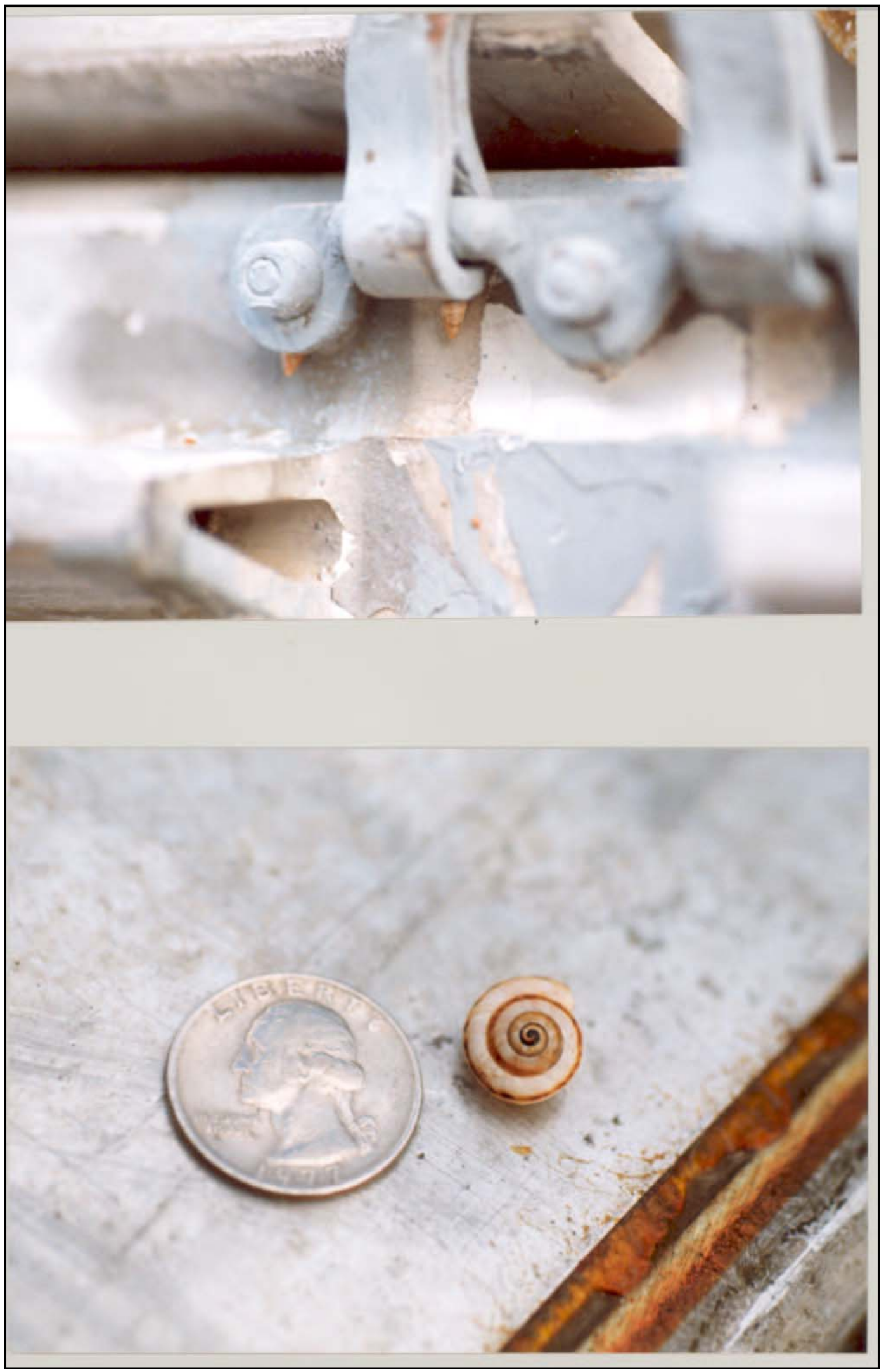

Figure C12. Snail eradication at Trapani, Italy, p. 3 of $\mathbf{3}$ (Source: Capt Mark A. Pomerinke) 


\section{Germany, 2000-2001}

United States Animal and

Department of Plant Health

Agriculture

Inspection Service

February 2, 2000

My Comments on the German Agricultural Pre-clearance for its Troops Returning From the Balkans

For the two years that I have been holding my position as Agriculture Advisor to EUCOM, I have been wondering how is it that, so much environmentally and health concerned West European countries, like Germany, were not taking any safeguard measures in their borders to prevent the entry of significant animal diseases and pests from risky neighboring areas. Therefore, although this German action was apparently initiated back in July 17, 1996, and apparently never reached us until now, it appears to be a well-taken step in the right direction.

Although the ruling is an individual initiative of Germany alone, it would be good if a similar concept might be adopted by the rest of NATO. Personally, I foresee this as a possibility once that a more European committed NATO force develops in the near future.

Although the ruling is directed to the German military, I suppose that it should be assumed that it has similar applicability to US forces being hosted by this country.

a. Comparison of the German Pre-clearance Standards with Those of the US.

Essentially, the German criteria parallel that of the US to the point that one may well supplement or satisfy the other. There are only a few details in which the German version falls short of US requirements; however, this might be due to some less stringent requirements by Germany because of its geographic latitude in relation to the neighboring countries. I explain.

1. Germany will require pre-clearance for all vehicles coming from Bosnia-Herzegovina, but not from other Balkan countries, whose clearance might be completed at German entry ports. The US requirement is for full pre-clearance from any offshore location, including its own offshore states and possessions.

2. The German rule will accept foreign canned meats for human consumption that has been heated to a minimum temperature of FC 300 . The US will not accept these unless they have been packed under USDA supervision in a pre-approved meat- packing establishment.

3. The criteria for entering hunting trophies from hoofed animals, although seems to basically conform with US standards, appears to be somewhat relaxed.

4. Although steam-cleaning of vehicles is an effective and acceptable practice, the US regularly calls for pressure-washing only to prevent possible damage to vehicle's rubber hose systems. (However, it should be noted that later on in the German directive, in 3. Procedures for the Return of Vehicles, it reads: "All vehicles, trailers and any equipment loaded on vehicles or trailers have to be cleaned with cold water prior to ..." Therefore, it does not appear to call for steam-cleaning here).

b. Measures to be taken for the return of Personnel (Item 1 under Attachments in the German Directive)

I am glad to see that this ruling goes along with recommendations that I formulated while reviewing pre-clearance activities in Bosnia for US pre-clearance (Please see enclosure of

Figure C13. Delcio Rivera comments on the German agricultural pre-clearance for troops returning from the Balkans, p. 1 of 2 
January 22, 1999). This will be an excellent support for US pre-clearance regulations and would be ideal if subsequently adopted by NATO forces.

c. US Armed Forces Implementation of German Directive

Basically, what needs to be done by the US Armed Forces to support and comply with this ruling is to apply the same criteria as established for US pre-clearance for all its incoming troops and equipment into Germany from the identified Balkan areas. However, to do this, there is a needed increment in the pre-clearance activities at the key US military installations therein, say Tuzla Eagle Base, and/or at German entry ports. The following needs to be improved or implemented:

1. The necessary vehicle washing facilities (If steam-cleaning and chemical disinfection of vehicles is to be required, provisions to do these would need to be established. The question remains whether this might be done at origin or would be required to be done at the German port of entry).

2. Provisions to pre-clear troops and their personal equipment (clothing, boots, etc.) at Balkan's US installations or at German ports of entry. This will require dedicated staff to perform inspections, apply necessary sanitary and dis-infection actions, etc.

3. German ports of entry compliance. US military or civilian personnel to perform entry inspections of troops and/or equipment, as necessary, to ensure compliance with the German ruling.

I think that the bottom-line in here is that, for the US Armed Forces to comply with this German ruling, additional personnel, resources, and establishments would need to be appropriated to perform the necessary procedures.

If it happens, as I may foresee, that a more or less similar ruling is adopted in the future by the entire NATO countries, it would be good for the US Armed Forces to prepare themselves to comply with this since, besides facilitating its own NATO sharing and presence, will also much support its own CTUS entry regulations.

Also, one must bear in mind that, although this ruling is now specific for certain areas in the Balkans only, it might be easily expanded to other areas or countries as animal or human disease conditions might appear.

Delcio Rivera

Agriculture Advisor to EUCOM

Enclosure

Figure C14. Delcio Rivera comments on the German agricultural pre-clearance for troops returning from the Balkans, p. 2 of 2 
Mr. Gerald Walker

Chief, Customs Policy Branch

U.S. Transportation Command

508 Scott Drive

Scott AFB, IL 62225-5357

ATTN: TCJ4-LTC

Dear Mr. Walker,

For many years, we thought that our longtime established MCI cargo program at Ramstein AB, Germany, was providing enough coverage to ensure the proper preclearance for agriculture purposes for all cargo either departing from or transiting through this base. You might be aware that this base has been for a long time the major transit hub for military cargo from the European theater been destined to CONUS. As a result of the forthcoming closure of the Rheim-Main cargo activity next to the Frankfurt Airport, the total or much of their handled cargo will move to Ramstein, making of this even a bigger cargo hub from this latitude.

During a review of inspection facilities during year 1999, we found that the major cargo operation at this base, that is, the AMS shipment of USAFE originated cargo, plus transit cargo from other US Armed Forces branches, mostly the US Army, was not subjected to any pre-clearance inspection at all. The much smaller cargo inspection program that we have known, only handles locally originated small cargo shipments. The first irregularity that we were able to identify was the large cargo warehouse itself, where many birds were nesting inside and discharging their droppings over the warehouse ceiling frames, floors, and cargo itself. The US is much concerned about bird manure and feather contamination because of the risk of transmissible bird diseases not existing in the US, such as the Newcastle Disease.

On determining the need for a properly established MCI pre-clearance program at this critical cargo facility, we initiated contacts with the AMS commanders at this base and failing to observe any positive response, extended the issue to the USAFE headquarters in Scott AFB, IL. My letter of July 29, 1999, addressed to General Robertson, Commander in Chief, HQ Air Mobility Command, was properly responded through

COL. Bonnie C. Cirrincione, Chief, Aerial Port Operations Division, and offered much support to our program needs.

However, as we have approached the different command levels at Ramstein AB, we have been bounced through different AMS command offices without any particular one of

Figure C15. Letter from USDA APHIS to U.S. Transportation Command expressing need for an agricultural pre-clearance program for DoD cargo shipped from Germany to U.S., p. 1 of 3 , (Source: Delcio Rivera, USDA-APHIS) 
Page No. 2, Mr. Gerald Walker, Chief, Customs Policy Branch

them willing to assume proper responsibility for the establishment of this program. (Please refer to the enclosed correspondence for your understanding of these contacts' results).

Meanwhile, late last year, and as a result of this inaction, six C-17 cargo aircraft from this base had to be detained for inspection and thorough cleaning and treatment of their cargo and some of the aircraft, because of findings of soil and extensive contamination with snails. The involved cost represented the removal of some of the aircraft from their regular duty to be treated by commercial fumigators and treatment and cleaning of the cargo, amounting to close to two million dollars.

In its hub function, Ramstein $\mathrm{AB}$ also moves a large number of cargo containers from the USAFE itself or other Armed Forces branches, that are not subjected to a formal preclearance inspection when they are shipped out of this base. Containers, or milvans, have been identified as one of the major means of soil and pest entrance into the US.

During our recent meeting in our attempt to advance the establishment of this necessary program, we were informed that a main reason for the not-so-positive reactions that we are experiencing from the different AMS local levels, is that AMS as such, is considered a direct branch under the jurisdiction of the DoD's USTRANSCOM, rather than the USAFE, as such. Being this the case, it seems logical to expect no urgency or desire from local AMS sub-division commands to compromise their commitment to support this program. Therefore, it has been suggested to us to approach USTRANSCOM directly for the expected reaction and support.

We are aware that you have taken leadership of the Customs Policy Branch and actually, we congratulate you for this well deserved recognition and promotion. As we have been working with you in the development of a new DoD directive to handle US entry of military retrograde cargo and property, as well as its entry into the worldwide theaters where the US military operates, we know that you have become very familiar with all these transportation and US re-entry issues.

Therefore, we would like to respectfully request your assistance in securing the corresponding sources that we should approach to attain our objective, but more critically, to request your own direct intervention in seeking a resolution for this issue.

As the DoD has already offered, it intends to support and abide by the requirements of the recently issued Executive Directive Number 13112, Invasive Species, that calls for an active role of several US agencies, including the departments of Defense, Transportation, Interior, State, Treasury, Agriculture, etc., to actively design measures to ensure the restricted entry of animal diseases and plant pests into the US. The US military, because of its particular operational mode in foreign latitudes and because of its intensive

Figure C16. Letter from USDA APHIS to U.S. Transportation Command expressing need for an agricultural pre-clearance program for DoD cargo shipped from Germany to U.S., p. 2 of 3 , (Source: Delcio Rivera, USDA-APHIS) 
Page No. 3, Mr. Gerald Walker, Chief, Customs Policy Branch

movement of property back into the US, has been identified as a high risk pathway for this possible entry.

Therefore, leaving Ramstein AB to continue with movement of its cargo back into the US

without any proper pre-clearance, would be contradictory to the objectives of this

executive order, besides posing a continuous risk for the possible entry of foreign restricted organisms into the US.

Your attention and assistance in this concern will be much valued and appreciated.

Respectfully,

Delcio Rivera

Agriculture Advisor to EUCOM

Enclosures

Copy:

COL Bonnie C. Cirrincione, Chief, Aerial Port Operations Division

Figure C17. Letter from USDA APHIS to U.S. Transportation Command expressing need for an agricultural pre-clearance program for DoD cargo shipped from Germany to U.S., p. 3 of 3, (Source: Delcio Rivera, USDA-APHIS) 
This is a report of a review inspection of German Air Force military equipment that was shipped from the German Port of Cuxhaven around April 22, 2001, intended to participate in the yearly multinational military exercises denominated "Roving Sands". To cope with US entry requirements, the military property is thoroughly washed and cleaned to meet the standards of the US Department of Agriculture (USDA). This year and because of the incidence of Foot and Mouth Disease (FMD) in parts of Europe, the US Military Pre-clearance Program in EUCOM (US Military European Command), was asked to assist and support the efforts of the German Air Force in rendering their equipment to full compliance of special FMD restrictions. A unit of three SMCI (Senior Military Customs Inspectors) were assigned to work with the German Air Force (GAF) airmen to wash and clean the equipment. This cleaning was initiated by the GAF personnel at one of their military installations and was to be completed at the embarkation port of Cuxhaven, at which site, the SMCIs would complete the overview of a final washing/cleaning and inspect the equipment to meet USDA entry standards. To further ensure sterilization of the equipment against any possible FMD contamination, the GAF established a disinfecting unit at the portside to disinfect every unit before it was put aboard the ocean carrier, GE m/v Sloman Provider. The disinfectant utilized was the one regularly used by the German military for their property incoming from FMD prone areas, such as The Balkans. This is "Venno Vet Super 1" at a $1 \%$ solution.

While the equipment was on its voyage to the US port of Beaumont, TX, a major debate developed at the State of Texas, regarding the acceptability of military equipment from an FMD general declared area. Although Germany has not so far been identified as an FMD country, the US regards the entire of Europe as FMD territory. As a result of this debate, the intended participation of other NATO nations due to take part in the exercise, The Netherlands and the United Kingdom (UK), were notified through their diplomatic channels to cancel their participation, at least by utilizing their countries' generated military property. Therefore, cleaning/washing in progress of the Netherlands equipment and advanced plans for the same action by the UK were detained.

Since the German carrier containing the GAF equipment was already entering the Beaumont, TX port when the cancellation order was issued, it was apparently decided to authorize its unloading and subjection to entering inspection by USDA port personnel. Information that was filtered to us through the US Pentagon's sources, indicated that the equipment was inspected and declared as acceptable by USDA port inspectors. However, on a second inspection performed by what appears to be a State of Texas Veterinary Medical Officer, declared half of the equipment as not acceptable for entry. A total of 32 vehicles and five mil-van containers loaded with different equipment were rejected. This equipment was to be returned to Germany in the same ocean carrier.

Figure C18. Report on German military equipment transport to U.S. for Exercise Roving Sands, p. 1 of 3 (Source: Delcio Rivera) 
1 made the decision to attempt to inspect this equipment on its return because of three reasons: 1) I was challenged by my employing agency USDA, as to the validity of our pre-clearance inspections. If rejections of this magnitude, $50 \%$, were taking place, what was the value and effect of our pre-clearance actions. This reasoning sounded very legitimate. 2) If the rejection was, as proclaimed, resulting from defective cleaning/washing and therefore, non-valid certification by USDA supporting US military staff. Then, in this case, it was to my responsibility as USDA Agriculture Advisor to EUCOM, to seek means and alternatives through training and further development of the SMCI inspectors, to correct and enhance procedures to prevent any future wrongful performance of such magnitude. 3) If the rejection was the cause and effect of political decisions out of USDA's and mine control; then I needed to know for at least, protect the dignity and performance of our US military SMCI inspectors that certified the shipment to be in USDA's compliance to the best of their knowledge.

The equipment arrived back in the "Sloman Provider" to Cuxhaven, GE on May 31, 2001. I, together with US Army Sergeant Robert Maresh, a well trained and much experienced SMCI inspector, were at the portside awaiting to inspect the equipment. Since this is a roll-on/roll-off type vessel, we were authorized and had easy access to the first level hold where the majority of the vehicles were and immediately began inspection of these. Sergeant Maresh and myself had previously established "the rules of the game". We were not to use any partiality in the acceptance or refusal of the findings. We were simply to scrutinize the equipment to the best of our knowledge and abilities and determine, based on actual findings, whether it was realistically dirty/contaminated to clearly denote its non-compliance with USDA requirements, or whether it was reasonably clean to meet these USDA standards. Sergeant Maresh and myself didn't do any common inspection. We crawled and rolled under each individual piece of equipment, from front to bottom, to carefully examine every possible crevice where dirt, plant material, manure, or any other contaminant might be concealing. We carefully examined and rolled our hands and fingers over axles, transmission cases, gas/oil tanks, platform frames, spare wheels/tires, springs, differential cases, steering mechanisms, inside drive cabins, loaded cargo and containers, to the extend that we would not miss any possible dirt or other contaminated space. We experienced some curious findings. The first one was that the equipment had been evidently rolled over an ocean-side sandy area. Traces of evident seashore sand were in the wheel wells and some other structures. This must have been collected while the equipment was rolled in or out of the carrier at Beaumont since this is not possible at Cuxhaven. During the course of my inspection, I removed from the undercarriage of a truck what seemed to be a clump of soil. I thought; "This is it". However, on smashing it between my fingers, it came to be a clump of hardened grease with a top smear of dust that resembled dirt. In another case, I saw what looked to be obvious dirt over a metal frame. However, on close check, it came to be dusty rust from a metal part.

Sergeant Maresh found evidence in two vehicles that he inspected, to have justified further washing or cleaning of small crevices, one each in each vehicle, where dirt was showing. These findings in no way would have refused the entire vehicles since the rest

Figure C19. Report on German military equipment transport to U.S. for Exercise Roving Sands, p. 2 of 3 (Source: Delcio Rivera) 
of them were totally clean. A little brushing off of the one crevice each in the two vehicles, would have been action enough to render them totally acceptable. Findings by Sergeant Maresh are detailed in his separate report.

The five mil-van containers were inspected by Sergeant Maresh, as they were unloaded from the carrier. Although these were commingled with other shipped containers, he secured the numbers of the five ones that were previously shipped. He found them to be totally clean and fit for entry into the US under the USDA standards.

Once the vehicles were rolled off the carrier and stayed in a hard-standing pier area, we went over them once again to examine each one of them a second time. Our stringent and much thorough inspection lasted uninterrupted from 10:00 AM to 03:00 PM.

Conclusion: No matter how much we tried, we were not able to find any evidence whatsoever of dirt or other contamination. Port of Beaumont inspectors claimed that they found massive dirt contamination to the level of removing 30-35 pounds of dirt from a vehicle. Unless they requested another re-washing of these vehicles at their port, evidence that always remain in an area where soil has been removed was not apparent. Soiled areas that have been washed, no matter how extensively, always leave a smear that resembles soil or dirt. This fact has confused many USDA inspectors in my experience. The only way to determine this is by robing and scratching the area with the hand or nails to remove any present soil. We saw several vehicle parts with this appearance but, on close examination, only the smear and no soil/dirt whatsoever, has remained.

Our conclusion was that the vehicles and mil-vans, with the couple of exceptions listed above, were clean to the point that it would have been very difficult to make them any cleaner. Therefore, we were not able to find any biological evidence for the refusal of these and determined that they were fully acceptable for entry into the US under USDA's standards.

(Signed)

Delcio Rivera

Agriculture Advisor to EUCOM

Figure C20. Report on German military equipment transport to U.S. for Exercise Roving Sands, p. 3 of 3 (Source: Delcio Rivera) 


\section{Southwest Asia, 2004}

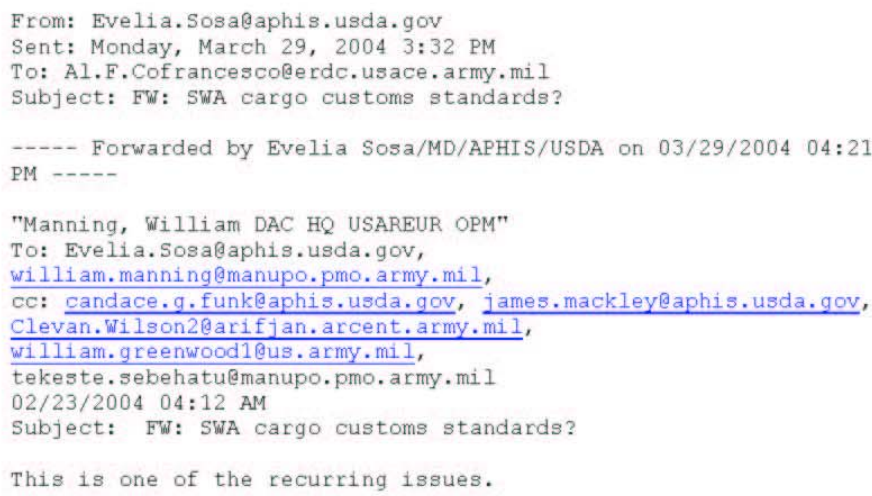

Figure C21. Message relating issue of cleaning U.S. military equipment transported from Southwest Asia to Europe, p. 1 of 2 (Source: Ms. Evelia Sosa, USDA-APHIS) 
W. L. Manning

Military Attaché, Agriculture Advisor, EUCOM

-----Original Message-----

From: Szostek, Robert Mr., HQ USAREUR OPM

Sent: Monday, February 23, 2004 8:30 AM

To: Greenwood, William A. Mr DAC HQ USAREUR OPM; Manning, William

DAC HQ USAREUR OPM

Subject: FW: SWA cargo customs standards?

Gents,

This came in from the web site. For your action.

-----original Message-----

From: Wilson, Clevan CIV AMC LSE SWA

[mailto: Clevan.Wilson2@arifjan.arcent.army.mil]

Sent: Monday, February 23, 2004 8:07 AM

To: 'webinfo@manupo.pmo. army.mil'

Subject: SWA cargo customs standards?

Importance: High

We are trying to confirmed with European Customs, there is not a

requirement to agriculturally clean equipment coming from SWA to

Europe. However, if the ship has only a stop-over in Europe, down

loading part of the equipment and then continuing on to

Continental US (CONUS) with the remaining equipment will there be

a requirement to agriculturally clean all of the equipment on the ship.

Please confirm whether or not equipment with a final destination of ConUS can not be loaded on a ship if all the equipment on the ship has not been agriculturally cleaned?

Respectfully,

Clevan Wilson

Future Operations

AMC LSE SWA

318-825-2203/2531 CELL 011-965-980-8756

Clevan. Wilson2@arifjan. arcent.army. mil

Figure C22. Message relating issue of cleaning U.S. military equipment transported from Southwest Asia to Europe, p. 2 of 2 (Source: Ms. Evelia Sosa, USDA-APHIS) 
From: Evelia.Sosa@aphis.usda.gov

Sent: Thursday, May 20, 2004 11:04 AM

To: Al.F.Cofrancesco@erdc.usace.army.mil

Subject: Military Cargo Clearance-Dirty Equipment and Containers

Customs and Border Protection reported equipment contaminated

with soil arriving at the ports of Beaumont and Corpus Christi.

The information is anecdotal, not specific (dates, names of

ships, number of pieces of equipment, etc were not provided).

APHIS is asking CBP to provide more specifics to be able to trace

back the origin of the equipment, and responsible units. This

will help for future shipments.

The following is a portion of the message from $\mathrm{CBP}$ :

...The Ports of Corpus Christi and Beaumont are finding numerous containers highly contaminated with soil. The contamination is mostly on the outside, but several have been found with high soil contaminations inside. The wheeled equipment is also heavily soiled. On one vessel, we will have to steam clean or disinfect the deck due to soil contamination from the containers. This is causing concern with the military.

Both ports have reported that the highly soiled equipment and containers are arriving from Kuwait. The Port of Corpus is receiving military equipment from Fujairah, Kuwait. The military in Beaumont, TX would not disclose the port of lading for shipments arriving in Beaumont of the redeployed equipment, only the country as being Kuwait.

These shipments are not precleared to my knowledge, however, the inspections and cleaning are costing the military, ports and the government money and time to clear and clean the soiled cargo.

Is there anything we can do to alert the millitary in Kuwait to perform some type of preloading inspection and cleaning?

Figure C23. Message describing soiled military equipment and containers arriving in Corpus Christi and Beaumont ports from Kuwait 


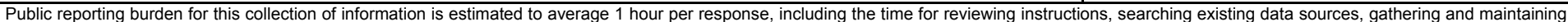

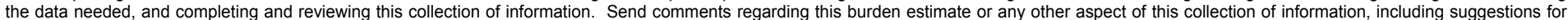

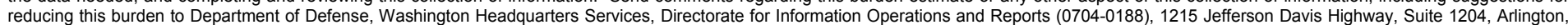

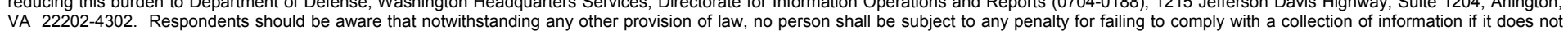
VA 22202-4302. Respondents should be aware that notwithstanding any other provision of law, no person shall be sube
display a currently valid OMB control number. PLEASE DO NOT RETURN YOUR FORM TO THE ABOVE ADDRESS.

\begin{tabular}{l|c}
$\begin{array}{l}\text { 1. REPORT DATE (DD-MM-YYYY) } \\
\text { July } 2007\end{array}$ & $\begin{array}{c}\text { 2. REPORT TYPE } \\
\text { Final report }\end{array}$ \\
\hline
\end{tabular}

\section{TITLE AND SUBTITLE}

Transfer of Invasive Species Associated with the Movement of Military

Equipment and Personnel

3. DATES COVERED (From - To)

5a. CONTRACT NUMBER

5b. GRANT NUMBER

5c. PROGRAM ELEMENT NUMBER

5d. PROJECT NUMBER

$01-163,03-123$

Alfred F. Cofrancesco, Jr., David R. Reaves, and Daniel E. Averett

5e. TASK NUMBER

5f. WORK UNIT NUMBER

8. PERFORMING ORGANIZATION REPORT NUMBER

ERDC/EL TR-07-8

Environmental Laboratory, U.S. Army Engineer Research and Development Center, 3909

Halls Ferry Road, Vicksburg, MS 39180-6199; U.S. Department of Agriculture, Animal

Plant Health Inspection Service, Riverdale, MD 20737

9. SPONSORING / MONITORING AGENCY NAME(S) AND ADDRESS(ES)

10. SPONSOR/MONITOR'S ACRONYM(S)

U.S. Department of Defense Legacy Resource Management Program

Washington, DC

11. SPONSOR/MONITOR'S REPORT NUMBER(S)

\section{DISTRIBUTION / AVAILABILITY STATEMENT}

Approved for public release; distribution is unlimited.

\section{SUPPLEMENTARY NOTES}

\section{ABSTRACT}

This document provides a general overview of the current process that exists to clean, inspect, and regulate the movement of invasive species through ports of embarkation and debarkation. The Department of Defense rapidly moves extensive quantities of personnel and equipment throughout the world and invasive species are hampering these operations. Every military unit that passes through a port of embarkation and debarkation is subjected to scrutiny and inspections to preclude the movement of invasive species from one region of the world to another. Depending on the region where personnel and equipment are moving, the inspection and cleaning process can last weeks, even for small units. The costs in time and money are generally overlooked and have often been attributed to another operational requirement; however, as countries increase their awareness of invasive species, these costs and commitment will rise. Information compiled during this project indicates that over half a million man hours and \$16 million were needed to process 9 months of personnel and equipment through ports of embarkation in Kuwait during FY04. These requirements and costs will increase unless processes are established that assist the unit commanders in complying with requirements related to invasive species.

\section{SUBJECT TERMS}

Invasive species

Military movement

16. SECURITY CLASSIFICATION OF:

\section{Embarkation}

Debarkation

\begin{tabular}{|l|l|l|}
\hline a. REPORT & b. ABSTRACT & c. THIS PAGE \\
UNCLASSIFIED & UNCLASSIFIED & UNCLASSIFIED \\
\hline
\end{tabular}

\begin{tabular}{l|c|c|}
$\begin{array}{l}\text { 17. LIMITATION } \\
\text { OF ABSTRACT }\end{array}$ & $\begin{array}{c}\text { 18. NUMBER } \\
\text { OF PAGES }\end{array}$ \\
& 126 & \\
& & \\
& &
\end{tabular}

19a. NAME OF RESPONSIBLE PERSON

19b. TELEPHONE NUMBER (include area code) 